Florida International University

FIU Digital Commons

FIU Electronic Theses and Dissertations

University Graduate School

6-6-2013

\title{
The Relationship of Culturally Responsive Instruction and the Reading Comprehension and Attitude of Struggling Urban Adolescent Readers
}

Rona M. Olukolu

ronaandrea@yahoo.com

DOI: $10.25148 /$ etd.FI13080526

Follow this and additional works at: https:// digitalcommons.fiu.edu/etd

Part of the Curriculum and Instruction Commons, Junior High, Intermediate, Middle School Education and Teaching Commons, and the Secondary Education and Teaching Commons

\section{Recommended Citation}

Olukolu, Rona M., "The Relationship of Culturally Responsive Instruction and the Reading Comprehension and Attitude of Struggling Urban Adolescent Readers" (2013). FIU Electronic Theses and Dissertations. 910.

https://digitalcommons.fiu.edu/etd/910 


\title{
FLORIDA INTERNATIONAL UNIVERSITY \\ Miami, Florida
}

THE RELATIONSHIP OF CULTURALLY RESPONSIVE INSTRUCTION AND THE READING COMPREHENSION AND ATTITUDE OF STRUGGLING URBAN ADOLESCENT READERS

\author{
A dissertation submitted in partial fulfillment of \\ the requirements for the degree of \\ DOCTOR OF EDUCATION \\ in \\ CURRICULUM AND INSTRUCTION \\ by \\ Rona Moore Olukolu
}

2013 
To: Dean Delia C. Garcia

College of Education

This dissertation, written by Rona Moore Olukolu, and entitled The Relationship of Culturally Responsive Instruction and the Reading Comprehension and Attitude of Struggling Urban Adolescent Readers, having been approved in respect to style and intellectual content, is referred to you for judgment.

We have read this dissertation and recommend that it be approved.

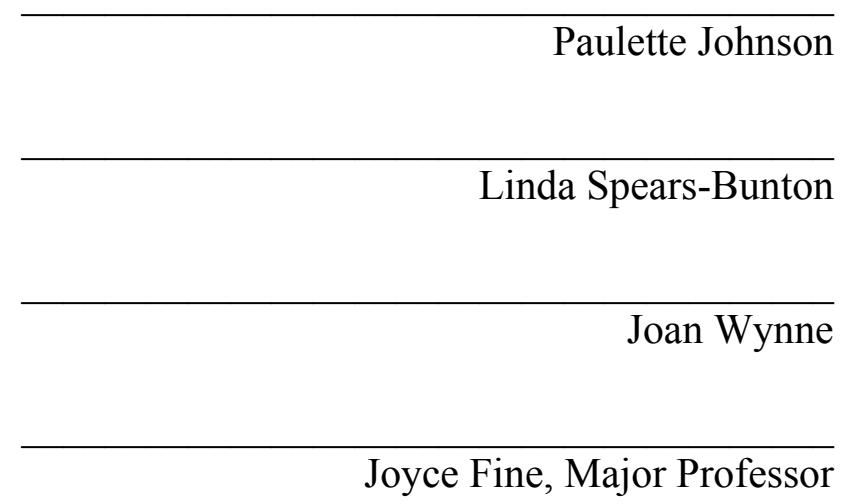

Date of Defense: June 6, 2013

The dissertation of Rona Moore Olukolu is approved.

Dean Delia C. Garcia

College of Education

Dean Lakshmi N. Reddi

University Graduate School

Florida International University, 2013 
(C) Copyright 2013 by Rona Moore Olukolu

All rights reserved. 


\section{DEDICATION}

I humbly dedicate this dissertation to my family, who has been a constant form of support and encouragement to me during this educational sojourn.

Posthumously, to my father, Arthur Moore, a very special dedication is extended to you. You are my mentor, my teacher, my friend, my inspiration. My life has never been the same since you've passed. I owe the biggest gratitude to you for initiating this process. You would have loved to be here to witness this moment, but you have been called to a higher place. Thank you for believing in me and inspiring me to pursue my dreams. "Gone too soon".

To my mother, Rebecca Moore, thank you for your constant love, care and support during this journey. You are a tower of strength and fortitude and you continue to carry the flag that keeps us united as a family.

To my loving husband, Dr. Olusoji Leo Olukolu, thank you for being patient, and for giving me the time to engage in this process. You provided academic and moral support when I felt like giving up. Your determination to help me succeed has been notable. You are my inspiration and I love you very much.

To my uncle and aunt, Walter and Irlina Moore, I have the greatest admiration for you. You stepped in as my parents, embraced and treated me no differently than your own children. Thanks for your weekly phone calls, just simply to check on me.

To my siblings, Susan, Esther, and Keron, thank you for your prayers, love, and support which helped me to persevere. 


\section{ACKNOWLEDGMENTS}

First and foremost, I want to thank the Almighty and Omnipotent God for granting me wisdom, understanding, and knowledge to execute this project to the point of completion. Without you, heavenly Father, none of this would have been possible.

I would like to thank the members of my committee for all their efforts in ensuring that I get to this final point. My Major Professor, Dr. Joyce Fine, has done more than her fair share in mentoring me through this process. Thank you Dr. Fine for unearthing my latent potentials and exposing me to the world of research, which was the stepping stone for me to be able to present at conferences. Dr. Paulette Johnson, I thank you immensely for sharing your statistical knowledge which was integral in helping me to analyze my data. Dr. Linda Spears-Bunton and Dr. Joan Wynne, I thank you for accommodating me on your busy schedules to share your wealth of knowledge and to offer your guidance and support. Dr. Linda Bliss, your invaluable feedback has enhanced the outcome of this study. I thank you all for your expertise, time, and commitment, without you this dissertation would never have come to realization.

Personally, I would like to extend my sincere gratitude to Mrs. Diane Kelly, for contributing her curriculum initiatives towards the success of this study. Your intellectual thoughts and ideas have made a marked difference to the outcome of this study.

I am indeed grateful to all my family, friends, and colleagues for your support and words of encouragement throughout my tenure at Florida International University.

Finally, I would like to thank Mr. Carlton Campbell and the School Board of Broward County for the permission to implement the study at the public school level. 


\author{
ABSTRACT OF THE DISSERTATION \\ THE RELATIONSHIP OF CULTURALLY RESPONSIVE INSTRUCTION AND HE \\ READING COMPREHENSION AND ATTITUDE OF STRUGGLING URBAN \\ ADOLESCENT READERS \\ by \\ Rona Moore Olukolu
}

Florida International University, 2013

Miami, Florida

Professor Joyce Fine, Major Professor

Culturally responsive instruction refers to the identification of relevant cultural aspects of students' lives and infusion of these into the curriculum. This instructional approach assumes that a culturally appropriate curriculum can potentially motivate, engage, and lead students to higher rates of achievement.

This quasi-experimental study $(N=44)$ investigated the relationship of culturally responsive instruction and the reading comprehension and attitude of struggling urban adolescent readers. The study incorporated the use of culturally responsive instruction using culturally relevant literature (CRL), the Bluford Series Novels, as authentic texts of instruction. Participants were seventh grade reading students at a Title I middle school in South Florida.

After a baseline period, two different classes were taught for 8 weeks using different methods. One class formed the experimental group $(n=22)$ and the other class formed the comparison group ( $n=22)$. The CRI curriculum for the experimental group embraced the sociocultural perspective through the use of small discussion groups in 
which students read and constructed meaning with peers through interaction with the Bluford Series Novels; gave written responses to multiple strategies according to SCRAP - Summarize, Connect, Reflect, Ask Questions, Predict; responded to literal and inferential questions, while at the same time validating their responses through evidence from the text. The Read XL Basal Reader curriculum of the comparison group utilized a traditional form of instruction which incorporated the reading of passages followed by responses to comprehension questions, and teacher-led whole group discussion.

The main sources of data were collected from the Gates-MacGinitie Reading Tests (GMRT), the Florida Assessments for Instruction in Reading (FAIR), and the Rhody Secondary Reading Attitude Assessment (RSRAA). Statistical analyses were performed using Repeated Measures ANOVAs.

Findings from the study revealed that the experimental participants' reading attitudes and FAIR comprehension scores increased when compared to the comparison group. Overall, the results from the study revealed that culturally responsive instruction can potentially foster reading comprehension and a more positive attitude towards reading. However, a replication of this study in other settings with a larger, random sample and a greater ethnic variation is needed in order to make full generalizations. 


\section{TABLE OF CONTENTS}

CHAPTER

PAGE

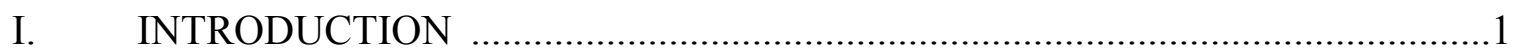

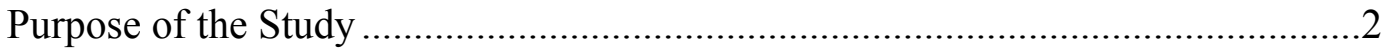

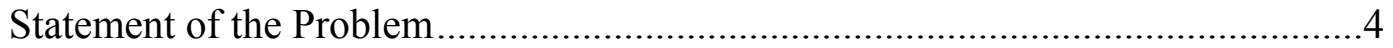

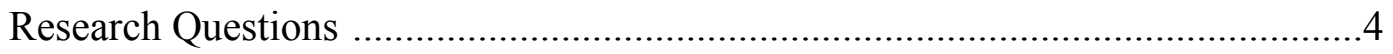

Hypotheses ............................................................................................

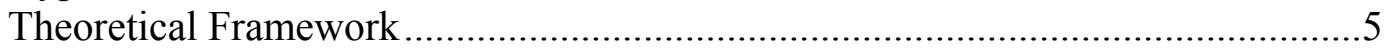

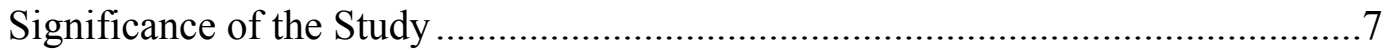

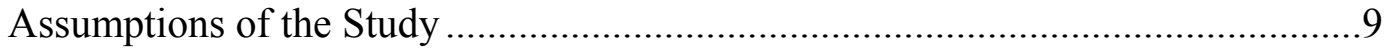

Delimitations of the Study ........................................................................... 9

Operational Definition of Terms .............................................................. 9

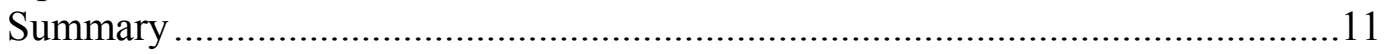

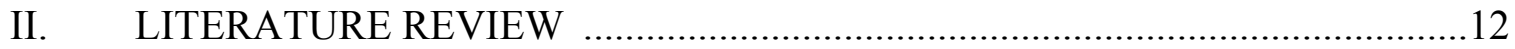

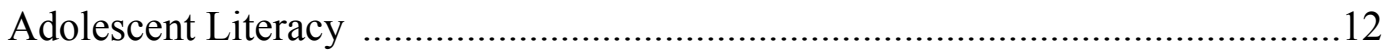

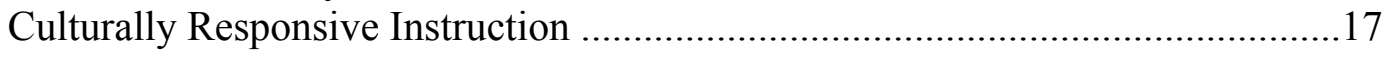

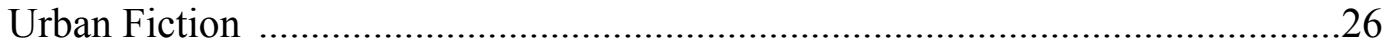

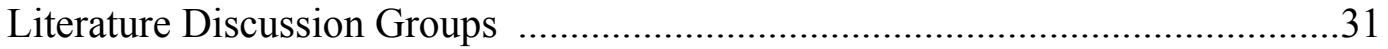

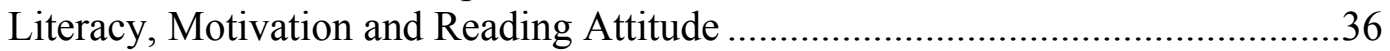

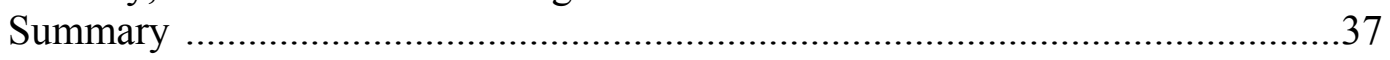

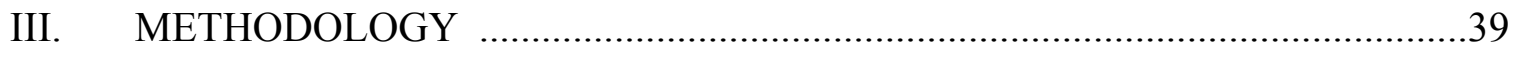

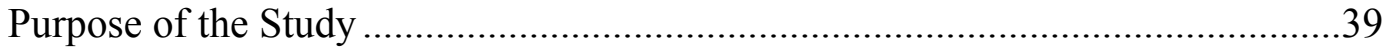

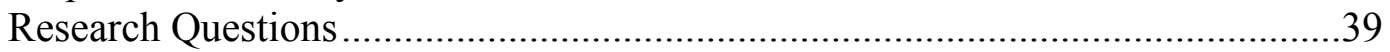

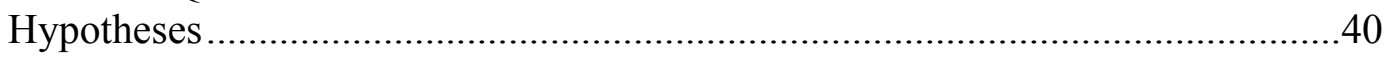

Quasi-Experimental Research Design ...........................................................40

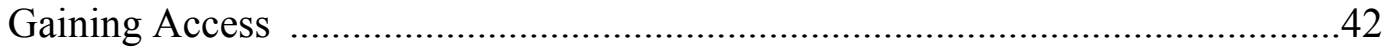

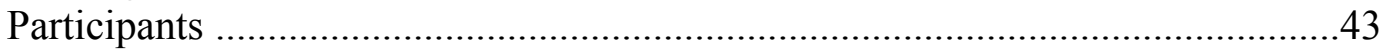

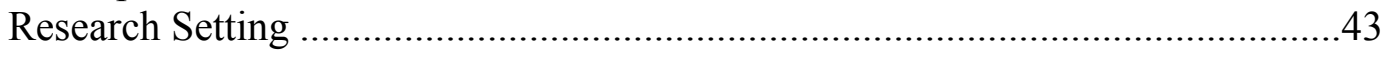

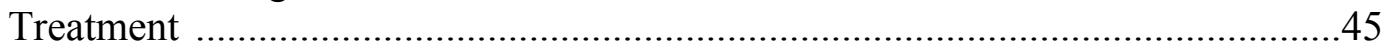

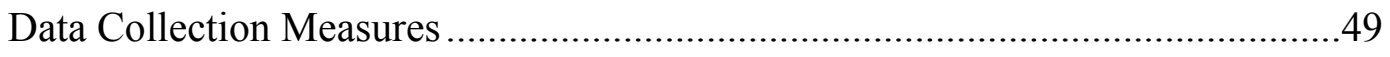

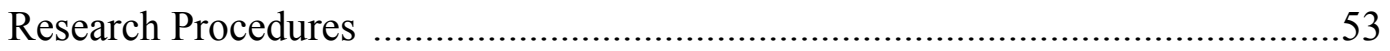

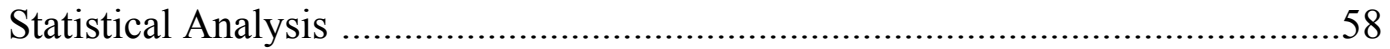

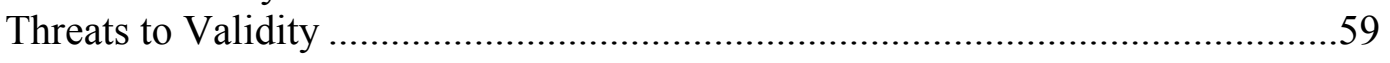

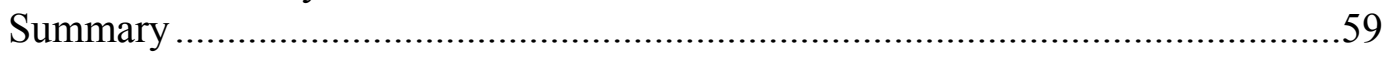

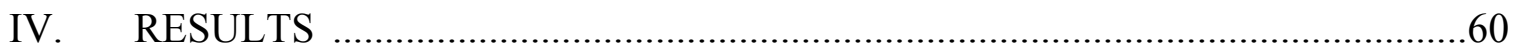

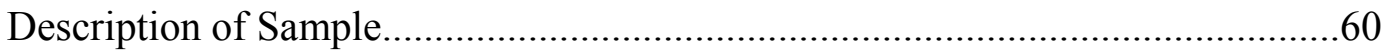

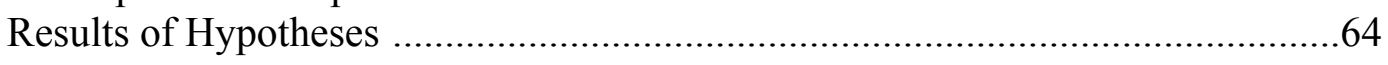

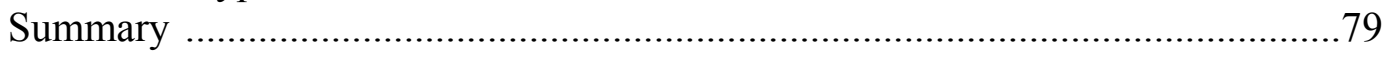




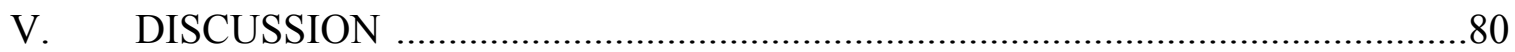

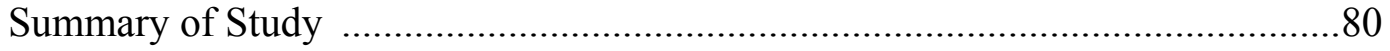

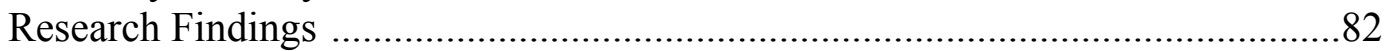

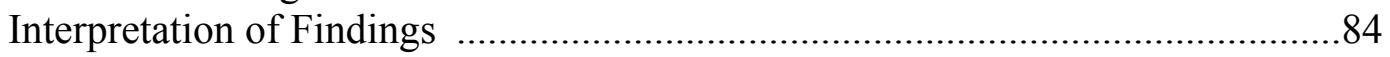

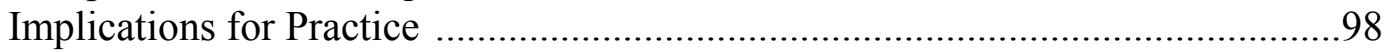

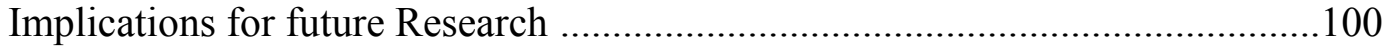

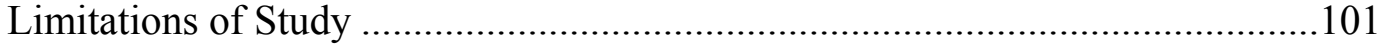

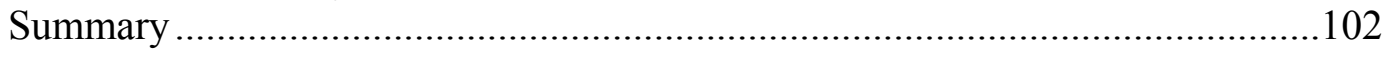

REFERENCES [............................................................................... 104

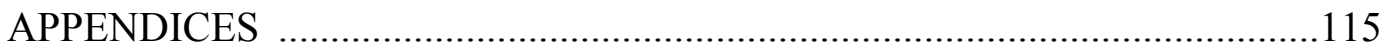

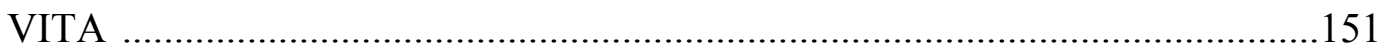




\section{LIST OF TABLES}

TABLE

PAGE

1. Analysis of Variance Repeated Measures Design ............................................41

2. Weeks of Instruction, Titles, and Page Lengths of Bluford Novels .....................53

3. Demographic Variables of Study Participants by Group....................................63

4. Mean (SD) Comprehension Raw Scores for Gates MacGinitie Reading Tests by Group..............................................................................65

5. Mean (SD) Reading Comprehension Scores for FAIR by Group .......................65

6. Reading Assessment Scores of Bluford Series Novels for the Experimental Group.

7. Reading Assessment Scores of Read XL for the Comparison Group.

8. Overall Mean (SD) Scores of Rhody Secondary Reading Attitude Assessment (RSRAA) by Group .70

9. Mean Scores of Negative Item Responses on the RSRAA by Group .72

10. Mean Scores of Negative Item Responses on the RSRAA by Group .74

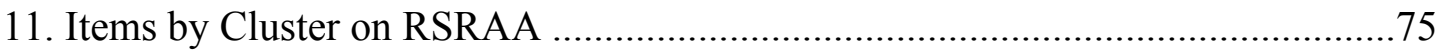

12. Other Recreational Mean (SD) Scores of RSRAA by Group...............................76

13. General Reading Mean (SD) Scores of RSRAA by Group ............................... 77 


\section{LIST OF FIGURES}

FIGURES

PAGE

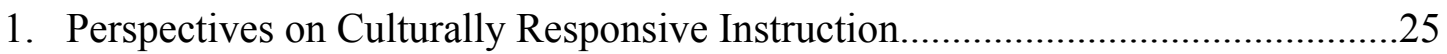

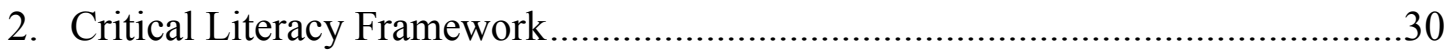

3. Components of Intervention Cycles ….....................................................49

4. Components of Instructional Framework for the Experimental Group ................54

5. Sequence of Instruction for the Comparison Group ........................................55

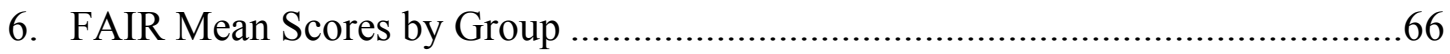

7. Bluford Mean Scores Across Time...................................................................68

8. Pre and Post Overall Mean Scores of RSRAA by Group ...................................71

9. Pre and Post Other Recreational Mean Scores of RSRAA by Group....................76

10. Pre and Post General Reading Mean Scores of RSRAA by Group .......................78 


\section{LIST OF ABBREVIATIONS AND ACRONYMS}

\begin{tabular}{|c|c|}
\hline ANOVA & Analysis of Variance \\
\hline AP & Assessment Period \\
\hline AYP & Adequate Yearly Progress \\
\hline CRI & Culturally Responsive Instruction \\
\hline CRL & Culturally Relevant Literature \\
\hline ESE & Exceptional Student Education \\
\hline ESOL & English for Students of Second Language \\
\hline FAIR & Florida Assessment for Instructions in Reading \\
\hline FCAT & Florida Comprehensive Assessment Test \\
\hline FDOE & Florida Department of Education \\
\hline FRL & Free and Reduced Lunch \\
\hline GMRT & Gates-MacGinitie Reading Tests \\
\hline LEP & Limited English Proficiency \\
\hline NCLB & No Child Left Behind \\
\hline RSRAA & Rhody Secondary Reading Attitude Assessment \\
\hline RQ & Research Question \\
\hline SBBC & School Board of Broward County \\
\hline SCRAP & Summary, Connect, Reflect, Asking Questions, and Predict \\
\hline SES & Socio Economic Status \\
\hline TA & Test Administration \\
\hline TI & Traditional Instruction \\
\hline $\mathrm{TL}$ & Traditional Literature \\
\hline
\end{tabular}




\section{CHAPTER I}

\section{INTRODUCTION}

Culture plays a critical role in the educational process, and can be employed as the foundation for culturally responsive instruction. Culturally responsive teaching, therefore, is defined as teaching that is rooted in the understanding of the role of culture in the teaching and learning process (Adams, Bondy, \& Kuhel, 2005). Instructional practices that embrace issues of culture show positive impacts in optimizing learners to become successful readers (Beaulieu, 2002). Specifically, "culturally responsive instruction can bring students of diverse backgrounds to high levels of literacy by promoting engagement through activities that reflect the values, knowledge, and structures of interaction that students bring from the home" (Au, 2001, p. 1). Public schools have seen a demographic shift with an increased number of students who are not considered to be part of mainstream culture; culturally responsive instruction can be used as a means to provide effective learning opportunities for these students. A classroom that is more culturally appropriate and more motivating will engage students and lead to higher rates of achievement because there is personal interest in the subject taught, which contributes to a deeper level of comprehension processing (Worthy, Moorman, \& Turner, 1999).

Research that advocates for culturally responsive instruction identifies collaborative discussion of text and student-centered learning environments as major tenets in developing and supporting students' understanding of text (Callins, 2006; Ladson-Billings, 1995; Nichols, Rupley, \& Webb-Johnson, 2000; Risko and WalkerDalhouse, 2007; Schmidt, 2003; Stoicovy, 2002). Social learning environments such as 
literature discussion groups are supportive learning environments for fostering culturally responsive instruction. Culturally responsive instruction is supported by Vygotsky's sociocultural theory of learning that incorporates social interaction as integral to a child's academic development (Vygotsky, 1978). In social learning environments, learning occurs through active, interpersonal communication, and reading and writing development is acquired by social and cultural processes (Houge \& Geier, 2009). Comprehension is the overall goal of reading; therefore, using culturally responsive instruction as a way to enhance learning may foster reading growth and further increase a positive attitude towards reading.

\section{Purpose of the Study}

Greenleaf and Hinchman (2009) stated that many adolescents process textual information at a literal level, which is insufficient for true comprehension. These students must be able to employ inferential skills and cognitive strategies to read and interpret text, as there is a constant need to access increasingly more difficult information for content areas through the process of reading (Rasinski, 2000), which is even more crucial as students progress through their school life. With these increasing reading demands, some adolescents exhibit greater reading deficiencies and over time, and reading proficiency decreases because there is (a) less emphasis on reading instruction at the secondary level (Moje, 2008); (b) an increasingly diverse student population, which creates a cultural mismatch between teachers and students (Coleman, 2000); (c) an increase in reading demands, coupled with increasingly challenging reading material (Biancarosa \& Snow, 2004); and (d) a disconnect between public or in-school literacy and private or out-of-school literacy (Faulkner, 2005). As a result of this reading 
deficiency, struggling urban adolescent readers may need more comprehension intervention to help them succeed in reading.

Apart from the challenging material that is present at this level, some adolescents also do not immerse themselves in reading that would enhance their educational and social opportunities and so the achievement gap begins to widen (Knoester, 2010). Children who come from homes where there is avid family literacy and parental involvement tend to be more engaged in the learning process and are more likely to use their experiences, history, and lifestyles to build on their learning (Huang \& Mason, 2008). However, an enigma remains as to exactly what will encourage positive reading attitudes and an increase in students' reading achievement.

One of the ways to potentially motivate, interest, and engage students may be through culturally responsive instruction. A classroom that is more culturally appropriate and more motivating may engage students and lead to a higher rate of achievement. To develop a culturally appropriate environment, the interests of students must be considered. Research continues to show that a learner is more motivated when there is a personal interest in the subject taught, and this allows the learner to engage in a deeper level of comprehension processing (Worthy et al., 1999). Additionally, when the context of teaching and learning is responsive to the students' culture, it allows students to make connections with their interests and experiences. This type of learning proves to be more significant and relevant for students; and teachers are able to capture students' prior knowledge and build on it. Some advocates of culturally responsive instruction claim that it promotes literacy and high achievement in students (Gay 2000; Ladson-Billings, 1995). Therefore, this study was undertaken to determine whether there was a 
relationship between culturally responsive instruction, using culturally relevant literature, and the reading comprehension and attitude of struggling urban adolescent readers.

\section{Statement of the Problem}

The present study investigated the relationship of culturally responsive instruction and the reading comprehension and attitude of struggling urban adolescent readers, who function at the level of literal text comprehension as opposed to inferential text comprehension. The study also embraced a sociocultural framework through the use of fictional literature that is culturally relevant and discussion groups in which students constructed meaning through reading, writing, and group interaction. Therefore, this study investigated whether or not the incorporation of students' culture into classroom learning will enhance positive reading attitudes and promote greater reading achievement.

\section{Research Questions}

The central research question explored in this study was: What is the relationship between culturally responsive instruction and the reading comprehension and attitude of struggling urban adolescent readers? Subsidiary questions were:

1. Will struggling adolescent readers who participate in culturally responsive instruction that uses culturally relevant, urban literature, show greater reading comprehension than struggling adolescent readers in a comparison group using traditional literature and methods?

2. Will struggling adolescent readers who participate in culturally responsive instruction that uses culturally relevant, urban literature, develop a more 
positive attitude toward reading than struggling adolescent readers who do not participate in this instruction?

\section{Hypotheses}

The study was guided by two major hypotheses:

1. Struggling urban adolescent readers, who participate in culturally responsive instruction that uses culturally relevant literature, will show greater reading comprehension growth when compared to students who do not participate in culturally responsive instruction using culturally relevant literature, as measured by the Gates-MacGinitie Reading Tests (GMRT) and the Florida Assessments for Instruction in Reading (FAIR).

2. Struggling urban adolescent readers, who participate in culturally responsive instruction that uses culturally relevant literature, will demonstrate a more positive attitude toward reading when compared to students who do not participate in culturally responsive instruction using culturally relevant literature, as measured by the Rhody Secondary Reading Attitude Assessment (RSRAA).

\section{Theoretical Framework}

This study was situated within the theoretical framework of Culturally Responsive Instruction (CRI). CRI is a form of pedagogy used to empower students intellectually, socially, emotionally, and politically by the use of relevant cultural references that impart knowledge, skills, and attitudes (Ladson-Billings, 1994). Pang (2005) has noted that "CRI is an approach to instruction that responds to the sociocultural context and 
seeks to integrate the cultural content of the learner in shaping an effective learning environment" (p. 336). Gay (2010) has defined CRI as a framework for instruction that builds upon "the cultural knowledge, prior experiences, frames of reference, and performance styles of students to make learning encounters more relevant and effective for them" (p. 31). Ladson-Billings $(1994,2001)$ has proposed academic achievement, cultural competence, active teaching methods, and student-centered discourse as important tenets in a culturally responsive teaching environment. Moreover, Gay (2000, 2010) embraced this cultural sensitivity towards the curriculum as one that validates learners through sociocultural realities while at the same time empowering them as they contextualize their learning.

Employing CRI as a pedagogical approach may help to (a) meet the needs of diverse learners due to the ever changing demographics in classrooms throughout the United States, (b) link the school to the world of the student by incorporating the student's values and culture, and (c) build upon students' strengths and make learning more student-centered (Callins, 2006; Ladson-Billings, 1995; Nichols, Rupley, WebbJohnson, \& Tlusty, 2000; Schmidt, 2003; Stoicovy,2002). Culturally responsive practices can potentially engage and motivate children as they affirm and validate their cultural identify through text representations (Ladson-Billings, 1994).

CRI is built on the sociocultural theory of learning, which embraces social interaction as optimal to a child's academic development (Vygotsky, 1978). This theory is based on the belief that knowledge and skills can be obtained when students interact and participate in activities with others. Social interactions can be a vehicle to students' literacy development because student learning can be guided and expanded through peer 
interactions (Verhoeven \& Snow, 2001). Moreover, CRI is based on the premise that culture is indispensable in the understanding and control of the educative processes (Pai, Adler, and Shadiow, 2006). Therefore, this study was undertaken to explore the relationship of CRI and the reading comprehension and attitude of struggling urban adolescent readers, through the use of high interest, authentic, and culturally relevant texts that students can identify with.

\section{Significance of the Study}

This study is significant because it seeks to explore the use of culturally responsive instruction in enhancing reading comprehension and attitude of struggling urban adolescent readers. Moreover, the significance of the problem lies in the fact that some adolescents continue to struggle with reading and are deemed to be less than proficient in reading according to state test data. The National Assessment of Education Progress (NAEP) in its evaluation of a national representative sample of eighth graders reported that $76 \%$ scored at or below the NAEP basic achievement levels in reading, where basic achievement level indicates a partial mastery of fundamental knowledge and skills required for reading proficiency (National Center for Education Statistics, 2011a; Rampey, Dion, \& Donahue, 2009). Additionally, the 2011 NAEP Trial Urban District Assessment (TUDA) report revealed that eighth graders showed no significant increase in reading when compared to eighth graders who participated in the test in 2009, with many, still performing at or below basic levels of proficiency (National Center for Education Statistics, 2011b).

Despite the poor performance as evidenced by standardized reading tests, some struggling urban adolescents are inclined to gravitate to, and become engaged in the 
reading of urban fiction, fiction that highlights cultures and ways of life that are reflective of various historically marginalized groups (Gibson, 2010). As students gravitate to urban fiction, they have been shown to develop strengths in their private or out-schoolliteracy skills (Faulkner, 2005; Morris, Hughes-Hassell, Agosto, \& Cottman, 2006; Tatum, 2008). Contrary to the traditional forms of text that are utilized in the public school, urban text spurs the highest rates of engagement for adolescents (Worthy, et al., 1999). More specifically, Gibson (p.565) has stated that "populations of adolescent African American girls who have been traditionally disengaged from school texts and, in many cases, labeled remedial learners are engaging and reading urban fiction." Therefore, she has stated that engagement with urban fiction as a form of genre in the teaching and learning environment, can be a conduit for incorporating students' reading interests or out-of-school literacy with their in-school literacy to promote reading achievement, and may also function as a foundation for culturally responsive teaching. According to Gay (2010), culturally responsive teaching is validating when it acknowledges and legitimizes the reading cultures of students. However, there is limited research on how culturally responsive instruction (CRI), using urban fiction as literature that is culturally relevant, can be implemented to increase the reading proficiency of struggling urban adolescent readers.

As a result of this deficiency in reading, this study became significant and investigated the use of culturally responsive instruction through the use of high interest, authentic, and culturally relevant texts with which students can identify. As students interact with such texts, they may attain high literacy levels, build critically thinking skills, and construct meaning from text as they are comfortable to discuss text that speaks 
to their lives, culture, and environment. In support of culturally responsive instruction, Ladson-Billings (1994) claimed that academic achievement can be procured if students are able to validate their culture through literature. Sims (1982) referred to this validity of culture as culturally conscious, where literature is written from the standpoint of students' lived experiences (p. 49).

\section{Assumptions of the Study}

The following underlying assumptions of the study were made by the researcher:

1. Student participants will be honest in reporting their responses to the researcher.

2. Children can learn in social environments where participants construct meaning in a supportive learning environment.

\section{Delimitations of the Study}

The participants in this study were limited to students of diverse backgrounds, mainly seventh-grade African American and Hispanic students, in an urban middle school in South Florida. The variables in the study were delimited to culturally relevant literature (Bluford Series), and students' attitude and comprehension. Also, the researcher implemented the study and interpreted the results of the study; and the participants were students who were taught by the researcher on a daily basis.

\section{Operational Definition of Terms}

For the purpose of this study, the following terms are defined within the context of the study to provide a clear understanding:

Culturally responsive instruction. A type of instruction that may meet the needs of struggling urban adolescent readers, through the use of the Bluford Series novels as 
authentic texts that may enhance social discourse and allow readers to make personal connections in a supportive classroom environment.

Culturally relevant literature. The use of the Bluford Series of novels as literature or authentic texts that reflect the real life and everyday experiences of students in their school, home, and communities.

Bluford Series. A series of 4 books, chosen from a collection of 18 books that deals with realistic relations to urban life. They were chosen based on high interest, authenticity, and the realism of the genre.

Rhody Secondary Reading Attitude Assessment. A survey that measures the reading attitude of each student prior to the intervention and after the intervention.

Reading comprehension. The process of reading and responding to literature to obtain meaning through literal and inferential questions.

Response to literature. A written response to what students read. This response to literature was measured using multiple strategies in SCRAP. A researcher-created rubric was used to measure how students responded to the reading.

Discussion groups. A group of four students in heterogeneous groups, who met to collaborate and discuss the reading of culturally relevant literature (Bluford Series). Students' ability to discuss was measured by a checklist and teacher observation of each student's ability to generate a question, respond to a question, and piggy-back on someone's idea or view point. Students responded to the literature in SCRAP (Summarize, Connect, Reflect, Ask questions, and Predict) to support their discussions.

Struggling readers. Recognized as failing to meet the basic and proficient reading levels, level three to five, according to the state standardized test, Florida 
Comprehensive Assessment Test (FCAT) score. These struggling readers have performed at the reading levels one and two, and need an intensive reading curriculum.

\section{Summary}

In this chapter, the introduction, statement of the problem, and purpose of the study were presented. In addition, research questions were posed with relevant hypotheses. The underpinning theoretical framework of the study, significance of the study, assumptions of the study, delimitations of the study, and definition of operational terms were also presented. Literature related to this study is reviewed in Chapter 2. Chapter 3 describes the quasi-experimental methodology that was used to conduct this study. Chapter 4 presents the results of the statistical tests using tables, figures, and narratives. Finally, chapter 5 summarizes the study, and provides an interpretation of the

findings. The implications for practice and future research, followed by the limitations of the study are presented. 


\section{CHAPTER II}

\section{LITERATURE REVIEW}

The purpose of this study is to examine the impact of culturally responsive instruction using culturally relevant literature on the reading comprehension and attitude of struggling adolescent readers. This chapter provides a literature review that is organized in five sections: (a) adolescent literacy; (b) culturally responsive instruction; (c) urban fiction (d) literature discussion groups; and (e) literacy, motivation and reading attitude. A summary is also presented.

\section{Adolescent Literacy}

Adolescent literacy has been overshadowed by early childhood and primary literacy studies for years (Stevens, 2008). As students mature into adolescence, emphasis on reading instruction at the school level receives less attention (Moje, 2008) and students' attitude towards reading begins to diminish (Worthy et al., 1999). The emphasis that is placed on reading during the early years is somehow lost in the middle and later years of schooling (McCormack \& Paratore, 2003; Moore, Bean, Birdyshaw, \& Rycik, 1999). The scaffolding of reading instruction that permeates the formative years of school is not usually a part of middle-grade instruction when students are expected to have a mastery of reading strategies. Moreover, much of the research design is focused on early literacy development, but in more recent years, there has been a thrust toward research in adolescent literacy (Lenters, 2006).

As students advance through school, they display more negativity and reluctance towards reading, which results in a decline in their reading competence (Worthy, 1998). This attitude is more commonly evident at the secondary level and can contribute to some 
of the failures that adolescents experience. Moreover, as students advance to young adolescence, a general decline in overall academics is mostly evident in the performance of those who are diverse and economically disadvantaged (Neuman \& Celano, 2001; Ryan \& Patrick, 2001). A need for an overall attempt on the part of schools to attract students to reading is needed (Worthy, 1998).

Contributory factors leading to a decline in reading can be attributed to ability level; interest in material; disconnect between public or in-school literacy and private or out-of-school literacy (Faulkner, 2005; Hinchman, Alvermann, Boyd, Brozo, \& Vacca, 2004) stimulation by other forms of media, such as television; and a general lack of motivation. Children whose experiences, history, and lifestyles are reflected in their learning are more engaged in the learning process and are more likely to come from homes where there is avid family literacy and parental involvement (Huang \& Mason, 2008).

On the contrary, many other students may become apathetic to reading due to their environmental or cultural situations, lack of motivation, and lack of aptitude. Likewise, the incapability or resistance to reading may be linked to their culture, ability, or language differences, contrasting with their immediate educational environment. "Too often, the culture of the school experienced by the child is very different from the culture of the family and community in which the child lives" (Stoicovy, 2002, p. 2). This cultural mismatch is referred to as cultural discontinuity. Cultural discontinuity occurs when there is misunderstanding between teachers and students in the classroom as well as the overall school (Brady, 1996; Nichols et al., 2000). Cultural discontinuity can lead to disagreements, misunderstandings, and eventual failure for students (Coleman, 2000). 
Cultural discontinuity is also defined as "a school-based behavioral process where the cultural value-based learning preferences and practices of many ethnic minority students - those typically originating from home or parental socialization activities-are discontinued at school" (Tyler et al., 2008, p. 281). For example, culture contributes to cognitive performance among African American students and so they are more predisposed to learn when there is a socialization process. Some challenges that African Americans encounter in academic achievement can be attributed to the cultural discontinuity between home and school. As a result, the achievement gap continues to widen between African Americans and Caucasians, showing low-income African American students underperforming and at risk for learning (Boykin, Coleman, Lilja, \& Tyler, 2004; Tyler et al., 2008).

The type of reading materials that are available for use at the school level may also be contributory to the disinterest in reading exhibited by students. Students will probably develop a greater inclination to read, once they are given interesting reading material that gains their attention (Ivey, 1999; Ivey \& Broaddus, 2001). Teachers should ensure that students are not underserved by the text provided for them to read.

Furthermore, teachers need to build students' textual lineages — that is, students' personal connections to text to make learning more meaningful (Tatum, 2008). Sims (1997) claims that students must engage in reading text that "reflects the racial, ethnic, and social diversity of our pluralistic society and of the world.

Once negativities and resistance are engrained in students' psyches, they create barricades to guard their feelings of failure, and their reading success begins to decrease (Paterson \& Elliot, 2006). Finding innovative ways to increase student reading is a 
critical challenge for teachers. They are faced with the dual task of imparting reading instruction and at the same time trying to improve their students' attitudes toward reading in a way that motivates them and further promotes their reading achievement. A classroom that is more culturally appropriate and more motivating will engage students and lead them to a higher rate of achievement. To develop such a culturally appropriate environment, the interests of students must be considered. A learner is more motivated when there is a personal interest in the subject taught, which allows the learner to engage in a deeper level of comprehension processing (Worthy et al., 1999).

Adolescent literacy has received much attention within the last decade due to the No Child Left Behind (NCLB, 2002) legislation in the United States. NCLB supports early learning with early childhood education as a means of preventing later learning difficulties. Research has shown that many adolescents are at risk for reading difficulty and continue to struggle with the academics due to more challenging material at higher grades. Most struggling readers "can read words accurately, but they do not comprehend what they read ... [and] lack the strategies to help them comprehend what they read" (Biancarosa \& Snow, 2004, p. 8). Other adolescents still lack phonemic skills and struggle with the problem of decoding, which is also a barrier to their learning (Paterson \& Elliott, 2006). In contrast, some research shows that struggling adolescent readers are more proficient in decoding than in comprehension (Brasseur \& Hock, 2006). Thus, adolescent readers may need more than comprehension intervention to help them to succeed in reading.

Approximately $40 \%$ of high school graduates are ill-equipped with literacy skills that are needed for work (Conklin, Curran, Gandal, \& Matthew, 2005). Moreover, $8^{\text {th }}$ - 
$12^{\text {th }}$ graders' performance in reading was reported at less than the proficient level with only a one-point increase since 2005 (National Assessment of Education [NAEP], 2000; Rampey, Dion, \& Donahue, 2009). Twelfth graders showed a 6-point decline in performance from 1992 to 2007 (U.S. Department of Education, 2008). Adolescents need to be equipped for the accelerating $21^{\text {st }}$-century literacy demands of society to become literate citizens who are able to participate in the global economy.

Some of the factors that account for this poor literacy development in adolescents include: (a) failure of elementary teachers to teach reading effectively; (b) lack of cognitive strategies to read and interpret complex texts; (c) limited sustained reading; (d) limited discussion about text; (e) examination and curriculum demands; (f) content coverage as opposed to scaffolded instruction; and (f) lack of teacher expertise in response to individual literacy needs (Greenleaf \& Hinchman, 2009). To reverse the declining levels of adolescent literacy, trivial solutions attributed to high-stakes assessment combined with teacher bonuses for improved test scores have been suggested (Santa, 2006). Such exogenous and superficial forces are not worthy solutions for the complex problem of adolescent literacy.

In this context, teachers often teach to fit the criteria of the test. However, there are four essential ideas that promote the literacy development of adolescents: (a) classroom communities and relationship, (b) direct strategy instruction and teacher modeling, (c) internalizing principles and philosophy of learning, (d) and professional expertise (Santa, 2006). Correspondingly, the following nine overlapping instructional strategies to promote literacy development in adolescence were recommended in Reading Next (Biancarosa \& Snow, 2004): (a) direct, explicit comprehension instruction; 
(b) effective instructional principles embedded in content; (c) motivation and selfdirected learning; (d) text-based collaborative learning; strategic tutoring; (e) diverse texts; (f) intensive writing; (g) a technology component; and (h) ongoing formative assessment of students. To support the instructional framework, the following infrastructural strategies should also be included to achieve effective literacy instruction: (a) extended time for literacy; (b) professional development; (c) ongoing summative assessments of students and programs; (d) teacher teams; and (e) a comprehensive and coordinated literacy program. Such infrastructural components provide support both for the tedious task of achieving success with instructional strategies and for adolescents' literacy growth (Moore at al., 1999). Incorporating the above strategies can in fact increase the reading achievement of today's youth (Biancarosa \& Snow, 2004).

In a holistic or even piecemeal way, certain aspects of the above characteristics have been implemented in schools, but they have still failed to produce the kind of literacy achievement that adolescents need to be successful. A classroom framework that supports culturally responsive instruction is also needed (Au, 2000; Gay 2000; LadsonBillings, 2001).

\section{Culturally Responsive Instruction}

Research supporting culturally relevant instruction as a means of engaging students and the benefits of such classroom environments is replete in the literature (Gay, 2000; Ladson-Billings, 1995a; Shealey \& Callins, 2007). However, research on its implementation is lacking. Culturally responsive instruction is defined as the identification of relevant cultural aspects of students' lives and infusing such into the curriculum so that it becomes part of instruction. Teaching in this manner allows an 
educator to contextualize the teaching-learning process (Stoicovy, 2002) by creating an environment that allows students to make connections with their interests and experiences. Learning then is more significant and relevant as teachers are able to capture students' prior knowledge and build on it (Guthrie \& Wigfield, 2000; Raphael \& Walstrom, 1986).

Culturally responsive instruction has been shown to promote literacy and high achievement in students (Gay, 2000; Ladson-Billings 1995). Students of diverse backgrounds increasingly populate classrooms, creating racial, ethnic, cultural, and linguistic diversity. This situation calls for a diversification in learning - a type of learning that both taps into students' experiences culturally, ethnically, and linguistically and gives them a medium to ably function at their zone of proximal development (ZPD; Vygotsky, 1978). The ZPD is the space between what students can accomplish independently and what they can accomplish with the help of others (O'Donnell-Allen, 2006).

The concept of culturally responsive instruction, also known as culturally responsive pedagogy, incorporates many terms undertaken by various researchers including culturally responsive, culturally appropriate, culturally congruent, culturally compatible, and culturally relevant (Stoicovy, 2002). The underlying factor is the need for a more potent connection between the student's home culture and the school. Though the concept of instruction that is responsive to students' needs seems beneficial in a way that facilitates learning, many drawbacks may impede the success of a culturally responsive pedagogy, such as (a) the mismatch between the teacher's culture and that of the student (Au, 2000); (b) unpreparedness of the teacher to incorporate culturally 
responsive pedagogy; (c) language, ethnicity, and race is not reflective of the dominant culture (Risko \& Walker-Dalhouse, 2007); (d) preconceived and stereotypical notions about various ethnicities and their academic abilities (Stoicovy, 2002); (e) the measuring of academic achievement through the lens of standardized test (Ladson-Billings, 1995);

(f) curriculum and resources that are not harmonious to the student's background; and (g) teacher education programs inadequately preparing educators to integrate culturally responsive instruction. A rigorous program therefore, needs to be implemented wherein teachers have a new perspective, a new vision, and a new way of doing, with limited reliance on the transmission model of instruction (Alvermann, 2001).

Based on the above research, a culturally responsive intervention is needed to (a) meet the needs of diverse learners due to the ever changing demographics in classrooms throughout the United States, (b) link the school to the world of the student by incorporating the student's values and culture, and (c) build upon students' strengths and make learning more student-centered (Callins, 2006; Ladson-Billings, 1995; Nichols, Rupley, \& Webb-Johnson, 2000; Schmidt, 2003; Stoicovy, 2002).

One study examined the Kamehameha Early Education Programme (KEEP), which was well suited for and reflective of Hawaiian culture (Au \& Jordan, 1981). The children involved in the study represented a group of under-performing Hawaiians. 'Talk story,' a common traditional storytelling aspect, was employed in the reading lessons and resulted in increased levels of reading achievement. The KEEP study showed that participation in culturally responsive approaches to reading does enhance reading achievement. However, no further evidence or replication of this study in other settings with other target groups exists to draw a comparison on its effectiveness. 
Rice (2005) emphasized the importance of a reader's background on the ability to construct meaning. This qualitative study involved a group of eight White students who were given the task to read and discuss four Hispanic-American, multi-cultural literature in discussion groups over a four-day period. What resulted is that students were unable to identify with the universal themes in the novel as a result of the difference in their socioeconomic status and ethnicity compared to the characters presented in the novel. Rice referred to this situation as aesthetic restriction and discussed the significance of one's sociocultural frame-class, race, and gender on the interpretation of text.

Another study used a cultural modeling framework as a guide to designing culturally responsive instruction (Risko \& Walker-Dalhouse, 2007). Cultural modeling was used as a method to facilitate literacy instruction with explicit connections between content and literacy goals as well as students' knowledge and experiences. For instruction, the model follows this sequence: (a) identify content to be taught, (b) identify problems embedded in the content that require higher-level thinking, (c) identify language arts skills and strategies for students to learn, (d) identify students' prior knowledge, including patterns of language used in their community, home, and with peers, (e) select multiple texts to supplement school texts that represent the culture of the students, (f) start instruction with texts that build upon students' knowledge and experiences, and (g) engage students in reading and discussing texts or in collaborative writing about the content. The model embraced two important characteristics: (a) respect for differences, and (b) use of the differences as learning resources.

This study embraced the results of seminal studies that employed the cultural modeling framework approach to teach a cultural-historical activity to $9^{\text {th }}$-grade 
underachieving students using the features of the African American language as a teaching tool (Lee, 2001, 2004). The teacher's role was to supply the knowledge base and scaffold instruction. The model allowed for metacognition, student-generated questions, text significance, and writing enhancement. With such promising results, the sequence for this framework embodies similarities to what is being done in schools today. However, research is lacking as to how the use of culturally relevant text may inform instruction.

Additionally, McCarthy, Wallace, Lynch, and Bennally (1991) give credence the importance of making classroom instruction compatible with children's culture in an investigation with Navajo (Native American) children. He postulated that although the passivity and non-verbalized disposition of some Navajo children have been relegated to aspects of negativity, there are modes of lesson presentations that may potentially inform the teaching and learning context in a way that facilitates success.

This study was conducted with Navajo children, using a bilingual-bicultural social curriculum in a K-9 school setting. Incorporated into the study were open-ended questioning, inductive/analytical reasoning, and student verbalization. Participants in the study ranged from grades K-9. The lessons were scaffolded by the teacher, who incorporated local aspects, materials, events, and situations within the community to encourage discussion. Children enthusiastically responded to the natural situations that were part of their public daily lives through discussions in small and large group settings. Their prior experiences provided the validation for them to learn and apply new content through analytical reasoning, discussion with peers and teachers using their second language. Students' learning styles were changed from passive learners to actively 
engaged learners. This supports the need for incorporating cultural aspects and funds of knowledge (Gay, 2010) into the student learning to increase academic success.

Moreover, Sheets (1995) worked with low performing Latino students with a history of academic failure, using a culturally relevant framework to teach Spanish through conversational literature and culture as opposed to grammatical rules. The results of Sheets' study positively impacted the students' academic performance. After one year, they were able to enroll in advanced Spanish language and literature courses which were previously offered only to gifted or honors English-speaking students.

The success of Sheets' study was attributed to the fact that the teaching/learning context embraced their native language, thereby by making them more proficient in their language of culture which supports the theory of culturally responsive instruction.

Some tips that an educator can employ to ensure a successful, culturally responsive program have been suggested: (a) communicate high expectations, (b) use active teaching methods, (c) facilitate learning, (d) demonstrate cultural sensitivity, (e) have positive relationships with families and community, (f) reshape the curriculum, (g) provide culturally mediated instruction, (h) promote student-controlled classroom discussions, and (i) provide small group instruction and cooperative learning (Shealey \& Callins, 2007).

An educator who is capable of implementing the above characteristics has started on a journey with the aim to reach the students where they learn best. This concept bears some similarities to the theory of multiple intelligences which is based on the notion that children learn through various intelligences, depending on their areas of strength (Gardner, 2000). The ramifications are such that students will become intrinsically 
motivated, have a feeling of self-worth, and become more focused as they have a vested interest in what is occurring. This type of instruction gives students a voice and then learning becomes more meaningful through discussions and collaborative learning. Moreover, educators will have a more profound understanding of the cultural, ethnic, linguistic, and socioeconomic diversities that form parts of the classroom and create a learning environment that fosters learning and success.

To date, most of the research is saturated with the benefits of culturally responsive instruction. Research has established why culturally responsive instruction is needed; however, the question of implementation (how) is still left unanswered. Research is needed to capture the ways in which culturally responsive instruction can be employed to allow students to attain the type of achievement that would make them successful.

Given the lack of studies on implementation, there is a need to find a replicable framework that embodies the concept of culturally responsive instruction. Although culturally responsive instruction is potentially an excellent means of meeting students' needs, just simply providing tips for a culturally responsive instruction do not suffice. Questions still need to be answered as to what factors make instruction culturally responsive. For example, when students work in groups, combined with culturally relevant material, the proclivity exists for a greater transaction with text (Ladson-Billings, 1995; Schmidt, 2004; Schmidt \& Pailliotet, 2001; Tatum, 2000). Literature discussion groups provide a context for such occurrence.

While there are many contributors championing the merits of culturally responsive instruction on students' motivation and academic achievement, some major 
contributors to this field of research include Geneva Gay, Gloria Ladson-Billings, James Banks, Jacqueline Irvine, Lisa Delpit, Sonia Nieto, and Kathryn Au.

Figure 1 outlines the definitional perspectives unearthed by some of these majors players in the research field. They have postulated that schools can utilize the cultural and linguistic strengths of marginalized groups as a way to deal with the growing diversity and underachievement in schools. 


\begin{tabular}{|c|c|c|}
\hline $\begin{array}{l}\text { James Banks, 1991 } \\
\text { "a transformative process } \\
\text { that embraces the need to } \\
\text { help 'students to develop } \\
\text { the knowledge, skills, and } \\
\text { values needed to become } \\
\text { social critics who can } \\
\text { make reflective decisions } \\
\text { and implement their } \\
\text { decisions in effective } \\
\text { personal, social and } \\
\text { political action" (p.131). }\end{array}$ & $\begin{array}{l}\text { Gloria Ladson-Billings, } \\
\underline{\mathbf{1 9 9 4}} \\
\text { "a comprehensive } \\
\text { pedagogy that empowers } \\
\text { students intellectually, } \\
\text { socially, emotionally, } \\
\text { and politically by using } \\
\text { "cultural referents to } \\
\text { impart knowledge, skills, } \\
\text { and attitudes" (p.382). }\end{array}$ & $\begin{array}{l}\quad \text { Lisa Delpit, 1995 } \\
\text { "using students' } \\
\text { cultural capital to make } \\
\text { education relevant by } \\
\text { developing the } \\
\text { 'knowledge and skills } \\
\text { each student already } \\
\text { possesses, while at the } \\
\text { same time adding new } \\
\text { knowledge and skills to } \\
\text { that base" (p. 67). }\end{array}$ \\
\hline $\begin{array}{l}\quad \text { Geneva Gay, 2000 } \\
\text { "using the cultural } \\
\text { knowledge, prior } \\
\text { experiences, frames of } \\
\text { reference, and } \\
\text { performance styles of } \\
\text { ethnically diverse students } \\
\text { to make learning } \\
\text { encounters more relevant } \\
\text { to and effective for them. } \\
\text { It teaches to and through } \\
\text { the strengths of these } \\
\text { students" (p. 29). }\end{array}$ & $\begin{array}{l}\text { Culturally } \\
\text { Responsive } \\
\text { Instruction } \\
\text { Sonia Nieto, 2003 } \\
\text { upholds "the notion that } \\
\text { rather than deficits- } \\
\text { student's backgrounds are } \\
\text { assets that students can } \\
\text { and should use in the } \\
\text { service of their learning } \\
\text { and that teachers of all } \\
\text { backgrounds should }\end{array}$ & $\begin{array}{l}\text { Kathryn Au, 2001 } \\
\text { instruction that "can } \\
\text { bring students of } \\
\text { diverse backgrounds to } \\
\text { high levels of literacy } \\
\text { by promoting } \\
\text { engagement through } \\
\text { activities that reflect } \\
\text { the values, knowledge, } \\
\text { and structures of } \\
\text { interaction that students } \\
\text { bring from the home" } \\
\text { (p.1). }\end{array}$ \\
\hline & $\begin{array}{l}\text { develop the skills to teach } \\
\text { diverse students } \\
\text { effectively" (p.7). }\end{array}$ & \\
\hline
\end{tabular}

Figure 1. Perspectives on culturally responsive instruction 


\section{Urban Fiction}

Urban fiction, also referred to as urban literature, is regarded as contemporary literature, that is positioned within realistic urban contexts and embraces societal issues, dilemmas, and lived experiences of young adolescents (Guerra 2012). The term 'urban fiction' was coined around the 1960s and 1970s and gained popularity through novelists like Donald Goines and Robert Beck (Gibson 2010; Hill, Perez, \& Irby, 2008), who wrote about the realistic stories and experiences of urban living. The terminology then was relegated to perspectives of hip-hop literature, black pulp fiction, ghetto lit, gansta lit, rap, and street literature. The urban fiction genre of literature experienced a renaissance in the year, 1999 with the novel, Souljah's, The Coldest Winter Ever and has continued to increase in popularity over the past decade (Brooks \& Savage, 2009).

Many urban adolescents may connect to urban fiction through characterization and self-identification (Bean \& Moni, 2003; Gibson 2010, Guerra, 2012). Consequently, this connection can potentially be a means for culturally responsive teaching, thus linking students' home culture to their schools' culture, while at the same time validating and legitimizing their interests as learners (Gay 2010; Ladson-Billings, 1995). Additionally, disengaged, unmotivated, and remedial readers have also found urban fiction to be enticing, and so are more inclined to reading and interacting with issues presented within the genre (Osborne, 2001), while at the same time promoting their literacy acquisition. This surge in the reading of urban fiction continues to be evident among teenage populations in both urban and suburban areas who may connect vicariously or emotionally through the realism of the genre (Morris, Hughes-Hassell, Agosto \& Cottman, 2006). Moreover, researchers (Guerra; Mason \& Au, 1991) have 
claimed that when adolescents can identify themselves through the lens of the literature that they read, academic, social, and personal benefits can be derived.

However, a dichotomy exists with the subjects or themes that are presented in urban fiction novels. These subjects include incarceration, racism, crime, substance abuse, teen parenthood, violence, family conflicts, divorce, poverty, and political issues (Bean \& Moni, 2003; Morris et al., 2006) that are relevant to the lives of students and the world in which they live. Guerra (2012, p. 386) stated that urban fiction is viewed on one hand as, "a compelling expression of inner-city culture", but on the other hand is viewed as "fiction that reinforces stereotypes" within urban communities. With such content, building a case for the use of urban fiction in schools may seem challenging and controversial. However, authors like Anne Schraff, Paul Langhan, Walter Dean Myers, Gary Soto, Sharon Flake, and Jacqueline Woodson have written teen-friendly appropriate urban fiction novels situated within realistic urban contexts with similar themes found in street lit, but void of the depicted language and situations (Brooks \& Savage, 2009; Morris, 2011). Bean and Moni posited however, that there is call for optimism about the powerful nature of this genre in enhancing literacy acquisition for teens. Accordingly, Gibson (2010) postulated the importance of embracing the genre as one that is relevant to the reading interests of adolescents as opposed to discharging its potential value.

In the context of teaching and learning, educators may find that engagement with urban fiction may be a medium for representing culturally responsive teaching which embraces the cultures and interests of learners as significant tenets. Like other forms of literature, urban fiction can be used to teach elements of plot: character development, 
setting, plot structure and literary analysis: imagery, metaphor, and other forms of figurative language (Guerra, 2012). Moreover, urban fiction builds independent reading, connects to the lives of students (Fordham, 1993 ) and engages students in reading, an attitude not realized and procured from the use of traditional school literature (Gallo, 2003). More notably, urban fiction can potentially promote students' response to text (Rosenblatt, 1995) and critical literacy (Bean \& Moni, 2003; Leland, Ociepka \& Kuonen, 2012) skills by creating a medium for engagement in discourse with an effort to cultivate critical interpretations and connections to text. This view of textual interpretation aligns itself with Freire's (1979) philosophy on humanization which illustrates the power of critical consciousness or conscientization (Sims, 1997; Spears-Bunton \& Powell, 2009) on the part of individuals to examine perspectives; "learn to perceive social, political, and economic contradictions and to take action against the oppressive elements of reality" (Freire, p. 17).

Consequently, teachers can bridge concepts in urban fiction and draw parallels between traditional and contemporary forms of literature, thereby validating students' reading interests and improving learning outcome. Morrell and Duncan-Andrade (2002) claimed that "hip-hop can be used as a bridge linking the seemingly vast span between the streets and the world of academics" (p.89). Morrell and Duncan-Andrade utilized hip-hop (song) in juxtaposition with traditional or canonical text (poetry) to increase motivation and build critical literacy skills. Students made interpretations on two pieces of text - poetry and hip-hop, analyzed and critiqued each piece in terms of literary and historical period identify and identified connections. Similarly, Whelan (2007) discussed a high school English teacher's employment of urban fiction to teach themes found in 
hip-hop (rap) poetry that paralleled those in Shakespeare. The teacher was able to bridge the themes across texts, in this case traditional and contemporary text, as a means to ensure comprehensibility and build literacy understanding.

Powell and Rightmyer (2011) posited that curriculum content should serve the “dual person of validating students' personal experiences and heritages", thus allowing students the opportunity to question the text representations (p. 127). Bean and Moni (2003) have postulated a critical literacy framework (Figure 2) through which urban fiction can be deconstructed. This framework was utilized to teach critical discourse to adolescent readers, using a young adult urban novel. The framework allows for the scaffolding of discussion where questions are centered on novel structure, reader positioning, and gaps and silences. Through this medium, teachers can initiate discussions and challenge students to engage in critical dialogical practices as it relate to urban text, "which may be culturally relevant to some students as a means of enhancing critical literacy skills" (Gibson, 2010, p.572). 


\section{Structural Prompts}

\section{Critical Discussion Prompts}

- Where does the novel come from? (its historical and cultural origin)

- What social function does the novel serve? (Discourse in fictional

worlds often mirrors and sheds light on power relationships in society)

\section{Subject and Reader Positioning}

- How does the adult author construct the world of adolescence in the novel?

- Who is the ideal reader for this novel?

- How far do you accept this positioning?

- What other positions might there be for reading this novel?

\section{Gaps and silences}

- Who gets to speak and have a voice in the novel and who doesn't?

- What is left out of the novel? (this may include events that take place outside of school)

- How else might these characters' stories be told?

- These characters inhabit certain places and spaces where they construct

their identities, What alternative places and spaces could be sites for

constructing identity?

\section{Classroom Transformations}

- How might we rewrite this novel to deal with gaps and silences?

Figure 2. Critical discussion prompts. "Critical literacy framework" by Bean and Moni, 2003. Journal of Adolescent \& Adult Literacy, 46, p. 645.

Though research has alluded to the potential benefits of this genre to increase literacy acquisition, many are based on anecdotal representations as opposed to statistically representations (Brooks \& Savage, 2009). Herein, illustrates the need for more research on the methodology, utility and implementation of this genre as a means of improving reading comprehension and reading attitude of struggling urban adolescent readers. According to Morris (2011, p. 23) "street lit is necessary for teens who seek the genre because it informs them that they are literate readers of their own worlds and that they have a voice and place in life's reality. 
Moreover, Gibson (2010) stated the following:

Because culturally relevant teaching encourages students to take pride in their cultural affiliations, engagement with urban fiction may promote the message of taking pride in being a part of the culture of reading urban fiction. This outlook may help to enhance students' perceptions of themselves as readers, their investment in reading, and, ultimately, their reading achievement—one of the goals of culturally responsive teaching. (p. 570).

\section{Literature Discussion Groups}

Literature discussion groups have been touted as one classroom framework that can be used to engage students in the social process of reading (Kong \& Fitch, 2002; Wilfong, 2009; Wolf \& Rickard, 2003; Van den Branden, 2000). Involvement in discussion groups is a democratic and social process that gives students a spirit of community, wherein they can construct meaning as they interact, transact, and build on each other's ideas (Cole, 2003, p. xix; Morocco \& Hindin, 2002). Moreover, "reading comprehension and engagement improves when students participate in discussion" (Lipson, 2007, p. 36). Two common forms of literature discussion groups are Book Clubs and Literature Circles, but this review is limited to the confines of Book Clubs. Despite the type of discussion group, some common features are: book selection by students, organization of small groups, and discussions to promote a rich understanding of text (Gunning, 2004).

Peer interactions during discussion groups are a powerful tool that allows for autonomy in the thinking and literacy process. In one study, 19 fifth graders of Caucasian descent were heterogeneously placed in discussion groups according to both ability, as indicated by their standardized reading scores, and gender (Clark, 2009). The researcher examined comprehension of the stories read by retelling. Students participated in a pre-discussion, group discussion, and a post discussion retelling of the story. The 
higher ability-level students showed greater comprehension with post-discussion of story retelling than the lower ability-level readers. Even though students were not taught comprehension strategies, they were able to employ a few strategies such as questioning and evaluating in their group discussions. Despite this, the study shows a lack of metacognitive strategies employed by students. Training in metacognitive awareness is needed for students to be able to use their conditional (when to use) and procedural (how to use) knowledge for comprehension. Results confirmed that if teachers have certain expectations, they should provide a model for students.

Similarly, another study looked at literature discussion groups with an immigrant population in an elementary school located in an urban and culturally diverse school district in the United States (Medina, 2010). The students were fifth graders, originally from Mexico and El Salvador. This study focused on using discussion groups both to analyze bilingual literature from a global perspective and to help students form an identity to understand who they are through connections to the literature. In examining the discourse among the immigrants in story-telling and discussion groups, the author observed disparity in the social and cultural context of the discussion. Essentially, when students connect to the literature, many teachers see this as an indication of text comprehension. Also, students can acquire a deeper meaning of text when they can connect their experiences and culture to text.

There is an underpinning understanding that if immigrants can successfully engage in a discussion and, moreover, connect to the literature, then children in the United States school system should also be able to accomplish the same task, with fewer challenges. Though there is much credence to this article, the situation may not 
necessarily be the same everywhere. One has to also consider the geographical region, the background, culture and ethnicity of these children, which would allow for a variation in thought, and perspectives in the literature being studied. The fact that these students were interacting with bilingual literature may have given them an advantage due to their prior experience. In many instances, students interact with text that they cannot connect with and so this limits their understanding of text.

One type of discussion group, the Book Club (Raphael, Florio-Ruane, George, Hasty, \& Highfield, 2004), is defined as a student-led participatory model which involves students in the constructive process of sharing, clarifying, and developing their understandings around specific text (Frei, 2006). A more pragmatic but similar definition of Book Club is a small groups of readers who meet regularly and systematically to discuss books, as well as other texts, chosen by the its members (O'Donnell-Allen, 2006). In such a setting, various response methods are used to prompt and extend discussion, and Book Club membership varies accordingly. Participation in Book Clubs gives students ownership of reading and learning; students more actively participate in the reading process through discussions with their peers; and classroom discussions become more meaningful for students as they participate in the construction of their own knowledge (O’Donnell-Allen). Book Clubs are also conducive for the teaching of multiple strategy instruction (Raphael, Florio-Ruane, \& George, 2001).

The Book Club is one way of addressing young adolescents' intellectual, social, emotional, and moral development (Raphael, Florio-Ruane, George, Hasty, \& Highfield, 2004). Additionally, the Book Club strategy helps to empower students as they interact in small groups, creating an opportunity for marginalized voices to be heard (Wilfong, 
2009). Similarly, student learning is enhanced when the classroom provides a sense of community, where students can interact comfortably with their peers, as well as with the teacher (Wolf \& Rickard, 2003). Students' voices are valued because power is distributed, they are provided with choices, and they have a sense of freedom. Book Clubs are a social experience that provides a sense of community (Wilfong, 2009; Wolf \& Rickard, 2003).

In one study, researchers worked with 60 middle school students in Book Clubs and saw increased motivation in students' attitude towards reading as measured by an attitude survey that was completed prior to and after the study (Whittingham \& Huffman, 2009). The results of the study revealed that being exposed to Book Clubs has a positive effect on students who are resistant to reading. Despite the positive effects, it is unclear if motivation increased because students volunteered to be a part of the Book Club experience or if motivation increased because of the level of engagement and the fact that students were conversing about independent reading books as opposed to a traditional Book Club where the same book is discussed. There is no indication as to the demographics, including ethnicity, ability level of the participants in the study, or the type of text, which questions the generalizability of the study.

Another study offers a more comprehensive view of the nature of a Book Club to engage readers in elementary fourth- and fifth-grade classrooms (Kong \& Fitch, 2002). The school was situated in an urban setting, and the participants were very diverse linguistically and culturally. The school sought to meet the needs of immigrant children, many of whom came from homes where English was the second language. This study stood out from previous studies because it embraced a Book Club program as opposed to 
a Book Club discussion, incorporating numerous literacy skills. The Book Club program had four components: (a) Book Clubs (small-group discussions), (B) community share (whole-class discussions), (c) reading, and (d) individual writing. Student discussions were central to the program. Students were assessed by their portfolio entries, informal observations, and an end-of-year self-assessment. This study allowed for extensive literacy engagement and a variety of ways to examine student performance.

Likewise, the Book Club program was implemented in another study with students who had learning disabilities in the areas of reading, decoding, and comprehension (Paxton-Buursma \& Walker, 2008). The study focused on piggybacking as a strategy to increase participation in classroom discussion. Piggybacking allows students to connect with or build on someone's ideas through conversation. The instructional context was labeled as a resource room where seventh and eighth grade students came for language arts instruction. Seven students participated in the study—six Caucasians, and one Hispanic student from a suburban setting. Five out of the seven students were on free or reduced lunch. Piggybacking, building on the discourse of others, significantly increased their engagement in text-based student-led discussion and increased their thinking skills. This process was successful because of the level of scaffolding that the teacher provided as students connected their ideas with each other. Despite the type of discussion group, children still have to acquire the skill of understanding how to think and what to do as they engage in reading for comprehension. 


\section{Literacy, Motivation, and Reading Attitude}

Why is motivation important in adolescents' literacy learning? As students move into middle and high school, their motivation to read decreases (Guthrie \& Wigfield, 2000). Using culturally relevant literature may motivate children to demonstrate more interest in reading and foster positive reading attitudes. According to Wang (2000), "If children do not like reading or if they think reading is boring, their negative attitude toward reading will hinder their reading improvement” (p. 120). Accordingly, if the reading attitude is positive this will engender more positive reading engagements with text, which consequently may increase academic achievement.

In 2001, Panofsky reported that the engagement is a critical characteristic in reading because it contributes to motivation and builds reading attitudes. Engaged readers are motivated, strategic, knowledgeable, and socially interactive (Guthrie, McGough, Bennett, \& Rice, 1996). When readers are engaged in the process of reading, they become motivated to comprehend (Verhoeven \& Snow, 2001). They use knowledge to proactively create new understanding from text, and they interact socially in their approach to literacy.

In one study on Book Club and motivation, adolescents would "read if the book is a good read, if the book is accessible, and if they have some ownership in the selection" (Lapp \& Fisher, 2009, p. 559). The study also supported other studies (Noguera, 2003) that claim the support of peers in reading, thinking, and sharing as pivotal to adolescents who are being motivated to read. Moreover, adolescents interact in a social world, which means that they can extend this to their interactions in a Book Club environment or literature discussion groups. Social motivation for reading builds interpersonal 
relationships because children who discuss books with a community of peers are likely to be motivated readers (Guthrie \& Cox, 2001).

Additionally, researchers have touted positive reading attitudes as pivotal to successful reading especially for struggling readers, who tend to exhibit negative reading attitudes because of their ability (Parker \& Paradis, 1986). On the contrary, other researches have denoted that regardless of ability students must display positive reading dispositions (Lazarus \& Callahan, 2000). Despite the school of thought, a major objective maybe to get struggling adolescent readers to the point where they can enjoy reading and then use that level of enjoyment as a foundation for other initiatives

Overall, in order to support children's motivation towards literacy and promote positive reading attitudes, learning experiences must be meaningful and authentic to stimulate critical thinking in reading and writing. Though the role of motivation and its effects on comprehension may seem positive, students' expectations to do well may be the stimulating factor that promotes their level of engagement.

\section{Summary}

This study pivots around the theory of culturally responsive instruction and embraces the sociocultural theory of learning, which embraces social interaction as optimal to a child's academic development (Vygotsky, 1978). According to Vygotsky, all learning occurs as a function of collaboration with more knowledgeable others. The use of discussion groups as a social construct for learning has shown positive results. All the studies that discussed Book Club embraced the positive effects of allowing students to learn through social interactions. Though the process of operating a Book Club may vary from situation to situation, and from activity setting to activity setting, it is generally 
seen as a source for building literacy community that encourages collaborative learning, higher level thinking, and constructive perspectives, which are responsive interactions that promote learning.

The use of culturally responsive urban fiction, supported by a discussion group in a Book Club framework, can aid struggling urban adolescents in raising awareness of the reading process, strategy use, and overall advancement in reading comprehension and reading attitude. It can also get students to move beyond surface-level comprehension in order to get the deeper meaning of text and to engage in critical discourse.

This chapter provided a literature review in five sections: (a) adolescent literacy; (b) culturally responsive instruction; (c) literature discussion groups; (d) urban fiction; and (e) literacy and motivation. A summary was also presented. Chapter 3 provides an explanation of the methodology. 


\section{CHAPTER III}

\section{METHODOLOGY}

This chapter begins with the purpose of the study, followed by the research questions and hypotheses repeated from Chapter 1. It further describes the research design, gaining access, participants, research setting, treatment, data collection measures, research procedures, and statistical analyses that was conducted. The threat to validity and limitations are also provided. The chapter concludes with a summary.

\section{Purpose of the Study}

The purpose of this study was to examine the relationship of culturally responsive instruction using culturally relevant literature and the reading comprehension and attitude of struggling urban adolescent readers.

\section{Research Questions}

The central research question explored in this study was: What is the relationship between culturally responsive instruction and the reading comprehension and attitude of struggling urban adolescent readers? Subsidiary questions were:

1. Will struggling adolescent readers who participate in culturally responsive instruction that uses culturally relevant, urban literature, show greater reading comprehension than struggling adolescent readers in a comparison group using traditional literature and methods?

2. Will struggling adolescent readers who participate in culturally responsive instruction that uses culturally relevant, urban literature, develop a more 
positive attitude toward reading than struggling adolescent readers who do not participate in this instruction?

\section{Hypotheses}

The study was guided by two major hypotheses:

1. Struggling urban adolescent readers, who participate in culturally responsive instruction that uses culturally relevant literature, will show greater reading comprehension growth when compared to students who do not participate in culturally responsive instruction using culturally relevant literature, as measured by the Gates-MacGinitie Reading Tests (GMRT) and the Florida Assessments for Instruction in Reading (FAIR).

2. Struggling urban adolescent readers, who participate in culturally responsive instruction that uses culturally relevant literature, will demonstrate a more positive attitude toward reading when compared to students who do not participate in culturally responsive instruction using culturally relevant literature, as measured by the Rhody Secondary Reading Attitude Assessment (RSRAA).

\section{Quasi-Experimental Research Design}

The study utilized a quasi-experimental research design (Newman, Newman, Brown, \& McNeely, 2006). The study made use of a manipulated, active independent variable, which was the instructional strategy (CRI) that was implemented with a convenience sample of students. The experimental group received the treatment of CRI using CRL. This group was composed of students from periods five and six (Block), and 
the comparison group was composed of students from periods one and two (Block), who were instructed using the designated classroom material. Both the experimental and comparison classes were instructed by the researcher of this current study. Due to fact that the sample of participants formed a non-randomized sample, the design can be referred to as non-equivalent. An independent sample $t$ - rest was conducted between the two groups to compare the ages of the participants. A Repeated Measures Analysis of Variance (ANOVA) was designed to test the subjects across multiple assessments (Hinkle, Wiersma, Jurs, \& Stanley, 2003). A Repeated Measures Analysis of Variance (ANOVA) was also conducted on the RSRAA scores, as well as the four individual clusters of the RSRAA - Reading at the library, Reading at home, Other recreational reading, and General reading. The design is represented in Table 1.

Table 1

Analysis of Variance Repeated Measures Design

\begin{tabular}{lccccc} 
Groups & Week & $\begin{array}{c}\text { Type of } \\
\text { Treatment }\end{array}$ & $\begin{array}{c}\text { Week } \\
1\end{array}$ & $\begin{array}{c}\text { Type of } \\
\text { Treatment }\end{array}$ & $\begin{array}{c}\text { Week } \\
10\end{array}$ \\
\hline Experimental & $0_{1-2-3}$ & $0_{\mathrm{x}}$ & $0_{2}$ & $0_{\mathrm{x}}$ & $0_{1-2-3}$ \\
Comparison & $0_{1-2-3}$ & $0-_{\mathrm{x}}$ & $0_{2}$ & $0-_{\mathrm{x}}$ & $0_{1-2-3}$
\end{tabular}

Note. 1 = RSRAA, 2 = GMRT, 3 = FAIR; Type of Treatment = X = CRI, $-\mathrm{X}=$ Traditional Instruction (TI) Pretests were administered during Week 1; Mid Study Assessment was administered at the end of Week 5; Posttests were administered during Week 10.

Participants were assessed at three different points, first to collect baseline data, followed by the remaining two test administrations (TA) to monitor progress over time. The between-subjects variable is the type of instruction, CRI for the experimental group 
and the traditional instruction (TI) for the comparison group. The within-subjects variable was the testing time, weeks 1, 5, and 10 for the Gates-MacGinitie Reading Tests (GMRT), and weeks 1 and 10 for Florida Assessments for Instruction in Reading (FAIR) and the Rhody Secondary Reading Attitude Assessment (RSRAA). Following the preintervention when the pretests (week 1) were administered, there were two intervention cycles: Intervention Cycle 1 and Intervention Cycle 2. Each intervention was followed by a test administration (TA) at week 5 and week 10 respectively.

The use of repeated measures analysis allowed the researcher to assess each student's progress over time to determine individual gains in performance. Testing and maturation effects were controlled since identical tests were given to both the experimental and comparison groups over the same period of time.

\section{Gaining Access}

In an effort to carry out this investigation, the researcher received permission from the School Board of Broward County (SBBC) to be allowed to implement the intervention using Culturally Responsive Instruction at the school level. Having received the permission to carry out this study, the researcher proceeded to the school/ institutional level. On receiving permission from the SBBC to carry out the study, and prior to the intervention at the school level, further permission was received from the principal to implement the study. A formal written letter was delivered to the principal of the school, informing him about the components of the study, the proposed impact on student achievement, and the suggested classes that the researcher wanted to participate in the investigation. Parental consent and assent letters were drafted and sent home for parents to sign as an indication for students' to participate in the study (see Appendices B and C). 


\section{Participants}

The participants in this study were struggling urban adolescent students - Black and Hispanic - in the seventh grade, who scored a level 1 or level 2 in the 2012 Florida Comprehensive Assessment Test (FCAT), where level 1 is the lowest possible scale score and level 5 is the highest possible scale score. These participants did not meet the level of proficiency in reading according to the state and district cut scores, and therefore followed an intensive reading curriculum of 90 minutes of daily instruction in reading, (equivalent of approximately two periods of instruction). The sample consisted of a combined total of 44 students $(N=44)$ forming a convenience sample, or non-randomized sample from two classes (periods 1/2 and 4/5) in a single urban South Florida school. Both classes were taught by the researcher/ practitioner. Periods $4 / 5$ formed the experimental group and periods $1 / 2$ formed the comparison group. Written permission from a parent or guardian was required before each child participated.

According to the school's data, many of the students for this study are of the same socioeconomic status (SES) and are classified as economically disadvantaged, which means that they participate in the Free and Reduced Lunch (FRL) program.

\section{Research Setting}

This study was conducted at an urban middle school in south Florida. The school serves a population of 1,515 students from Grades 6 through 8 with over 80 teachers. The student population is an ethnic/racial mix of $6.73 \%$ White, $47.72 \%$ Black, $36.7 \%$ Hispanic, 2.64\% Asian, 1.72\% Indian, 0.26\% Pacific, and 4.22\% Multi-Racial. The Exceptional Student Education (ESE) population consists of 213 students, representing $14.1 \%$ of the school's population; English for Students of Second Language (ESOL) 
population represents $9 \%$, and the Free and Reduced Lunch (FRL) population represents $70 \%$.

Over the course of time, the school has changed in its demographics and socioeconomic status. With over $70 \%$ of the students on the FRL program, the school has been classified as a Title I school. Many of these students live within close proximity and commute by walking, but a large number commute by school buses, as well as private transportation due to reassignment. A reassignment gives a student the opportunity to request a school where seating is available, outside of his/her assigned school boundary.

The school has been receiving a grade "A" for approximately 12 years by the Florida Department of Education (FDOE) for its students' performance on the Florida Comprehensive Assessment Test (FCAT) with the exception of the year 2008, when the school received a grade of a "B". Additionally, the school failed to meet Adequate Yearly Progress (AYP) for two consecutive years and more, 2009-2012 (Florida Department of Education, 2005) because the various subgroups (i.e., Blacks, Hispanics, Whites, ESOL, FRL, ESE) did not make sufficient learning gains on the FCAT according to the NCLB standards and the results of the FCAT. "Title I schools that do not make AYP for more than two consecutive years are required to provide additional services to students and to implement defined strategies for improving school performance" (Florida Department of Education, 2005, para 3). Over the years, the school has received intermittent visits from the district to provide intervention, to monitor the progress of students, and to display as a model Title 1 school. 


\section{Time Frame for Intervention}

\section{Treatment}

Participants in both the experimental and the comparison groups were assessed on different measures at intervals along the course of the study. At the onset of the study, the pretests, the Gates MacGinitie (GMRT), the Florida Assessments for Instruction in Reading (FAIR), and the Rhody Secondary Attitude Assessment (RSRAA), were administered and the expectations for the study were discussed. There were two intervals of intervention cycles: Intervention Cycle 1 and Intervention Cycle 2. Each intervention cycle lasted for approximately 20 days. Following Intervention Cycle 1 (end of week 5), a test administration (TA) of the comprehension portion of the GMRT was given to determine the impact of the instruction on the reading comprehension of students. Following Intervention Cycle 2 (week 10), another TA of the GMRT, FAIR, and RSRAA were administered. The GMRT was the only test given after every intervention cycle. The FAIR and the RSRAA were administered twice, at the beginning (week 1) and at the end of the study (week 10). In addition to the GMRT and FAIR, reading comprehension, discussion questions, and tests were administered as an instructional measure to guide students' literal and inferential comprehension and to test the text-based knowledge of the novels (Bluford Series) and stories (Read XL) within each intervention cycle.

\section{Experimental Group}

The participants in the experimental group were given the treatment of CRI using $\mathrm{CRL}$ as a means of increasing their comprehension and overall reading performance over a period of 8 weeks. At pre-intervention (week 1) students were assessed on three measures to receive baseline information - the Gates-MacGinitie (GMRT), the Florida 
Assessments for Instruction in Reading (FAIR), and the Rhody Secondary Attitude Assessment (RSRAA). After baseline period and testing, the experimental group was exposed to the treatment of CRI using CRL, 5 days per week for eight weeks of intervention and two weeks of testing (pre and post intervention). A total of four Bluford Series novels were read over the course of the study. The reading of each of the four novels lasted for two weeks for a combined total of eight weeks.

For the Intervention Cycle 1, week two to week five, each participant in the experimental class read and discussed two culturally relevant Bluford Series novels with emphasis on vocabulary development, main idea, plot, theme, characterization, and literary analysis. One novel was read by all participants during weeks 2 and 3 . Following that, another novel was read by all participants during weeks 4 and 5 . The experimental group was further divided into five subgroups to form literature discussion groups of approximately four students per group. Discussion groups met twice per week and utilized the Discussion Prompts (Appendix I), and SCRAP to encourage discourse within the groups. The experimental group was also assessed on the content of the novel, after two weeks of reading and discussing with multiple choice questions designed according to Florida Comprehensive Assessment Test (FCAT) specifications. At the end of the $5^{\text {th }}$ week, in the middle of the study (end of Intervention Cycle 1), the experimental group was also assessed using the GMRT (mid study test) for a second time.

Intervention Cycle 2 was initiated during week 6 to week 9 and followed a similar format as Intervention Cycle 1. Each participant in the experimental class read and discussed another set of two culturally relevant Bluford Series novels for weeks 6 and 7 and weeks 8 and 9. The experimental group convened in their literature discussion 
groups of approximately four students per group to discuss the novel. Discussion groups met twice per week and utilized the Discussion Prompts (Appendix I), and SCRAP to encourage discourse within the groups. The experimental group was also assessed at the end of two weeks on the content of the novel, with multiple choice questions designed according to Florida Comprehensive Assessment Test (FCAT) specifications.

During week 10, end of Intervention Cycle 2 (post intervention), the experimental group completed GMRT for a third time, and FAIR and the RSRAA for a second time, marking the culmination of the study.

\section{Comparison Group}

The participants in the comparison group were instructed using their daily traditional instruction in Reading for the duration of the study ( 8 weeks). At preintervention (week 1) students were assessed on three measures to receive baseline information - the Gates-MacGinitie (GMRT), the Florida Assessments for Instruction in Reading (FAIR), and the Rhody Secondary Attitude Assessment (RSRAA). After baseline period and testing, the comparison group followed the traditional curriculum using the Read XL basal reader (district-assigned text), 5 days per week for eight weeks of intervention and two weeks of testing (pre and post intervention). A total of eight short stories were read from the Read XL basal reader (one story per week) over the course of the study.

For the Intervention Cycle 1(week two to week five), participants in the comparison class read four short stories from the Read XL basal reader and discussed each short story focusing on elements of plot, theme, characterization, and vocabulary. One short story was read each week, from week two to week five both independently and 
collaboratively- pairs and small groups - with teacher scaffolding. Participants responded to end of chapter questions which were used to guide whole group discussions of each story. As a post reading and discussion activity, participants completed the GIST Template (Appendix J) to summarize the main points of each story according to who, what, where, when, why, and how, followed by a 20-word summary (GIST)

The comparison group was also assessed on the content of two stories, after every two weeks of reading and discussing with multiple choice questions designed according to Florida Comprehensive Assessment Test (FCAT) specifications. The comparison group was not exposed to the treatment of CRI using CRL but was instructed in traditional literature. At the end of the $5^{\text {th }}$ week, in the middle of the study (end of Intervention cycle 1), the comparison group was also assessed using the GMRT (mid study assessment) for a second time.

Intervention Cycle 2 occurred during week 6 to week 9 and followed a similar format as Intervention Cycle 1. Each participant in the comparison group read independently and collaboratively and discussed four more stories from the Read XL basal reader - two stories for weeks 6 and 7 and two stories for weeks 8 and 9 . The comparison group continued with whole group discussion using end of chapter guiding questions from each story. The comparison group was also assessed at the end of every two weeks on the content of two stories, using the existing text-based FCAT type questions for the Read XL basal reader

During week 10, at the end of Intervention cycle 2 (post intervention), the comparison group was assessed with the GMRT for a third time, and the FAIR and 
RSRAA for a second time, marking the culmination of the study. Figure 2 displays the components of each intervention cycle for the experimental and the comparison group.
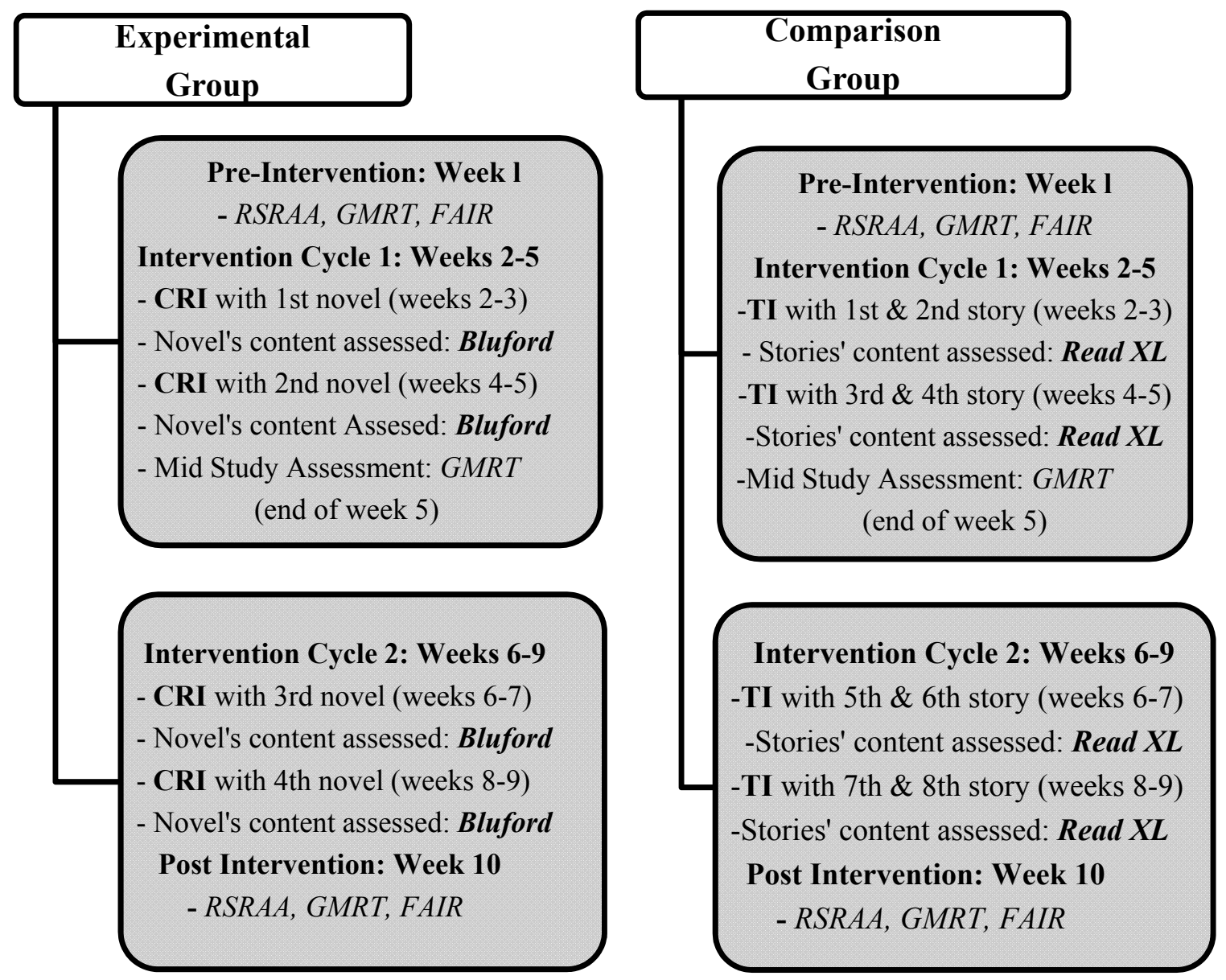

Figure 3. Components of intervention cycles.

\section{Data Collection Measures}

The goal of the study was to determine the relationship between implementing $\mathrm{CRL}$ in a program of $\mathrm{CRI}$ and the reading comprehension and attitude of low SES, Black and Hispanic, urban adolescent readers.

\section{Main Sources of Data}

\section{Rhody Secondary Reading Attitude Assessment (RSRAA). A 25-item} instrument administered to measure reading attitude according positive and negative 
items. Participants indicated their level of agreement or disagreement to each statement along a 5-point Likert-type scale, ranging from 1-5 for the positively stated items $(1=$ Strongly Disagree; 2 =Disagree; 3 =Undecided; 4 =Agree; $5=$ Strongly Agree) and a reversal from 5-1 for the negatively stated items ( $5=$ Strongly Disagree; 4 =Disagree; 3 =Undecided; 2 =Agree; $1=$ Strongly Agree). For analysis, the items are further categorized into four subscales called clusters: Reading in the library (items 9, 20), Reading in the home (items 4, 10), Other recreational reading (items 5, 11, 17, 22, 24, 25), and General reading (items 1, 2, 3, 4, 6, 7, 8, 12, 13, 14, 15, 16, 18, 19, 23). RSRAA has a test-retest reliability coefficient of .84 (Tullock-Rhody \& Alexander, 1980; Appendix D).

Gates-MacGinitie Reading Tests (GMRT). A standardized test used to test reading comprehension. Content validity was estimated with the Mantel-Haenszel Measure of Differential Item Functioning (Flippo \& Caverly, 2008), cross-validation with the Iowa Test of Basic Skills (ITBS), and construct validity estimates ranging from .79 to.81. For reliability estimates, Kuder-Richardson Formula 20 (K-R 20) internal reliability coefficients were .92 and .93 for the raw scores. Test-retest reliability coefficients were .90 for vocabulary, .74 for comprehension, and .88 for the total score (MacGinitie, MacGinitie, Maria, \& Dreyer, 2002).

Florida Assessments for Instruction in Reading (FAIR). FAIR is currently used in public schools to monitor the progress of all students, especially those students who achieved FCAT performances at Level 1 or 2 and have been identified as having reading deficiency. It is a computerized software program that is administered three times a year. FAIR provides four types of information: (a) Current Reading Ability; (b) 
FCAT Success Probability (FSP) which is a predicted probability of reading proficiency; (c) Lexile Range (Text Level); and (d) Cluster Area Scores. There are two major tasks for students: (a) the Broad Screen Progress Monitoring Tool for Reading Comprehension and (b) the Targeted Diagnostic Inventory. For the purpose of this study, only the Reading Comprehension Broad Screen Progress Monitoring Tool scores were analyzed. The Reading Comprehension portion has estimates of internal consistency reliability of 0.90 (Florida Department of Education, 2009; Greenberg \& Petscher, 2010).

\section{Secondary Sources of Data}

Reading response sheet. A researcher-created worksheet for students to record written responses according to the SCRAP Strategy (Appendix E).

Reading response prompts. The reading response prompts are a researchercreated list of sentence starters used as a scaffolding device to help students in initiating written responses to literature in the form of SCRAP (Appendix F).

Researcher-created rubric. A researcher-created rubric to measure the effectiveness of the SCRAP strategy on a student's ability to Summarize, Connect, Reflect, Ask Questions, and Predict their understanding of text through written responses. This instrument was given to other experts and teachers to determine validity and reliability estimates. Twelve Language Arts and Reading teachers were given this instrument to evaluate the appropriateness of the measure. Eighty-three percent of the teachers agreed that the instrument was valid based on its content and can be used as a reliable measure (Appendix G).

Discussion checklist. An instrument to measure a student's ability to discuss the literature. It was used for the researcher's observation of a student's ability to generate a 
question, respond to a question, and piggy-back on someone's idea or view point during discussion. A student's ability to carry out each task was indicated by a check mark. No validity or reliability estimates have been provided. This tool was used to monitor students during discussion (Appendix H).

Comprehension assessment. Researcher-created questions about the novels students read. Students responded to literal and inferential questions. Higher order reading comprehension skills modeled those covered in state standards, basal reading series, and standardized tests. The following skills were emphasized: vocabulary development, main idea, plot, theme, characterization, and literary analysis (Appendices $\mathrm{K}$ and $\mathrm{L})$.

Culturally relevant literature. A set of 4 novels from the Bluford Series (Comodromos, 2008) used for guided reading, independent reading, read aloud, and small group discussion (see Table 2). The Lexile Framework for Reading was used to calculate text difficulty for each novel. Overall, a Lexile measure indicates both a student's reading ability and the complexity of a text. The formula is based on word frequency and sentence length (Lennon \& Burdick, 2004; MetaMetrics, 2013). The Lexile measure of each novel ranged approximately from $570 \mathrm{~L}-760 \mathrm{~L}$, the reading level from $6^{\text {th }}-8^{\text {th }}$ grade, and the interest level from $7^{\text {th }}-12^{\text {th }}$ grade (Comodromos). 
Table 2

Weeks of Instruction, Titles, and Page Length of Bluford Series Books Read

\begin{tabular}{cccc}
\hline Weeks of Instruction & \multicolumn{1}{c}{ Titles } & Lexile Measures & Page Lengths \\
\hline $1-2$ & Lost and Found & $760 \mathrm{~L}$ & 125 \\
$3-4$ & Shattered & $670 \mathrm{~L}$ & 133 \\
$5-6$ & The Fallen & $640 \mathrm{~L}$ & 125 \\
$7-8$ & Breaking Point & $600 \mathrm{~L}$ & 144 \\
& & & \\
\hline
\end{tabular}

\section{Research Procedures}

\section{Pre-Intervention/Test Administration 1: Week 1}

During the first week of the study, pretests were given to provide baseline data in an effort to determine the current level of performance and the general attitude towards reading for each student in the experimental and the comparison classes after receiving regular instruction. During the pre-intervention, the experimental and comparison groups received the following three measures to determine baseline data: GMRT and FAIR which measured comprehension; and RSRAA, which measured reading attitude.

Additionally during this time, the students in the experimental group were informed about the procedures of the study and the implementation of CRI: The following was addressed: (a) group rotation and procedures which involved Beginning or Open Sharing activities with whole group, Independent Reading, Book Club with small discussion Groups, Whole Group Sharing after Book Club discussion; (b) components of SCRAP, a written response to literature used to monitor students' interpretation of text 
including Summary, Connect, Reflect, Ask Questions, and Predict (Appendix G); (c) discussion checklist, to monitor student participation in groups (Appendix H); and (d) discussion roles, following specific guidelines for group interaction (Appendix I).

Figure 3 displays the rotation of the instructional framework during the intervention. This rotational sequence was followed throughout the study by the experimental group. Students worked with the researcher, independently and collaboratively.

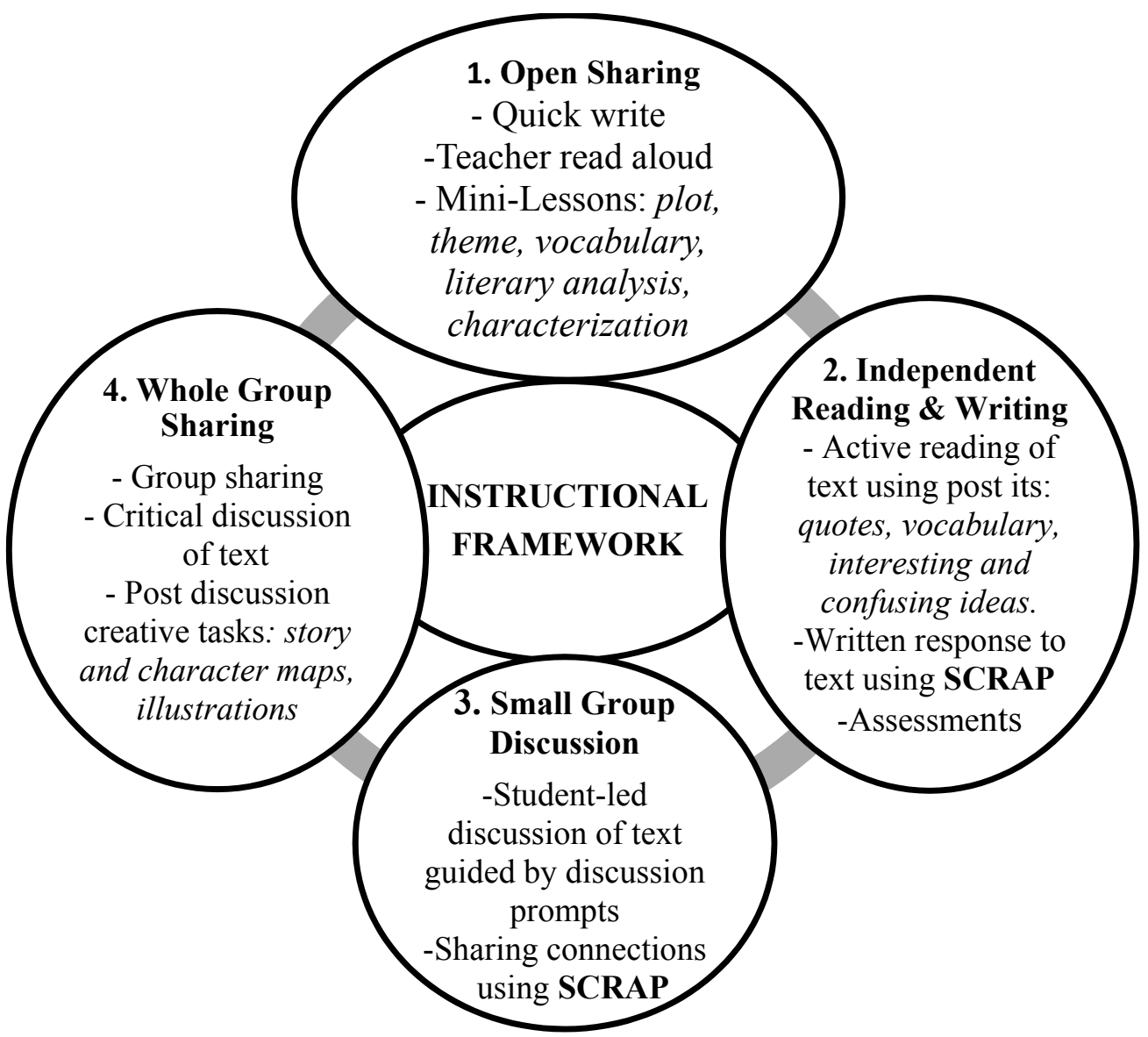

Figure 4. Components of instructional framework for the experimental group.

Likewise, the students in the comparison group were also informed about their expectations. The following were addressed: (a) whole group before reading activity (quick write and share); (b) independent and collaborative reading (pairs and small 
groups); (c) whole group discussion procedures; (d) discussion checklist, to monitor student participation in class discussions (Appendix H); and (e) components of the GIST Template, a written summarizing strategy (Appendix J).

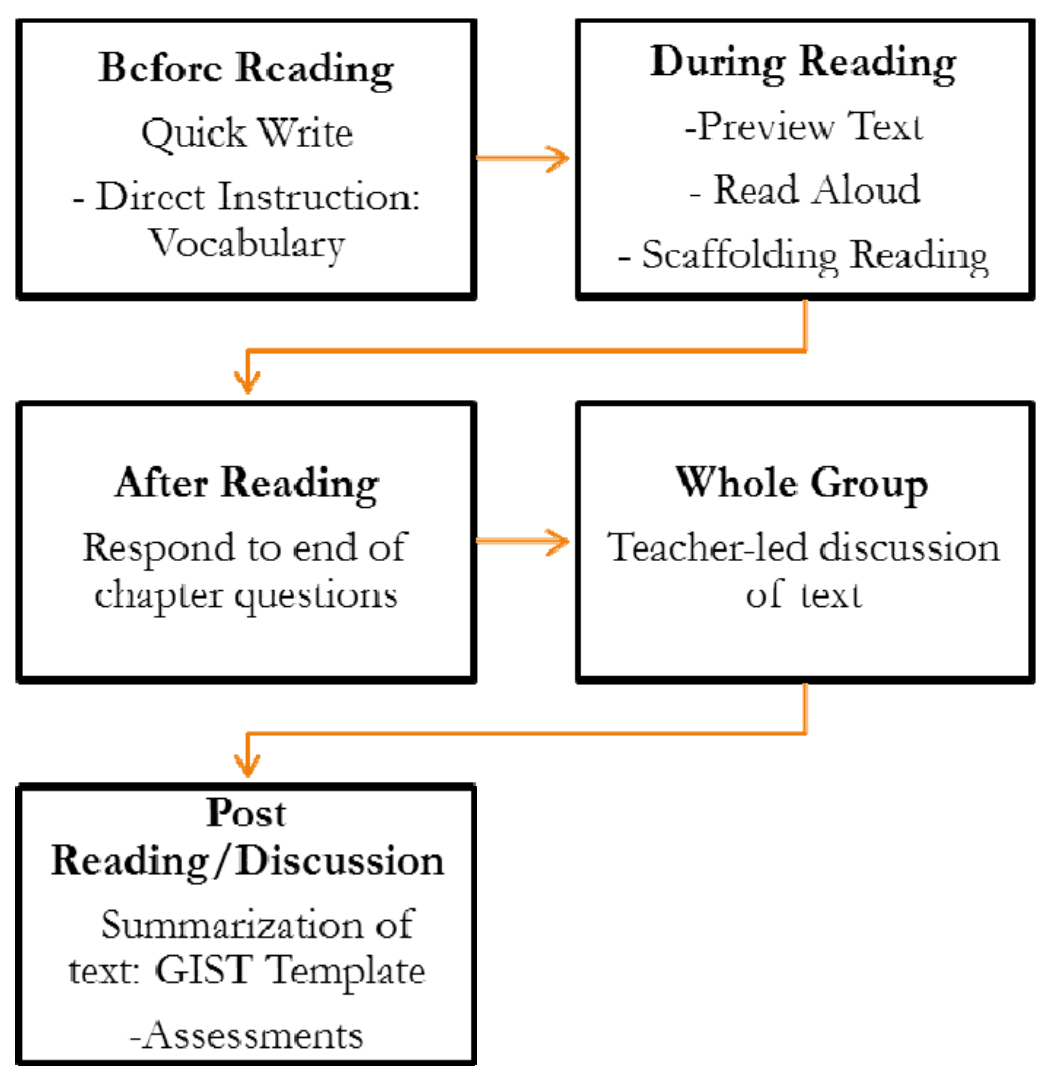

Figure 5. Sequence of instruction for the comparison group

\section{Intervention Cycle 1: Weeks 2-5}

Experimental Group. The experimental group read two CRL novels, using active strategies (recording challenging and/or interesting vocabulary, quotes, ideas) during reading to monitor their comprehension. Participants followed the pacing guide with the assigned pages for reading each day. During reading, students completed their pre-discussion or active reading tasks (recording vocabulary, quotes, interesting and confusing ideas), followed by a response to the reading, using the SCRAP strategy. This 
was done prior to meeting with their literature discussion groups. Daily classroom instruction lasted for a 90 minute block of time. The experimental group was required to discuss in their groups twice per week, using the guidelines for group interaction as specified by the Guidelines for Literature Discussion (Clark, 2009), as well the SCRAP to maintain dialogue within the group. The researcher monitored group discussions using the discussion checklist (Appendix H), took anecdotal notes, and provided feedback for the respective discussion groups.

Comparison Group. During this 4-week period, regular classroom instruction continued for the comparison group with the traditional instruction using the Read XL basal reader. Prior to the reading, the researcher pre-taught some key vocabulary words to help students comprehend the reading and to build background. The participants in the comparison group read independently and collaboratively - pairs and smalls groups according to the teacher's instructions. During reading, they recorded main ideas within each paragraph and identified elements of the plot, character, and theme. After reading, they responded to end of chapter questions, which were also used as a guide for whole group discussion. The researcher monitored whole group discussions using the discussion checklist (Appendix H). A summarizing activity followed whole group discussion, where participants used the Gist Template (Appendix J) to summarize the reading according to who, what, where, when, why, and how, followed by a 20-word summary (GIST). Daily classroom instruction lasted for a 90 minute block of time. 


\section{Test Administration 2: Week 5}

At the end of Intervention Cycle 1, the assessments, GMRT and FAIR were administered to monitor the progress of students in the experimental and comparison groups and to ascertain if there were any differences in reading comprehension scores between the two groups.

\section{Intervention Cycle 2: Weeks 6-9}

Experimental Group. The experimental group received CRI with another set of two CRL novels for 4 more weeks. The experimental group received another treatment of CRI. During this time, the experimental group read two CRL novels. Participants followed the pacing guide with the assigned pages for reading each day. During reading, students completed their pre-discussion or active reading tasks (recording vocabulary, quotes, interesting and confusing ideas), followed by a response to the reading, using the SCRAP strategy. This was done prior to meeting with their literature discussion groups. Each intervention lasted for a 90 minute block of time. The experimental group was required to discuss in their groups twice per week, using the guidelines for group interaction as specified by the Guidelines for Literature Discussion (Clark, 2009), as well the SCRAP strategy to maintain dialogue within the group. The researcher monitored group discussions using the group discussion checklist, took anecdotal notes, and provided feedback for the respective groups. Group discussions were recorded once every week.

Comparison Group. Regular classroom instruction continued for the comparison group with the traditional instruction using the Read XL basal reader. The comparison group continued with 4 short narratives from the Read XL basal reader. Prior to the 
reading, the researcher pre-taught some key vocabulary words to help students comprehend the reading and to build background. The participants in the comparison group read independently and collaboratively according to the teacher's instructions. During reading, they recorded main ideas within each paragraph and identified elements of the plot, character, and theme. After reading, they responded to end of chapter questions which were also used as a guide for whole group discussion. The researcher monitored whole group discussions using the discussion checklist (Appendix H). A summarizing activity followed whole group discussion, where participants used the Gist Template (Appendix J) to summarize the reading according to who, what, where, when, why, and how, followed by a 20-word summary (GIST). Daily classroom instruction lasted for a 90 minute block of time.

\section{Test Administration 3: Week 10}

During week 10, both the experimental and comparison groups completed the following three measures as post-tests: GMRT, FAIR, and RSRAA.

\section{Statistical Analysis}

A repeated measures analysis of variance (ANOVA) was designed to test the subjects across multiple assessments. In an effort to determine the kind of relationships that existed between the variables, the following statistical analyses were conducted. To examine research question 1- RQ1, a repeated measures ANOVA was conducted on the reading comprehension measure of GMRT and FAIR, where the between-subjects variable was the type of instruction-culturally responsive instruction (CRI) or traditional instruction (TI) or regular classroom instruction, and the within-subjects variable was the time (weeks 1, 5, and 10) of test administration. To examine research question 2- RQ2, 
an additional repeated measures ANOVA was carried out on the RSRAA where the between-subjects variable was the type of instruction - CRI or TI and the within-subjects variable, was the time (week 1 and week 10) of test administration. The software IBM SPSS v. 21 was used to perform all analyses. The .05 level of significance was used for all tests.

\section{Threats to Internal Validity}

The major threat to internal validity with this design is that the "group differences on the posttest may occur as a result of existing group differences rather than to a treatment effect" (Gall, Gall, \& Borg, 2006, p. 403). In this study, since the students were not randomly assigned, there may have been pre-existing differences. Therefore, the researcher needed to be aware of the threat of selection bias since this was not controlled.

\section{Summary}

Chapter 3 described the methodology that was used to conduct this study. At the onset, the purpose of the study, research questions and hypotheses repeated from Chapter 1 were presented. This chapter further described the research design, gaining access, participants, research setting, treatment, data collection measures, research procedures, and statistical analyses that were conducted. The threats to validity were also provided. In Chapter 4, the findings from both the experimental group and the comparison group are presented and discussed in relation to the research questions. In Chapter 5, a

summary for the study, implications for practice, implications for future research and the study's limitations are provided. 


\section{CHAPTER IV}

\section{RESULTS}

This study investigated the relationship of culturally responsive instruction and the reading comprehension and attitude of struggling urban adolescent readers. Culturally relevant literature was utilized as the means to promote reading comprehension and positive attitude toward the reading of struggling, urban adolescent readers.

This chapter presents the findings of the study using repeated measures analysis. First, a description of the sample is presented, followed by the results of the two research hypotheses: (a) struggling urban adolescent readers, who participate in culturally responsive instruction that uses culturally relevant literature, will show greater reading comprehension growth when compared to students who do not participate in culturally responsive instruction using culturally relevant literature, as measured by the GatesMacGinitie Reading Tests (GMRT) and the Florida Assessments for Instruction in Reading (FAIR) and (b) struggling urban adolescent readers, who participate in culturally responsive instruction that uses culturally relevant literature, will demonstrate a more positive attitude toward reading when compared to students who do not participate in culturally responsive instruction using culturally relevant literature, as measured by the Rhody Secondary Reading Attitude Assessment (RSRAA).

\section{Description of Sample}

A total of 44 students participated in the study, of whom 22 students formed the experimental group and 22 students formed the comparison group. A description of the students' sex, age, race/ethnicity, and school characteristics are discussed below. 


\section{Gender}

In the experimental group, $63.6 \%(n=14)$ of the sample were boys and $36.4 \%$ $(n=8)$ of the sample were girls. The comparison group was comprised of $77.3 \%$ $(n=17)$ boys and $22.7 \%(n=5)$ girls. Chi-square test results indicated that there was no significant difference in gender distribution by group, $\chi^{2}(1, N=44)=0.98, p=.322$.

Age

Based on the school's demographic data, the sample of students ranged from 1215 years of age. In the experimental group, $9.1 \%(n=2)$ of the participants were 12 years old, $45.5 \%(n=10)$ were 13 years old, $31.8 \%(n=7)$ were 14 years old, and $13.6 \%(n=$ 3) were 15 years old. The comparison group showed only a slight variation from the experimental group within the 13 and 14 years age group. Nine percent $(9.1 \%, n=2)$ of the participants were 12 years old, $59.1 \%(n=13)$ were 13 years old; $22.7 \%(n=5)$ were 14 years old, and 9.1\% $(n=2)$ were 15 years old. An independent samples $t$-test was conducted between the two groups to compare the ages of participants. There was no significant difference in mean ages for the experimental group $(M=13.5, S D=0.86)$ and the comparison group $(M=13.32, S D=0.78) ; t(42)=0.74, p=.466$.

\section{Race/Ethnicity}

In terms of race/ethnicity, $54.5 \%(n=12)$ were identified as Black students, and 45.5\% $(n=10)$ were identified as Hispanic students for the experimental group. In the comparison group, $72.7 \%(n=16)$ were identified as Black students, and $27.3 \%(n=6)$ were identified as Hispanic students. There was no significant difference in ethnic distribution by group, $\chi^{2}(1, N=44)=1.57, p=.210$. 


\section{School Characteristics}

The subjects who participated in the study were categorized as Level 1 and Level 2 according to the Florida Comprehensive Assessment Test (FCAT) in Reading. In the experimental group, there were $81.8 \%(n=18)$ Level 1 readers and 18.2\% $(n=4)$ Level 2 readers. In the comparison group, there were $77.3 \%(n=17)$ Level 1 readers and $22.7 \%(n=5)$ Level 2 readers. There was no significant difference by group for FCAT

Levels, $\chi^{2}(1, N=44)=0.14, p=.709$. There was not a significant difference by group for students with disabilities (SWD), also referred to as exceptional student education (ESE), $\chi^{2}(1, N=44)=0.09, p=.763$. Out of the overall sample of participants, $47.4 \%(n$ =21) were SWDs. Lastly, there was not a significant difference by group of their socioeconomic status as measured by participation in the Free or Reduced Lunch (FRL) program, $\chi^{2}(1, N=44)=0.12, p=.728$. Overall, $75 \%(n=33)$ of the students in this study were on Free and Reduced Lunch (FRL).

Table 3 shows a comprehensive view of the demographic variables distributed by sex, age, race/ethnicity, and school characteristics. The percentages of participants for each variable are also included. 
Table 3

Demographic Variables of Study Participants by Group

\begin{tabular}{|c|c|c|c|c|}
\hline Category & Groups & Variables & $f$ & Percent \\
\hline \multirow[t]{4}{*}{ Sex } & \multirow[t]{2}{*}{ Experimental } & Boys & 14 & 63.6 \\
\hline & & Girls & 8 & 36.4 \\
\hline & \multirow[t]{2}{*}{ Comparison } & Boys & 17 & 77.3 \\
\hline & & Girls & 5 & 22.7 \\
\hline \multirow[t]{8}{*}{ Age } & \multirow[t]{4}{*}{ Experimental } & 12 & 2 & 9.1 \\
\hline & & 13 & 10 & 45.5 \\
\hline & & 14 & 7 & 31.8 \\
\hline & & 15 & 3 & 13.6 \\
\hline & \multirow[t]{4}{*}{ Comparison } & 12 & 2 & 9.1 \\
\hline & & 13 & 13 & 59.1 \\
\hline & & 14 & 5 & 22.7 \\
\hline & & 15 & 2 & 9.1 \\
\hline \multirow{4}{*}{$\begin{array}{l}\text { Race/ } \\
\text { Ethnicity }\end{array}$} & \multirow[t]{2}{*}{ Experimental } & Black & 12 & 54.5 \\
\hline & & Hispanic & 10 & 45.5 \\
\hline & \multirow[t]{2}{*}{ Comparison } & Black & 16 & 72.7 \\
\hline & & Hispanic & 6 & 27.3 \\
\hline School & Experimental & FCAT Reading: & & \\
\hline \multirow[t]{9}{*}{ Characteri } & & Level 1 & 18 & 81.8 \\
\hline & & Level 2 & 4 & 18.2 \\
\hline & & ESE & 10 & 45.5 \\
\hline & & FRL & 16 & 72.7 \\
\hline & \multirow[t]{5}{*}{ Comparison } & FCAT Reading: & & \\
\hline & & Level 1 & 17 & 77.3 \\
\hline & & Level 2 & 5 & 22.7 \\
\hline & & ESE & 11 & 50.0 \\
\hline & & FRL & 17 & 77.3 \\
\hline
\end{tabular}

Note: $\mathrm{ESE}=$ Students with disabilities; $\mathrm{FRL}=$ Free and reduced Lunch 


\section{Results of Hypotheses}

\section{Hypothesis 1}

A repeated measures ANOVA was conducted to analyze the effect of using culturally responsive instruction that uses culturally relevant literature on the reading comprehension of struggling adolescent readers, compared to struggling adolescent readers using traditional literature and methods.

Both the experimental and the comparison groups were assessed using the comprehension subset of the Gates-MacGinitie Reading tests (GMRT) over three different times - week 1, week 5, and week 10. The GMRT comprehension subset produced three comprehension scores over the duration of the study. Additionally, both the experimental and comparison groups were assessed for comprehension on the Florida Assessments for Instruction in Reading (FAIR) during week 1 and week 10 of the study. The results from the ANOVA are shown in Tables 4 and 5 for comprehension scores on the GMRT and FAIR.

Gates-MacGinitie Comprehension (GMRT). Table 4 displays the analyses for the experimental and the comparison groups on comprehension scores of the GMRT. There was not a significant interaction of group by time on the raw comprehension scores, $F(2,84)=1.49, p=.232, \eta^{2}=.03$. The increases in comprehension over the 3 testing times did not differ by group. For the experimental group, there was an increasing trend over the three testing times, $(M s=14.86,15.36$, and 16.82) respectively, however it did not reach significance, $F(2,41)=2.23, p=.121, \eta^{2}=.10$. The comparison group did not show a significant increase in mean raw comprehension scores across the 3 times, $F(2,41)=0.66, p=.521, \eta^{2}=.03$ 
Table 4

Mean (SD) Comprehension Raw Scores for Gates MacGinitie Reading Tests by Group

\begin{tabular}{llrrc}
\hline Groups & Mean/SD & Week 1 & Week 2 & Week 3 \\
\hline Experimental & Mean & 14.86 & 15.36 & 16.82 \\
& SD & 4.62 & 3.63 & 3.72 \\
Comparison & Mean & 14.18 & & 14.18 \\
& SD & 6.67 & 4.73 & 6.31 \\
\hline
\end{tabular}

Possible range of scores $=0-48$

Florida Assessments for Instruction in Reading (FAIR). FAIR was an additional measure that was used as a pre and posttest measure to assess the participants' reading comprehension. Table 5 displays the analyses for the experimental and the comparison groups on comprehension scores of the FAIR. There was a significant interaction of group by time on the FAIR scores, $F(1,42)=7.59, p=.009, \eta^{2}=.15$. Using Fisher's LSD post hoc test, it was found that the experimental group's FAIR mean $(M=25.14)$ given during Assessment Period 2 (week 10) was significantly greater than the FAIR mean $(M=8.45)$ given in AP1 (week 1). However, for the comparison group, there was no difference between the AP1 $(M=16.09)$ and AP2 $(M=19.41)$.

Table 5

Mean (SD) Reading Comprehension Scores for FAIR by Group

\begin{tabular}{llcc}
\hline Groups & Mean/SD & Week 1 & Week 10 \\
\hline Experimental & Mean & 8.45 & 25.14 \\
& SD & 3.89 & 17.31 \\
Comparison & Mean & 16.09 & 19.41 \\
& SD & 14.74 & 14.60 \\
\hline
\end{tabular}

$\mathrm{AP}=$ Assessment Period 
Figure 6 displays a graph of the mean scores of the performance for the experimental and comparison groups on FAIR. According to Figure 6, both groups progressed from first to second test administration, with the experimental group performing significantly better than the comparison group. The experimental group increased, on average, 16.7 points compared to only 3.3 for the comparison group.

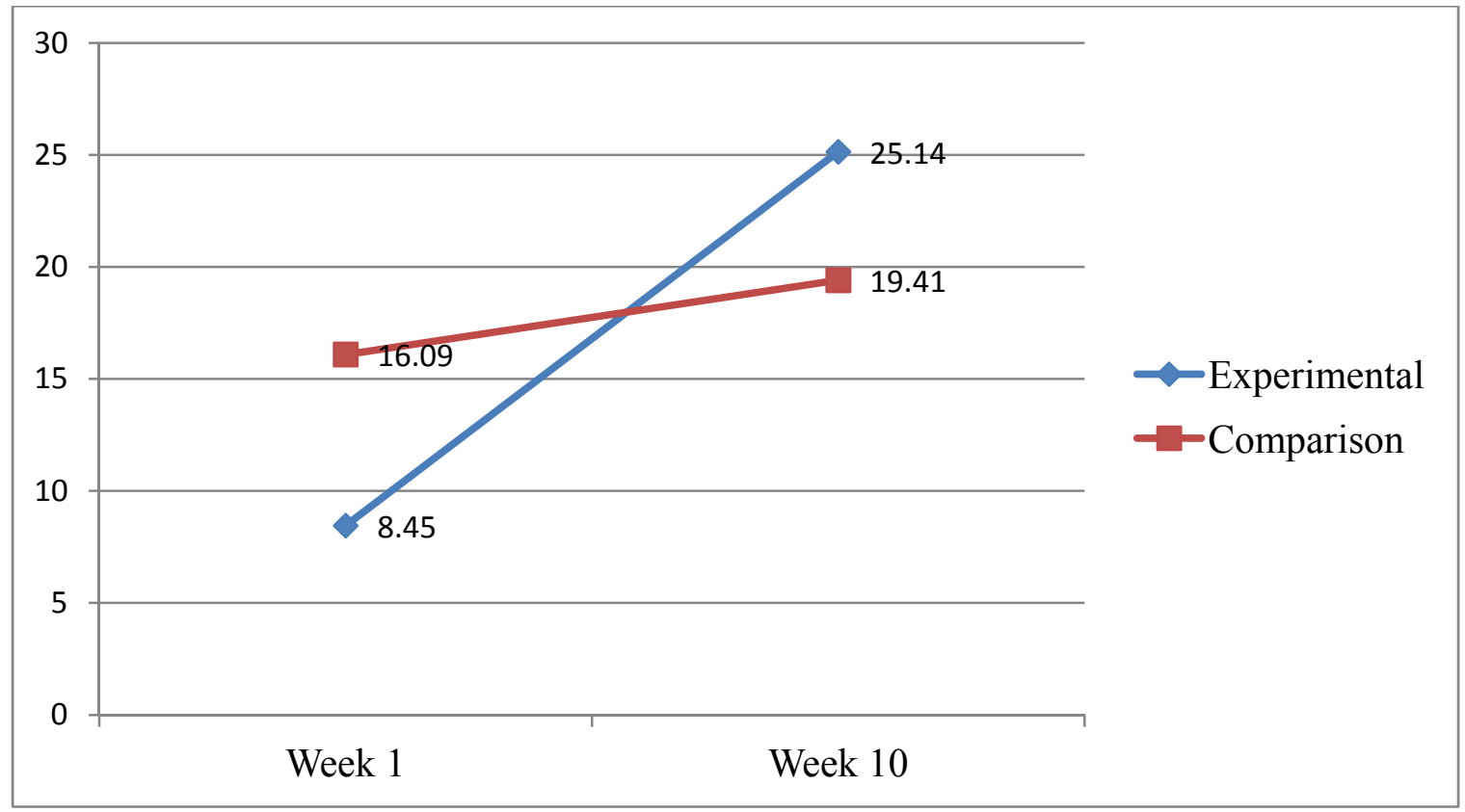

Figure 6. FAIR Mean scores by group at Assessment Periods1 (Week 1) and 2 (Week 10)

\section{Additional Tests to Assess Text-Based Understanding}

Although the additional testing for content was not hypothesized, for the purpose of grading and to ensure that the material read over the intervention period was understood, students were assessed on each of the four Bluford Series novels for the experimental group, as well as the eight stories from the Read XL basal reader for the comparison group. Both the experimental and comparison groups were instructed on grade level curriculum standards. The following section describes the mean scores of both groups on their respective assessments. Participants were assessed every two weeks 
over an eight-week intervention period, after the completion of a novel (experimental group) and after the completion of two stories from the Read XL basal reader (comparison group).

The assessments were comprised of reading comprehension questions to determine the literal and inferential understanding of text but these were not used as comparative measures between groups because the tests were linked to reading materials and were not comparable between groups. Tables 6 and 7 display the performance of the participants in the experimental and comparison groups over four assessments.

Bluford Series. According to Table 6, performance on the Bluford Series revealed that there was a significant time effect on the raw comprehension scores for the Bluford Series, $F(3,83)=16.75, p<.001, \eta^{2}=.44$.

Table 6

Reading Assessment Mean Scores of Bluford Series Novels for Experimental Group

\begin{tabular}{lcccc}
\hline Experimental Group & Week 3 & Week 5 & Week 7 & Week 9 \\
\hline Mean & 14.41 & 15.77 & 16.50 & 18.27 \\
SD & 2.17 & 2.37 & 2.41 & 1.12 \\
\hline
\end{tabular}

Possible range of scores $=0-20$

Figure 7 presents a further analysis of the performance of the experimental group over time. Accordingly, Fisher's LSD post hoc tests indicated that the raw comprehension mean scores on Bluford Series for week $9(M=18.27)$ was significantly higher than at weeks 7 and $5(M \mathrm{~s}=16.50,15.77)$ respectively, which were in turn significantly higher than week $3(M=14.41)$. This demonstrates that over time, mean scores increased significantly. 


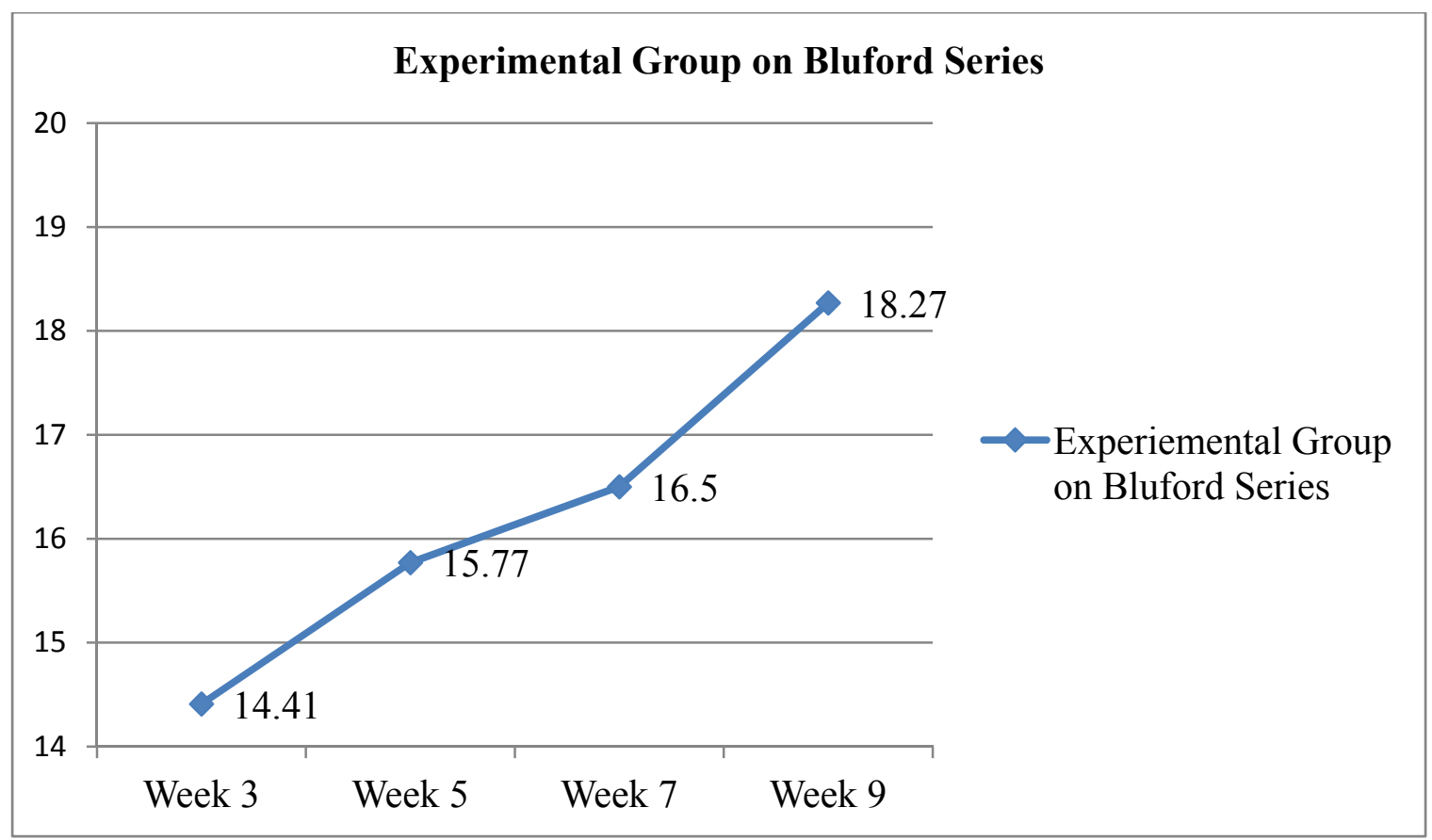

Figure 7. Bluford Mean scores across 4 times (weeks 3, 5, 7, and 9)

Literature Discussion Groups for Bluford Series. As part of the instructional framework, each novel was discussed twice weekly. Discussion in the respective groups revealed that participants were able to (a) make references to text as evidence for textbased understandings, (b) offer insights and oppose viewpoints, (c) piggyback and build on the ideas of others, (d) make connections to text, self, and world, and (e) generate questions, to gain clarity; confirmation; and raise critical awareness.

Read XL Basal Reader. In the comparison group, participants were assessed using READ XL text based questions to determine comprehension of the passages read. The results indicated that there was a significant time effect on the raw comprehension scores for READ XL, $F(3,63)=5.24, p=.005, \eta^{2}=.20$. Fisher's LSD post hoc tests indicated that the raw comprehension READ XL mean $(M=15.95)$ for week 7 and week $9(M=15.00)$ were significantly higher than at week $3(M=13.32)$ and week $5(M=$ 
12.64). In general, the comparison group's mean scores increased over the four assessments.

Table 7

Reading Assessment Mean Scores of READ XL for the Comparison Group

\begin{tabular}{lcccc}
\hline Comparison Group & Week 3 & Week 5 & Week 7 & Week 9 \\
\hline Mean & 13.32 & 12.64 & 15.95 & 15.00 \\
SD & 4.21 & 3.93 & 3.93 & 3.63 \\
\hline
\end{tabular}

Possible range of scores $=0-20$

\section{Hypothesis 2}

A repeated measures ANOVA was conducted to analyze the effect of using culturally responsive instruction that uses culturally relevant, literature on the reading attitude of struggling adolescent readers as compared to struggling adolescent readers using traditional literature and methods. Both the experimental and the comparison groups were assessed using the Rhody Secondary Reading Attitude Assessment (RSRAA) as a pre (week 1) and post (week 10) intervention measure. The results from the ANOVA are shown in Tables 8 through 12.

\section{Rhody Secondary Reading Attitude Assessment (RSRAA). The RSRAA} contained 25 items. In the interpretation of the items, some items were categorized as positive, meaning a positive attitudinal statement towards reading and negative, meaning a negative attitudinal statement towards reading. Table 8 gives the overall mean scores of the RSRAA. Tables 9 and 10 provide a breakdown of the positive and negative items and the responses of the means scores of both the experimental and comparison groups. 
Tables 11 and 12 provide the mean responses to the negative and positive items according to clusters.

For the overall mean RSRAA scores, there was a significant interaction of group by time, $F(1,42)=16.7, p<.001, \eta^{2}=.29$. The improvements in reading attitudes over the two testing times significantly differed between the experimental group and the comparison group.

Table 8

Overall Mean (SD) Scores of Rhody Secondary Reading Attitude Assessment (RSRAA) by Group

\begin{tabular}{llcl}
\hline Groups & Mean/SD & Week 1 & Week 10 \\
\hline Experimental & Mean & 75.77 & 83.82 \\
& SD & 13.68 & 13.49 \\
Comparison & Mean & 75.23 & 71.64 \\
& SD & 15.49 & 18.17 \\
\hline
\end{tabular}

Range of Scores $=25-125$

Figure 8 graphs the results of the RSRAA. Fisher's LSD post hoc tests indicated that the reading attitudes for the experimental group and the comparison group were the same initially but over time the experimental $(M=83.82)$ performed significantly better than the comparison $(M=71.64)$. The experimental group's mean increase of 8.05 points was significantly higher when compared to the comparison group's change $(M=-3.59)$.

These results support Hypothesis 2, struggling urban adolescent readers, who participate in culturally responsive instruction that uses culturally relevant literature, will demonstrate a more positive attitude toward reading when compared to students who do 
not participate in culturally responsive instruction using culturally relevant literature, as measured by the RSRAA.

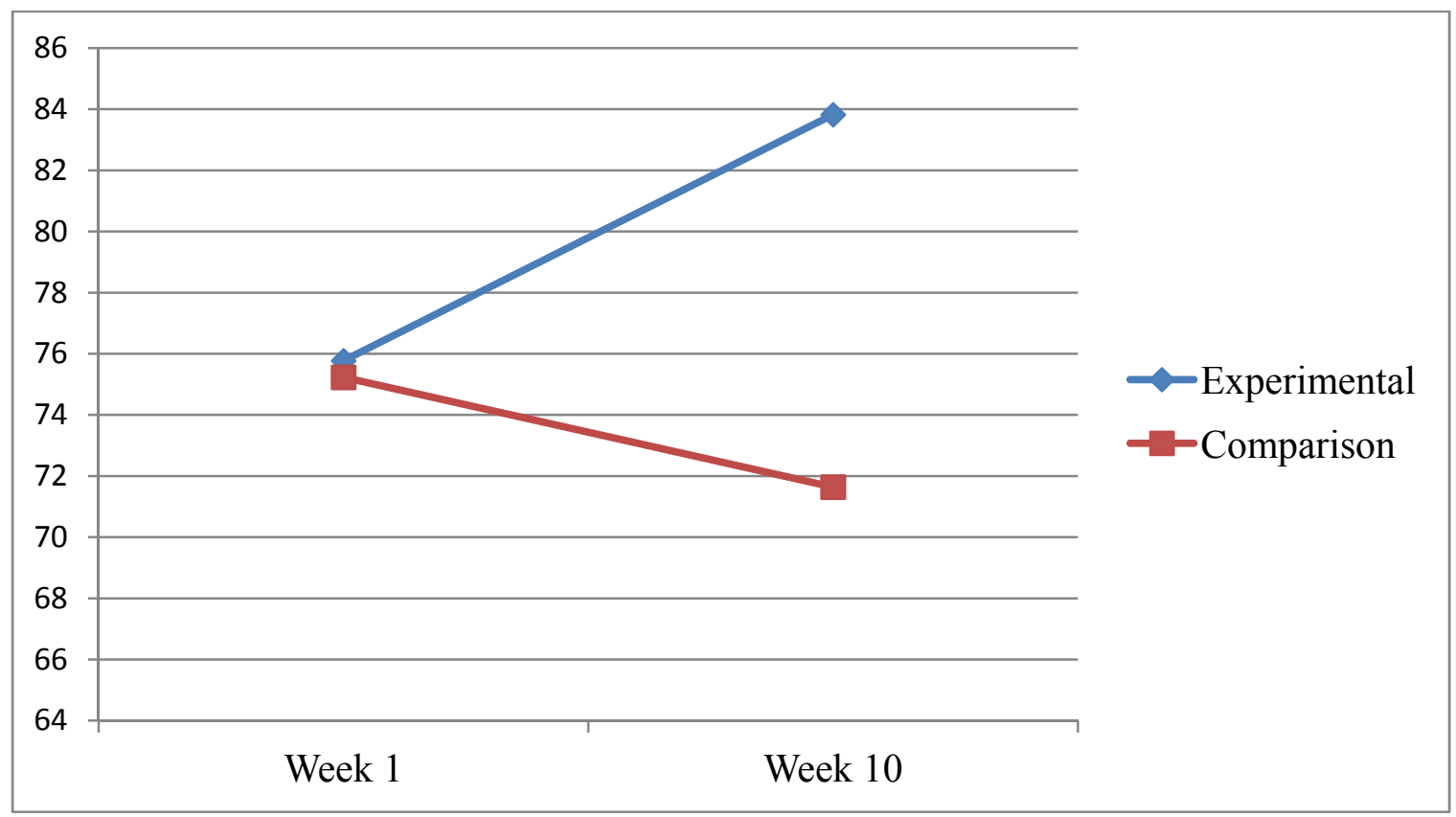

Figure 8. Pre and Post overall Mean scores of RSRAA by group

Positive Items. Table 9 details the positive items from the RSRAA and the mean responses and differences for each item. For each positive reading item, the overall mean scores for both the experimental and comparison groups are given for pre (week 1) and post (week 10), indicating the overall attitude towards reading for that particular reading item. The scores ranged in scale from 1-5 along a continuum of strongly disagree to strongly agree with the stated item. A very strong disagreement to a positively stated item received a score of 1 (strongly disagree). A very strong agreement to a positively stated item received a score of 5 (strongly agree). For example, the positively stated item, You read a lot, may be responded to along the Likert-Scale as 1= Strongly Disagree, 2 = Disagree, 3 = Undecided, $4=$ Agree, and 5 = Strongly Agree. (TullockRhody \& Alexander, 1980). For the experimental group, 11 out of 13 mean responses 
revealed positive increases in reading attitude, compared to 5 out of 13 for the comparison group from pre-to-post. The largest increases were seen in the items, You like to broaden your interest through reading and You love to read for the experimental group.

Table 9

Mean Scores of Positive Item Responses on the RSRAA by Group

Positive Items on RSRAA

Experimental Comparison

Pre Post Inc Pre Post Inc

22 You like to broaden your interest through reading.

$\begin{array}{llllll}2.36 & 3.23 & \mathbf{. 8 7} & 3.45 & 2.45 & \mathbf{- 1 . 0 0}\end{array}$

7 You love to read.

$\begin{array}{llllll}2.50 & 3.27 & .77 & 2.32 & 2.14 & \mathbf{- . 1 8}\end{array}$

6 You get really excited about books you have read.

$\begin{array}{lllllll}3.05 & 3.45 & .45 & 2.91 & 2.55 & \mathbf{- . 3 6}\end{array}$

10 You like to stay at home and read.

$\begin{array}{lllllll}2.23 & 2.64 & .41 & & 1.82 & 2.14 & .28\end{array}$

20 You generally check out a book when

$\begin{array}{llllll}3.09 & 3.50 & \mathbf{4 1} & 2.45 & 2.91 & \mathbf{. 4 6}\end{array}$ you go to the library.

23 You read a lot.

$\begin{array}{lllllll}2.27 & 2.59 & \mathbf{. 3 2} & 2.27 & 2.32 & \mathbf{. 0 5}\end{array}$

25 You like to get books for gifts.

$\begin{array}{lllllll}2.00 & 2.32 & .32 & 2.23 & 2.00 & \mathbf{- . 2 3}\end{array}$

4 You have a lot of books in your

$\begin{array}{lllllll}2.86 & 3.14 & .28 & 2.73 & 2.95 & .22\end{array}$
room at home.

17 You like to share books with your friends.

$\begin{array}{llllll}2.64 & 2.86 & .22 & 2.45 & 2.36 & \mathbf{- . 0 9}\end{array}$

24 You like to improve your vocabulary so you can use more words.

$\begin{array}{lllllll}3.86 & 4.00 & .14 & 3.59 & 3.68 & .09\end{array}$

8 You like to read books by well known authors.

$\begin{array}{llllll}3.05 & 3.18 & .13 & 2.91 & 2.50 & \mathbf{- . 4 1}\end{array}$

15 You like to read to escape from problems. 
5 You like to read a book whenever you have free time.

$1=$ Strongly Disagree 2 = Disagree $3=$ Undecided $4=$ Agree $5=$ Strongly Agree

Negative items. Table 10 details the negative items from the RSRAA and the mean responses and difference for each item. For each negative reading item, the overall mean scores for both the experimental and comparison groups are given for pre and post, indicating the overall attitude towards reading for that particular reading item. For the negatively stated items, the scale was reversed with the scores ranging from 5-1 along a continuum of strongly disagree to strongly agree with the stated item. A very strong disagreement to a negatively stated item received a score of 5 (strongly disagree). A very strong agreement to a negatively stated item received a score of a 1(strongly agree). For example, a negatively stated item, I do not like to read, may be responded to any one of the following along a Likert-Scale as $5=$ Strongly Disagree $4=$ Disagree $3=$ Undecided $2=$ Agree 1 = Strongly Agree (Tullock-Rhody \& Alexander, 1980)

For the experimental group, 11 out of 12 mean responses revealed increases in disagreement with the negatively stated reading items, compared to 3 out of 12 for the comparison group from pre to post. The largest increases in disagreement for the experimental group were for the items You hate reading and You think reading is boring. These results demonstrated an increase in positive reading attitudes on the part of the experimental group. 
Table 10

Mean Scores of Positive Item Responses on the RSRAA by Group

\begin{tabular}{|c|c|c|c|c|c|c|c|}
\hline & \multirow[t]{2}{*}{ Negative Items on RSRAA } & \multicolumn{3}{|c|}{ Experimental } & \multicolumn{3}{|c|}{ Comparison } \\
\hline & & Pre & Post & Inc & Pre & Post & Inc \\
\hline 19 & You hate reading. & 3.23 & 4.05 & .82 & 2.77 & 3.68 & .91 \\
\hline 13 & You think reading is boring. & 3.23 & 3.86 & .63 & 3.32 & 2.77 & -.55 \\
\hline 18 & $\begin{array}{l}\text { You would rather someone just tell } \\
\text { you information so that you won't } \\
\text { have to read to get it. }\end{array}$ & 3.18 & 3.73 & .55 & 3.06 & 2.91 & -.15 \\
\hline 14 & $\begin{array}{l}\text { You think people are strange when } \\
\text { they read a lot. }\end{array}$ & 3.86 & 4.36 & .50 & 4.14 & 3.68 & -.46 \\
\hline 1 & $\begin{array}{l}\text { You feel you have better things to do } \\
\text { than to read. }\end{array}$ & 3.05 & 3.45 & .40 & 3.23 & 2.95 & -.28 \\
\hline 2 & You seldom buy a book. & 2.50 & 2.86 & .36 & 2.81 & 3.18 & .37 \\
\hline 16 & $\begin{array}{l}\text { You make fun of people who read a } \\
\text { lot. }\end{array}$ & 4.27 & 4.55 & .28 & 4.55 & 4.41 & -.14 \\
\hline 21 & It takes you a long time to read a book. & 2.86 & 3.14 & .28 & 3.32 & 2.68 & -.64 \\
\hline 12 & You think reading is a waste of time. & 4.05 & 4.23 & .18 & 3.45 & 3.14 & -.31 \\
\hline 11 & $\begin{array}{l}\text { You seldom read except when you } \\
\text { have to do a book report. }\end{array}$ & 2.82 & 2.95 & .13 & 3.0 & 2.68 & -.32 \\
\hline 9 & $\begin{array}{l}\text { You never check out a book from the } \\
\text { library. }\end{array}$ & 3.64 & 3.45 & -.19 & 3.64 & 3.50 & -.14 \\
\hline
\end{tabular}

RSRAA reading clusters. Both the positively and negatively stated reading items on the RSRAA were further subdivided into clusters: (a) Reading in the library, (b) 
Reading in the home, (c) Other recreational reading items, and (d) General reading.

Table 14 details which items are included in each cluster from the RSRAA.

Table 11

Items by Cluster on the RSRAA

Cluster

Item Number

Reading in the library $\quad 9,20$

Reading in the home $\quad 4,10$

Other recreational reading $5,11,17,24,24,25$

General reading $\quad 1,2,3,4,6,7,8,12,13,14,15,16,18,19,21,23$

Multivariate repeated measures ANOVA indicated that there was a significant interaction between group and time for the four Rhody clusters, $F(4,39)=7.03, p<.001$, $\eta^{2}=.42$. Further univariate repeated measures ANOVA on each Rhody cluster indicated significant interactions between group and time for Other recreational reading, $F(1,42)$ $=9.07, p=.004, \eta^{2}=.18$, and for General reading, $F(1,42)=14.67$, $p<.001, \eta^{2}=.26$

Table 12 and Figure 9 display the results of the analysis of the cluster, Other recreational reading cluster. Fisher's LSD post hoc test on Rhody's Other recreational reading indicated that the comparison group's attitude significantly decreased from Week $1(M=17.73)$ to week $10(M=15.55)$. The experimental group's increase in attitude from pre $(M=16.82)$ to post $(M=18.18)$ approached significance, $p=.11$. At post, the 
experimental group's $(M=18.18)$ attitude was significantly greater than that of the comparison group.

Table 12

Other Recreational Mean (SD) Scores of RSRAA by Group

\begin{tabular}{llcc}
\hline Groups & Mean/SD & Pre-Intervention & Post Intervention \\
\hline Experimental & Mean & 16.82 & 18.18 \\
& SD & 3.84 & 3.61 \\
Comparison & Mean & 17.73 & 15.55 \\
& SD & 3.48 & 4.54 \\
\hline
\end{tabular}

Range of Scores $=5-25$

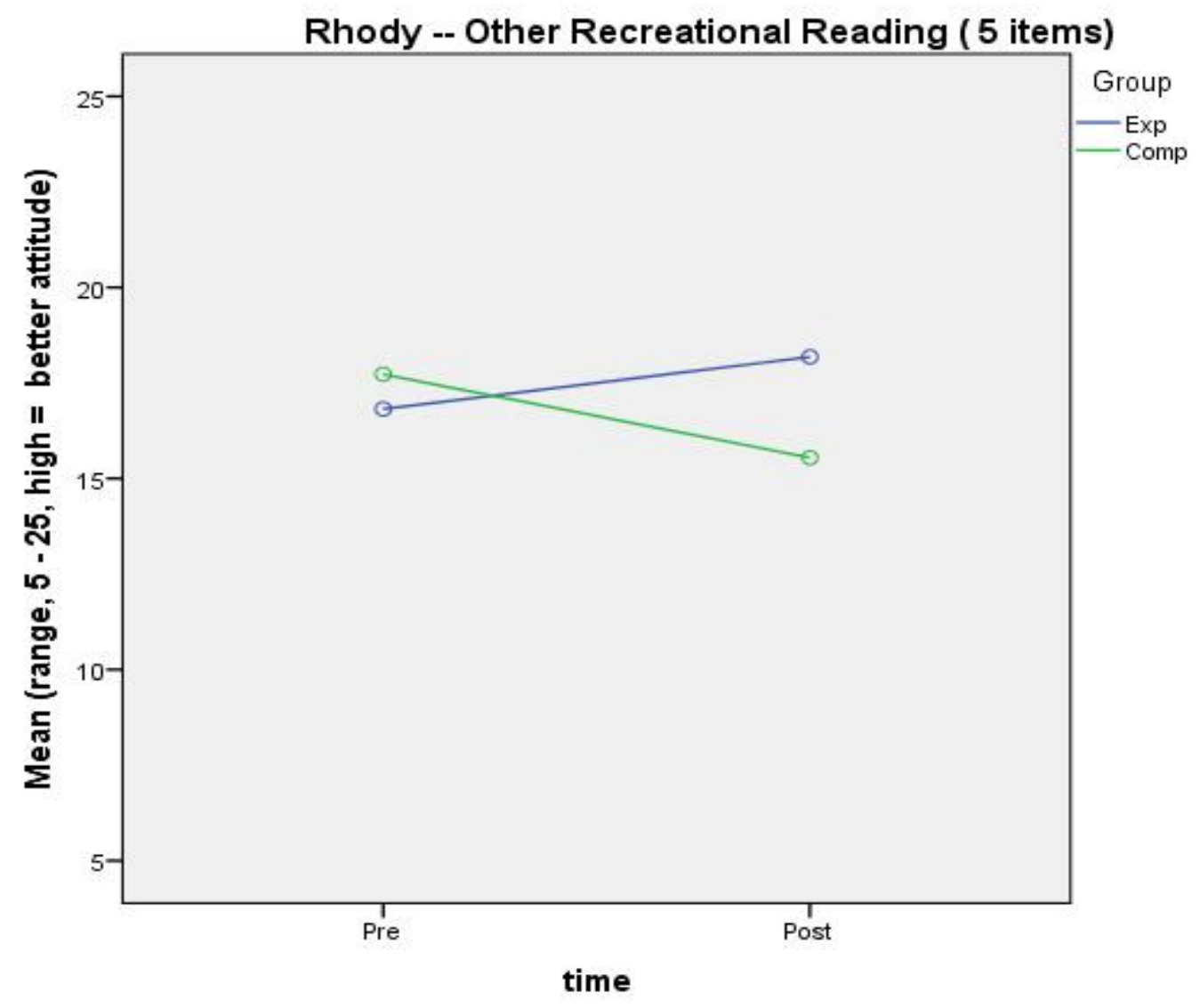

Figure 9. Pre and Post Other Recreational Reading Means of RSRAA by group 
Table 13 and Figure 10 display the analysis of the cluster, General reading.

Fisher's LSD post hoc test on Rhody's General reading cluster indicated that the experimental group increased significantly from pre $(M=47.00)$ to post $(M=52.82)$. At

Post, the experimental group's attitude was significantly better than that of the comparison group $(M=44.27)$.

Table 13

General Mean (SD) Scores of RSRAA by Group

\begin{tabular}{lccc}
\hline Groups & Mean/SD & Pre-Intervention & Post Intervention \\
\hline Experimental & Mean & 47.00 & 52.82 \\
& SD & 8.86 & 9.16 \\
\hline Comparison & Mean & 46.50 & 44.27 \\
& SD & 11.43 & 12.44
\end{tabular}

Range of Scores $=14-70$ 


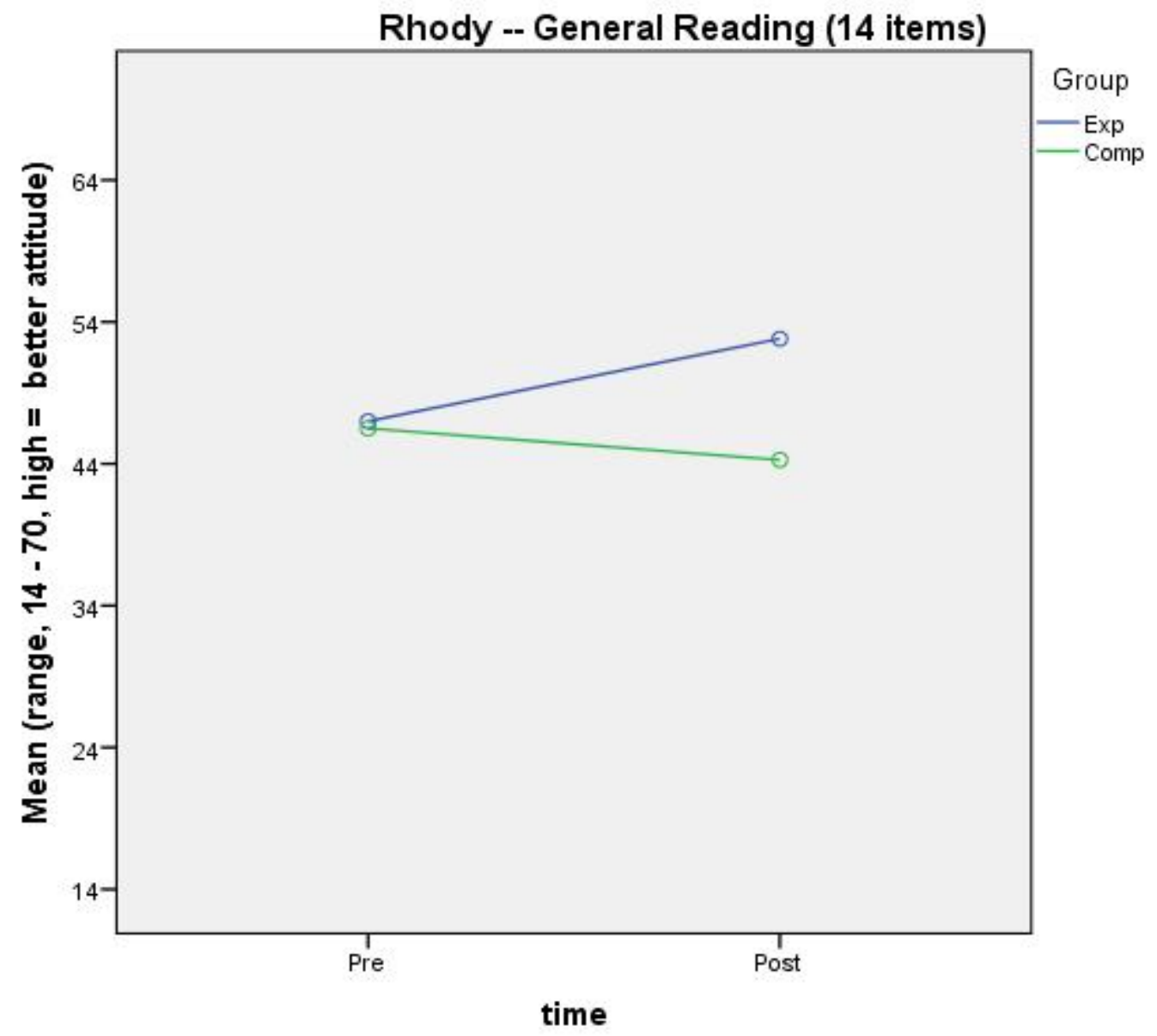

Figure 10. Pre and Post General Reading Means of RSRAA by Group 


\section{Summary}

Chapter 4 presented the results of the data in relation to hypothesis 1 and hypothesis 2 . For hypothesis 1 , with respect to the comprehension scores on Gates MacGinitie Reading Tests (GMRT) scores, there was not a significant interaction of group by time for this measure. Neither the experimental group nor the comparison group made significant gains over the course of the study for comprehension on the GMRT. However, comprehension on the Florida Assessments for Instruction in Reading (FAIR) showed a significant interaction of group by time demonstrating greater progress for the experimental group over the comparison group from the first to the second test administration.

Though the trends of the reading comprehension scores for the experimental group on the Bluford Series novels and comprehension scores for the comparison group on the Read XL basal reader, were not hypothesized, it should be noted that both groups showed significant effects on reading comprehension across the four testing times.

For hypothesis 2 , there was a significant interaction of group by time on the RSRAA. Both the experimental and the comparison groups performed the same initially but over time, the experimental group made more gains than the comparison group, showing a more positive attitude towards reading.

The results and implications of these findings for research and practice, and the overall limitations of the study are presented in Chapter 5. 


\section{CHAPTER V}

\section{DISCUSSION}

This final chapter presents a summary of the study, followed by a discussion on the research findings as analyzed by the data. An interpretation of the findings, implications practice, and an explanation of the study limitations are provided. This chapter concludes with recommendations for future research and a summary.

\section{Summary of Study}

This study investigated the relationship of culturally responsive instruction and the reading comprehension and attitude of struggling urban adolescent readers using a repeated measures ANOVA as the research design. Gay (2000) validates the use of culturally responsive instruction as instruction that is appropriates in augmenting, the social, academic, and cultural needs of students (Phuntsog, 2001). The present study hypothesized that (a) struggling urban adolescent readers, who participate in culturally responsive instruction that uses culturally relevant literature, will show greater reading comprehension growth when compared to students who do not participate in culturally responsive instruction using culturally relevant literature, as measured by the GatesMacGinitie Reading Tests (GMRT) and the Florida Assessments for Instruction in Reading (FAIR) and (b) struggling urban adolescent readers, who participate in culturally responsive instruction that uses culturally relevant literature, will demonstrate a more positive attitude toward reading when compared to students who do not participate in culturally responsive instruction using culturally relevant literature, as measured by the Rhody Secondary Reading Attitude Assessment (RSRAA). 
This study was conducted in a seventh-grade Reading classroom at a Title 1 middle school in South Florida. Two classes were utilized for this study and taught by the researcher. The study was comprised of a convenience non-randomized sample of 44 students, mainly Hispanic and Black students. The experimental group was comprised of 22 students and the comparison group was also comprised of 22 students. The experimental group received instruction with culturally relevant literature (Bluford Series), whereas the comparison group received instruction with traditional school basal series (READ XL).

To measure the progress of the participants in comprehension over time, the following tests were used (a) the Gates-MacGinitie Reading Tests (GMRT), of which comprehension portion was administered during week 1 (pre-intervention), week 5 , and week 10 (post intervention), and (b) Florida Assessments for Instruction in Reading (FAIR), administered as a pretest during week 1 and a posttest during week 10.

Additionally, to track the progress of text based understandings, the experimental and comparison groups were assessed every 10 days (end of every 2 weeks) on the instructional reading material used during the intervention (Bluford Series and Read XL basal reader respectively). The experimental group was assessed using teacher created tests, patterned according to the Florida Comprehensive Assessment Test (FCAT). A test was administered at the conclusion of every novel; therefore over the course of the intervention, each student was assessed on four Bluford Series novels. The comparison group was tracked using the existing text-based FCAT type questions from the Read XL basal reader during the same time periods as the experimental group. 
Reading attitude was measured using the Rhody Secondary Reading Attitude Assessment (RSRAA). This survey was administered to participants as a pretest and a posttest survey at the beginning and ending of the study. Reading attitudes were analyzed using positive reading items and negative reading items. To further analyze participants' reading attitudes, items on the scale were divided into clusters: Reading in the library; Reading in the home; Other recreational reading; and General reading.

\section{Research Findings}

\section{Hypothesis 1}

Hypothesis 1 examined whether struggling urban adolescent readers, who participate in culturally responsive instruction that uses culturally relevant literature, will show greater reading comprehension growth when compared to students who do not participate in culturally responsive instruction using culturally relevant literature, as measured by the Gates-MacGinitie Reading Tests (GMRT) and the Florida Assessment for Instructions in Reading (FAIR).

Repeated measures ANOVA for the comprehension subset of the GMRT did not support hypothesis 1 . When the experimental group was compared to the comparison group, there were no significant differences in time or interaction effects of group by time. However, the experimental group showed some increase in performance over time but it did not reach significance. The reading of culturally relevant literature did not impact reading comprehension growth as measured by the GMRT.

The FAIR results supported Hypothesis 1. There was significant interaction effects of group by time on reading comprehension. The experimental group made 
significant gains above the comparison group from the first assessment period (week 1) to the second assessment period (week 10).

The understanding of content was assessed using the instructional material Bluford Series and Read XL basal reader. Performance on the Bluford Series for the experimental group and the Read XL basal reader for the comparison group were analyzed individually. Both groups showed significant increases across time on the individual text-based comprehension.

\section{Hypothesis 2}

Hypothesis 2 stated that struggling urban adolescent readers, who participate in culturally responsive instruction that uses culturally relevant literature, will demonstrate a more positive attitude toward reading when compared to students who do not participate in culturally responsive instruction using culturally relevant literature, as measured by the Rhody Secondary Reading Attitude Assessment (RSRAA).

Repeated measures ANOVAs were used to test hypothesis 2 . The overall results of the RSRAA support Hypothesis 2, as there were significant differences over time by group, with the experimental group significantly outperforming the comparison group on the RSRAA. Additionally, the analysis of the RSRAA by clusters: (1) Reading in the library, (2) Reading in the home, (3) Other recreational reading, and (4) General reading; revealed that the experimental group showed significantly more improvement than the comparison group at post intervention (week 10) for the clusters of General reading and Other recreational reading. There were no significant differences for the first two clusters - Reading in the library and Reading in the home. 


\section{Interpretation of Findings}

The results of this study provide some support for previous studies on the potential benefits of culturally responsive instruction in the classroom environment ( $\mathrm{Au}$, 2001; Beaulieu, 2002; Gay, 2010; Ladson-Billings, 1995; Worthy, Moorman \& Turner, 1999). Some of the prior research studies focused more on diverse program with young children (Jordan, 1985); native Hawaiians (Au, 1998); small population of Caucasian students (Rice, 2005); a cultural modeling framework for implementation with high school students (Lee, 2001); teacher preparation programs (Villegas \& Lucas, 2002; Bergeron, 2008). What makes this study relevant to educational practice is the fact that very few research studies embrace culturally responsive instruction with urban adolescents over an extended period using an instructional framework to teach students incorporating their reading interests. Additionally, the participants in this study were primarily Black and Hispanic students, attending a Title 1 middle school.

Importantly, the intervention in this study made use of culturally responsive instruction using culturally relevant literature, a fictional urban series of novels called the Bluford Series, to inform classroom instruction of urban, struggling adolescent readers at the middle school level. Advantageously, the classroom teacher, who functioned as the researcher, would probably be able to identify contrasts between the regular school's curriculum and the curriculum used as the intervention, which could be meaningful in informing curricular initiatives. Furthermore, the researcher would be able to bridge students' lived experiences with aspects of the curriculum by instilling a caring and supportive environment, one of the tenets of culturally responsive instruction (Noddings, 2002). In this way, students may be able to make connections between their lives and the 
lives of the characters in the novels, thereby increasing text-based understandings. More so, subsequent to the study, the researcher could continue to build a culture of reading using high interest novels to increase reading achievement, and ultimately build reading stamina. Ivey \& Broaddus (2001) postulated that students will be more receptive to read, once they are given high interest reading material that gains their attention. The Bluford Series is a collection of 18 novels, set in urban America that addresses issues relevant to the lives of students in today's society. The Bluford Series was the primary novel for the instructional unit for the treatment group, which lasted for eight weeks. Central to the framework of the intervention was independent reading, discussion in groups, completion of writing activities, and responding to assessments.

\section{Hypothesis 1}

Investigating hypothesis 1 revealed whether struggling urban adolescent readers, who participate in culturally responsive instruction that uses culturally relevant literature, will show greater reading comprehension growth when compared to students who do not participate in culturally responsive instruction using culturally relevant literature, as measured by the Gates-MacGinitie Reading Tests (GMRT) and the Florida Assessments for Instruction in Reading (FAIR).

Recall that the first instrument that assessed reading comprehension was the GMRT. The second instrument that measured reading comprehension was the Florida Assessments for Instruction in reading (FAIR). ANOVA was used to test Hypothesis 1 and produced mixed results. In comparing the two instruments that measured comprehension, the experimental group made significant progress from the pretest to the posttest on the Florida Assessments for Instruction in Reading (FAIR) but not on the 
Gates-McGinitie Reading Tests (GMRT). However, the experimental group demonstrated an increasing trend in performance over the three testing times $(M s=14.86$, 15.36 , and 16.82) producing a medium effect $-\eta^{2}=.10$. This occurrence indicates that if the sample size was larger it would probably have increased the power and therefore the performance on the GMRT for the experimental group would have been significant.

On the FAIR measure, the experimental group's FAIR mean $(M=25.14)$ at AP2 (week10) was significantly greater than the FAIR mean $(M=8.45)$ at AP 1 (week 1$)$. The comparison group showed no gains in comprehension on the FAIR measure. The experimental group's increase, $(M=16.7)$ was significantly greater than that $(M=3.3)$ of the comparison group.

A further analysis of the results of Hypothesis 1 demonstrated incongruity between the assessment instrument-GMRT comprehension subset and the instructional material. Students were assessed on the GMRT which did not align to what they had read, so they may not have made the text- based connections to help them in understanding what they had read and to further take that understanding into responding to the assessment's questions. The fact that there were no significant differences between the two groups on the comprehension subset of the GMRT could also be attributed to (a) the lack of cultural relevance and interest to the content assessed in GMRT, (b) the inability to transfer reading skills and strategies from one reading context to another, and (c) the short text excerpts, that had no clear beginning or ending.

Performance on the FAIR, supported hypothesis 1 and showed significant differences between the groups' performance. This may be demonstrating (a) close relativity of the FAIR's content to the instructional material and the format of school 
assessments, (b) higher reading stamina due to FAIR's adaptive nature, and (c) a better application of reading skills and strategies that facilitated better responses to questions on the FAIR assessment.

Gates MacGinitie Reading Tests (GMRT). The results of hypothesis 1 are important to look at in relation to GMRT. Although the GMRT is recognized as a good diagnostic standardized measure, the content of the test did not align with students' reading interests. This finding supports the research of Worthy, et al. (1999) and Ivey and Broaddus (2001) who proposed that students will attend more to reading and become more motivated in the act of reading, if they are reading something that personally interests them. This finding aligns with Tatum (2008) who supports students' out-of school or public literacy as a more meaningful way to help students to learn. Though the reading passages of GMRT are short, students' lacked the background knowledge to construct meaning from what they read. Furthermore, the structure of the questions on the assessment did not follow the pattern of questioning that students are exposed to at school. This goes to show that struggling readers need consistency and structure in learning to help them to be successful.

The reading passages of GMRT demonstrated no indication of a beginning, middle, or end as in a regular narrative and the content of the passages engendered unfamiliarity to the population (Blacks and Hispanic) involved in the study, which probably deterred any profound meaningful connection with the text. Resulting from this lack of connection is a sense of "cultural discontinuity" where students' learning needs are forsaken and impedes them from building bridges to their learning. Cultural 
discontinuity can lead to disagreements, misunderstandings, and eventual failure for students (Coleman, 2000).

However, merits can be relegated to the fact that the GMRT provides a grade level of performance and a Lexile measure, which educators can use to place students in instructional reading groups according to their reading needs and provide differentiated instruction which will demonstrate a caring and inclusive learning environment as typified by culturally responsive instruction (Phuntsog, 1999).

Florida Assessments for Instruction in Reading (FAIR). The structure of the FAIR test seemed to have aligned more with the types of testing that students' are exposed to at school. More so, the instructional content of the novels (Bluford Series) incorporated the state standards and benchmarks that students are expected to know, which could be a reason for student success as well, due to the fact that FAIR is a state test . As a result, the performance on the FAIR demonstrated significant time effect for the experimental group from one test to another. This means that the reading comprehension percentile increased from the AP1 (Assessment Period 1) to AP2 (Assessment Period 2). This improvement could be due to the type and quality of instruction and/or to the adaptive nature of FAIR's reading comprehension test, where students are presented with passages that they can read and understand. The fact that the FAIR adapts to students' level, in some way support the research of Shealey and Callins (2007) who proposed that a culturally responsive program is one which implements active teaching methods and facilitates learning of all students in a culturally-mediated environment. 
The adaptive nature of the FAIR test to a student's reading level is great for instructional purposes. It allows an educator to analyze each student performance and create an education plan, differentiate instruction, and monitor students' learning which could improve students' reading ability. This supports Gay's (2002) concept of “cultural scaffolding", which proposes students' experiences as a means to increase academic success and build bridges to students' learning.

\section{Hypothesis 2}

An analysis of hypothesis 2 resulted in identifying whether struggling urban adolescent readers, who participate in culturally responsive instruction that uses culturally relevant literature, will demonstrate a more positive attitude toward reading when compared to students who do not participate in culturally responsive instruction using culturally relevant literature, as measured by the Rhody Secondary Reading Attitude Assessment (RSRAA).

The overall results of the RSRAA support Hypothesis 2 and is worthy of discussion. Testing hypothesis 2 revealed significant differences over time between the experimental group and the comparison group. These differences indicated that the experimental group demonstrated a more positive attitude to reading over time while the comparison group did not. More so, these differences may be due to the fact that students in the experimental group were reading novels (Bluford Series) that were of more interest to them and were more culturally relevant to them, which was a motivation for them to read more of those novel types. It may also be that adolescents in the experimental group were able to relate to the Bluford Series novels, make connections to what they read; make connections to the characters' experiences, which resulted in more 
engaged reading time and a more positive attitude towards reading. Rosenblatt (1995) claimed that students are inclined to become engaged in literary experiences when they can feel the validity of their own experience. Culturally responsive practices can potentially engage and motivate children as they affirm and validate their cultural identity through text representations (Ladson-Billings, 1994). When readers are engaged in the process of reading, they become motivated to comprehend (Verhoeven \& Snow, 2001).

A further analysis of the RSRAA by clusters: (1) Reading in the library, (2) Reading in the home, (3) Other recreational reading items, and (4) General reading; demonstrated that the experimental group's attitudes concerning General reading and Other recreational reading, improved significantly over the comparison group. The increases in General reading and Other recreational reading warrant a discussion, as struggling adolescent readers who were described as apathetic towards reading are now reading generally, and probably incorporating other genres, in addition to urban fiction for their choice of reading material. Another contributory factor could be that struggling adolescent readers feel a bit more confident in their ability to read a novel because they are interested in the literature, as well as for enjoyment because they find pleasure in what they are reading and so this increases their self-concept. Reading in the library and Reading in the home lacked any form of significance. An explanation for this occurrence may be related to the quantity of items in both clusters which in itself was a limitation. The fact that both clusters had only two items explains the lack of sufficient power in producing any significant effects for Reading in the library and Reading in the home. 
Rhody Secondary Reading Attitude Assessment (RSRAA). The results of the RSRAA showed that students' level of interest in the literature is a contributory factor in students' attitude towards reading. The Bluford Series novels, used as the culturally relevant text with the experimental group, motivated students to read and allowed them to develop a more positive attitude towards reading. The results of this study support Farnon (1996) who claimed that attitude affects reading achievement whether positive or negative. If the attitude is positive, then reading achievement tends to increase positively. Accordingly, Gillespie's (1993) also claimed that "for students to be successful readers they must have a positive affective predisposition toward reading instruction" (p. 336). This predisposition was exhibited by the experimental group during the intervention. It holds true then, that attitudinal factors may be important to consider in educational practice. Also, the fact that students interacted with their peers in groups, may have also influenced positive reading attitudes. If teachers are aware of students' reading attitudes, they can tailor instruction and incorporate activities and strategies that will promote positive attitudes toward reading and gradually reduce negative attitudes. Using some form of attitudinal survey will help teachers to determine students' attitude or feelings towards reading.

\section{Bluford Series}

The use of the Bluford series of novels with the experimental group as the culturally relevant text for this study may be deemed as one example of urban fiction that has the ability to motivate struggling adolescent readers to read independently; develop a love for reading; build on prior experiences and construct meaning; make connections; and replace negative reading attitudes with positive reading attitudes (Gibson, 2010). 
This could be as a result of the novels' relevance to the lived experiences and/or vicarious experiences of students and generally for its realistic relations to the some of today's youth. The results of the assessments procured from tests 1-4 showed significance $(p<$ $.001, \eta^{2}=.44$ ) which speaks to the cultural relevance of the text in maintaining reading interests and producing effective academic results. Also, the fact that there was an opportunity to engage in small group and whole group discussion of Bluford Series novels gave students a forum to become self-expressive, liberated, and empowered (Ladson-Billings, 1995; Gay, 2010). Potentially, to supplant this study, a "Cultural Literacy Connection Assessment (CLCA)" may be created and introduced to investigate the level of connection that students' experienced having read the novels.

The written response to the reading of the novel in the form of SCRAP provided different ways for students to respond to text using multiple strategies -Summarize, Connect, Reflect, Ask Questions, and Predict. An analysis of student's response showed their level of thinking about the text. The fact that students were required to use their written response (SCRAP) in their literature discussion groups, observably, bolstered students' efforts to do their best in documenting their thoughts and reflecting on the issues as presented in the novels. Overall, the use of culturally responsive instruction using the Bluford Series as the culturally relevant text provided validation for participants through the incorporation of out-of school literacy that embraced student-led activities to provide insights and build bridges to learning through home and school culture.

\section{Literature Discussion Groups}

Further use of the Bluford Series of novels was analyzed in the context of the literature discussion group to ascertain the degree of student talk and understanding of the 
novel with their peers. Cole (2003) and Lipson (2007) embrace the concept of discussion groups as a democratic and social process that gives students a spirit of community, wherein they can construct meaning as they interact and build on the ideas of their peers, while at the same time improving their reading comprehension and engagement through participation in group discussion. Participants were monitored by a discussion checklist (Appendix $\mathrm{H}$ ) as they engaged in group discussions, guided by discussion prompts (Appendix I). In this context, students were able to share their written response to text, ask questions, and discuss their reading of the novels. Anecdotal records from the discussion groups showed that students were able to (a) make references to text as evidence for text-based understandings, (b) offer insights and oppose viewpoints, (c) piggyback and build on the ideas of others, (d) make connections to text, self, and world, and (e) generate questions, to gain clarity; confirmation; and raise critical awareness.

Reference to text. Participants made reference to text while reading and discussing to provide evidence and build support for claims made during conversation, as a means to enhance collaborative understanding and reasoning. This constructive process allowed them to show text-based understandings (Morocco \& Hindin, 2002). For example, in the dialogue below, two students discussed text by making references for support and justification of thoughts.

Student 1: This book is one of my favorite things because of the drama in the text.

Student 2: Why?

Student 1: Because in every chapter you get to know something like, something real

Student 2: Can you show me an example in the story? 
Student 1: $\quad$ Like when Brisana in Chapter 7, hold on, let me look at the chapters. Like, what I was saying, on page 92, you all find it? "Read where Brisana and Hakeem were trying to practice through the auditions and stuff and that's when Darcy started to sing. Brisana was critical and said Darcy sounded horrible. So that basically makes me think that brings a lot of drama to it.

Offering insights and opposing viewpoints. Participants offered their individual views and interpretations on various circumstances in the reading during discussion with their peers. This behavior allowed students to understand that there are many ways to interpret a statement, a situation, or an action. When students' are given opportunities to share their viewpoints and perspectives during a teaching and learning context, they feel a sense of validity; they have a voice, and therefore become active participants in their learning and so may be more inclined to learn (Nieto, 1996). Also Fish (1980) promoted the discussions of literature that incorporated opposing viewpoints as a means to encourage tangible dialogue. For example, in the dialogue below, students interpret a situation from different perspectives.

Student 1: $\quad$ Did you believe what the dad did by lying to his family about going to work when he was actually at the alcoholics thing?

Student 3: Yeah, because he didn't want to stress the baby.

Student 1: $\quad$ But it's not stressing the baby if he doesn't want to get help. But the mother doesn't know that he was drinking because then the mother would get angry, like Jamie says.

Student 4: But as soon as he started doing it, he should have come clean.

Student 2: He did come clean.

Student 4: $\quad$ Yeah, when he did. 
Student 2: What? At the end, but he actually ...It was at the end after they went to the hospital. Yeah, because remember, Jamie started crying and then she said, "Dad, I have to tell you something," and then they had to go.

Student 4: But that was the beginning.

Student 3: No, no, no, she saw beer bottle caps in the backyard, and beer bottles in the bathroom downstairs. That's how he got caught. He should have just told them.

Student 1: $\quad$ No, you got to read it. You read it, go.

Student 3: $\quad$ READS FROM THE NOVEL: "Darcy was awakened by a strange sound, a scratching sound. It was coming from the backyard. She bolted upright in her bed. 'Please God, don't let it be what I think it is.' Darcy ran to the window and looked out, standing there alone in a yellow gown with her father. He was pulling beer bottles from the crawl space, opening them and pouring them gently into the grass. 'Thank you, God.' She heard me tossing the bottles one by one into the trash can."

Student 2: I'm not talking about that. I'm talking about when he got caught doing the bathroom thing with the beer bottles in the backyard. I'm not talking about the end when he dumped them out in the backyard.

Student 4: He got caught while he was in the shed because remember he started to hide the bottles under there.

Student 2: I disagree with you. Javier.

Piggybacking. Participants engaged in narrative text discussion as they 'piggybacked' on the ideas of their peers during discussion. Piggybacking allowed participants to strengthen the dialogue while learning through the responses of their peers while concurrently understanding how their peers view the characters and situations in order to construct meaning (Rosenblatt, 1995). Paxton-Buursma and Walker (2008) postulated that piggybacking during discussion of text creates an avenue for students to 
expand, elaborate and clarify contributed ideas form their peers. During the following dialogue, students are able to extend and question the ideas presented by their peers to gain clarity of information which helped them to think critically about the spoken material that they are presenting.

Student 1: Oh, give an example of what somebody's going through

Student 2: $\quad$ Like if somebody is about to get expelled, like they have close friends, and they don't want them to get expelled, and they help them.

Student 1: I have a question. "What might be the result of Vicki's grandpa's health if her grandma would still be alive?"

Student 3: Okay. What do you think the answer would be?

Student 2: I think that he would still be like not - he would be healthy.

Student 4: Yeah.

Student 2: That he would probably try to eat better, like salads like almost everyday.

Student 3: Yeah, like nutritious meals.

Student 1: If you were Vicki, what choice would you have made to make your grandpa sleep and take over your room?

Student 3: I would have let him.

Student 2: I would have made him sleep on the couch.

Student 1: But why? He's an older man and like he's having trouble walking and going to the bathroom and your room would be closer to the bathroom.

Student 2: I would let him because that would be bad to see him struggling.

Student 4: Yeah.

Student 1: How would you feel though? 
Student 4: $\quad$ Sad.

Student 1: No, but how would you feel about your room getting taking over and all your clothes being in like the living room or something?

Student 3: $\quad$ In boxes.

Student 4: I wouldn't be - that wouldn't really bother me.

Student 2: $\quad$ Yeah, you cannot watch TV every night.

Student 1: Why would that bother you because you could watch TV like before you go to bed, get up and turn on the TV, get a snack.

Making connections. Participants connected their personal lived experiences to those presented by the characters', events, and situations in the novel. This allowed them to engage in meaningful discourse that extended beyond the school level. Students made connections through text to self, text to text, and text to world in general as they made use of personal and collective experiences to increase text comprehension. Fall, Webb, and Chudowsky (2000) postulated that through text discussion, students can make connections which positively impacts comprehension. Following are two excerpts that dictate how two students connected with particular sections from the reading. One student connected personally (text-to-self), while the other student connected through media (text-to text) respectively.

Student 1: Darcy was partnered with a student she did not like to be around, reminds me of a time when my teacher chose my partner. I know how she feels and I can connect to that. I appreciate the fact the even though she did not like her, she still tried to make good with her and had the patience that I didn't have to work with her. 
Student 2: $\quad$ This reminds me of a movie called Summer Eleven. There were a lot of problems in this movie. There was a girl who did not like her Dad. They both have sisters, even a lot of friends, but the most of all they both have a lot of problems in their life.

A noteworthy point of discussion here is the contributions that facilitated the utility of the strategies by the students. It would seem that through the peer discussion of culturally relevant text, students took charge of their learning experiences and rose to high levels of expectation, felt a sense of comfort in their learning which further increased their self-concept and motivation to become participatory learners. Also, the use of the "Bluford Series of Novels" allowed students to tap into their prior knowledge experiences, which motivated them to express their ideas and actively engage in discussion looking critically at the positioning of the characters' and situations.

This disposition to dialogical and social interaction promoted an increase in cognitive performance which strongly aligns with Vygotsky (1978) social process of learning, where the claim is made that students are able to negotiate meaning (Branden, 2000) and increase their academic competence through peer interaction.

Furthermore, this empowerment to succeed coincides with Gay (2010) where she stated that, "empowerment enables students to be better human beings and more successful learners. Empowerment translates into academic competence, personal confidence, courage, and will to act" (p. 34).

\section{Implications for Practice}

The results of this study have implications for the practice of teaching Reading. Notably, the findings suggest that the reading of high interest and culturally relevant text complemented with literature discussion groups can improve reading comprehension and 
reading attitudes of struggling adolescent readers. Educators should look at the benefits of utilizing similar types of novels that are relevant to students' interests and lives for classroom reading instruction and incorporating similar activities as typified in this study as opposed to (1) utilizing novels that are on topics of less interest and (2) focusing on isolated reading skills deemed necessary to be successful on standardized tests.

The use of literature discussion groups may potentially give students a sense of voice, autonomy and liberation to engage in critical discourse while at the same time learn from their peers and construct meaning in a social context. Educators should incorporate activities in the classroom that give students an opportunity to engage in discussion in various ways - debate, Socratic Seminar, small-group discussion, fish bowl discussion, philosophical chair - in an effort to build their speaking skills, as well as discuss freely without the influence of a teacher.

In view of the fact that schools continue to increase in diversity with respect to learning styles, reading interests, and cultural and linguistic strengths of students, culturally responsive curricula may be developed to meet the children where they may learn best. However, this curriculum must be carefully developed and holistically implemented in ways that will be beneficial to all learners but more so to marginalized and disenfranchised learners.

Importantly, educators also have an important role in understanding the impact of culture on learning and how to bridge both aspects to impart or teach content in culturally responsive ways. In order to do this successfully, it is suggested that educators first develop a personal awareness of their own culture and be accepting of cultures that are different from theirs. According to Nieto (1996), "Teachers...need to understand and 
accept their own diversity and delve into their own identities before they can learn about and from their students" (p. 133).

Clearly, there is a need for teacher education programs to include culturally responsive teaching and dispositions to ensure that candidates enact this knowledge and teaching skill within the classroom as a way to affirm their views toward students' success. A change in the educational delivery is critical to address the struggle presented by some adolescent readers. There must be curricular consistency and transformation of the conventional teacher and student roles in order to procure the benefits from this form of pedagogy which embraces a holistic and in-depth approach to teaching and learning. However, struggling readers may not be the only group that may benefit from culturally responsive pedagogical environments, there is also real implications for those readers who exhibit reading apathy. This type of instruction may be beneficial if the reading material that is being offered by the school is high interest and motivating. Also, if the content that is read is also the material to assess students' knowledge, students' possibly will be more successful in the application of their knowledge. Apathetic or reluctant readers somehow seem to be at the brink of losing academic ground if the school offerings fail to interest them. To quote Nieto (2000), "When students feel connected to school, they identify as learners and they have a far greater chance of becoming successful students' (p.299).

\section{Implications for Future Research}

The results of this study have implications for future research. The federal and state governments continue to introduce legislations and regulations with performance standards for students. Students who struggle with reading and many minority students 
are still underperforming and lack the proficiency needed to meet the required performance standards. The achievement gap continues to widen and teachers are faced with the undue pressure to increase test scores. This context begs the question, "What educational component is missing in student's academic progress? How can struggling learners achieve high academic standards?" Research on culturally responsive teaching education and its implementation warrants more consideration.

A longitudinal study may be needed to further investigate how culturally responsive instruction can be infused in all academic disciplines. More specifically, a thematic approach to learning across disciplines using a culturally responsive approach is also notable. Introducing this concept across disciplines using themes will evoke greater and more profound learning opportunities and engagement for students.

Additionally, a future study could explore the development and utilization of a Likert-Scale, Cultural Literacy Connection Assessment (CLCA). This would be a selfreporting tool that measures the extent to which students connect or identify with the relevance of the literature to their own lives after reading and discussing culturally relevant literature. Moreover, it will provide insights to researchers and educators in the selection of relevant materials for use as well as provide a foundation for discussion on what makes a text, culturally relevant.

Future research should also investigate a mixed method approach to analyze the data, incorporating both quantitative and qualitative data to further analyze the effects of culturally responsive instruction with varied population, ethnic grouping and socioeconomic levels, an extensive sample size, multiple teachers, varying time frames, and various subject disciplines to further its utility. 


\section{Limitations of Study}

Some of the findings gleaned from this study are limited. The study was implemented with seventh-grade students from a South Florida Title 1 middle school. The sample of students in the study was composed of a small sample of mainly Black and Hispanic students with similar low socioeconomic levels. Due to the small sample size, small ethnic groups, and socioeconomic level, generalizability effects would be low. The sample size in this study contributed to limited power in some of the cases. A larger population could make generalizing a bit more logical and could produce more powerful results.

The fact that the Bluford Series novels were the lone urban fiction used in this study, does not guarantee that other novels that fit into this genre will achieve the same success. Therefore, incorporating more varied choices of urban fiction might be included in a replication study before any generalizations could be made.

The results of this study may not necessarily generalize to other populations of struggling readers in other classrooms, in other schools, school districts, grade levels, racial groups, ethnic groups, level of aptitude, or socioeconomic levels.

This particular study reflects the case of one individual teacher within an urban instructional context, who was also the researcher. As both the educator and researcher, there is the potential to inadvertently bias the findings and further impact the success of the study, and so this is an important consideration if the results are to be generalized.

However, the findings from this study can inform literature and add to current understanding regarding the implementation of culturally responsive instruction within the classroom environment. 


\section{Summary}

Findings from this study revealed that culturally responsive instruction using culturally relevant literature can be employed to help students increase their reading comprehension skills, as well as help them to develop more positive attitudes toward reading. More specifically, students were more successful when taught with CRI and assessed directly on the content read in way that paralleled instruction. This approach may contribute to the reduction of cultural and social marginalization that many struggling learners face in schools. 


\section{References.}

Adams, A., Bondy, E., \& Kuhel, K. (2005). Preservice teacher learning in an unfamiliar setting. Teacher Education Quarterly, 41- 62.

Alvermann, D. E. (2001, October). Effective literacy instruction for adolescents: Executive summary and paper commissioned by the National Reading Conference. Chicago, IL: National Reading Conference.

Anderson, R., Fielding, L., \& Wilson, P. (1988). Growth in reading and how children spend their time outside of school. Reading Research Quarterly, 23(3), 285-303.

Au, K. H. (2000). A multicultural perspective on policies for improving literacy achievement: Equity and excellence. In M. L. Kamil, P. B. Mosenthal, P. D. Pearson, \& R. Barr (Eds.), Handbook of reading research: Vol. III (pp. 835-851). Mahwah, NJ: Lawrence Erlbaum.

Au, K.H. (2001, July/August). Culturally responsive instruction as a dimension of new literacies. Reading Online, 5. Retrieved from http://www.readingonline.org/newliteracies/lit_index.asp?HREF=/newliteracies/x $\mathrm{u} /$ index.html

Au, K., \& Jordan, C. (1981). Teaching reading to Hawaiian children: Finding a culturally appropriate solution. In H. Trueba, G. Guthrie, \& K. Au (Eds.), Culture and bilingual classroom: Studies in classroom ethnography (pp. 69-86). Rowley, MA: Newbury House.

Bean, T. W., \& Moni, K. (2003). Developing students' critical literacy: Exploring identity construction in young adult fiction. Journal of Adolescent \& Adult Literacy, 46, 638-648.

Beaulieu, L. M. (2002). African American children and literacy: Literacy development across the elementary, middle, and high school years. In S. J. Denbo \& L. M. Beaulieu (Eds.), Improving schools for African American students (pp. 133-145). Springfield, IL: Charles C. Thomas.

Bergeron, B. S. (2008). Enacting a culturally responsive curriculum in a novice teacher's classroom: Encountering disequilibrium. Urban Education. 43(1), 4-28.

Biancarosa, G., \& Snow, C. (2004). Reading Next: A vision for action and research in middle school and high school literacy: A report to Carnegie Corporation of New York. Washington, DC: Alliance for Excellent Education. 
Boykin, A. W., Coleman, S. T., Lilja, A. J., \& Tyler, K. M. (2004). Building on children's cultural assets in simulated classroom performance environments: Research vistas in the communal learning paradigm. CRESPAR Technical Report No. 68.

Brady, P. (1996). Native dropouts and non-native dropouts in Canada: Two solitudes or a solitude shared? Journal of American Indian Education, 35, 10-20.

Brooks, W. \& Savage, L. (2009). Critiques and controversies of street literature: A formidable genre. The ALAN Review, 37(3), 48-55.

Callins, T. (2006). Culturally_responsive literacy instruction. Teaching Exceptional Children, 39(2), 62-65.

Clark, K. F. (2009). The nature and influence of comprehension strategy use during peerled literature discussions: An analysis of intermediate grade students' practice. Literacy Research and Instruction, 48(9), 95-119.

Cole, A.D. (2003). Knee to knee, eye to eye circling on comprehension. Portsmouth, NH: Heinemann.

Coleman, T. J. (2000). Clinical management of Communication Disorders in Culturally Diverse Children. Boston, MA: Allyn and Bacon.

Comodromos, E. (2008). Teacher's guide to the Bluford Series. West Berlin, NJ: Townsend Press.

Daley, P., \& Lawson, J. (2002). Scholastic Read XL Florida edition: Teacher's guide grade 7. New York, NY: Scholastic.

Fall, R., Webb, N., \& Chudowsky, N. (2000). Group discussion and large-scale language arts assessment: Effects on students' comprehension. American Educational research Journal, 37(4), 911-941.

Faman, N. (1996). Connecting adolescents and reading: Goals at the middle level. Journal of Adolescent \& Adult Literary, 39, 436-445.

Faulkner, V. (2005). Adolescent literacies within the middle years of schooling: A case study of a year 8 homeroom. Journal of Adolescent \& Adult Literacy, 49(2), 108117.

Flippo, R. F., \& Caverly, D. C. (Eds.). (2008). Handbook of college reading and study strategy research (2nd ed.). New York, NY: Routledge.

Florio-Ruane, S. \& deTar, J. (2001). Teacher education and the cultural imagination: Autobiography, conversation, and narrative. Mahwah, NJ: Lawrence Erlbaum. 
Fordham, S. (1993). "Those loud Black girls": Black women, silence, gender "passing" in the academy. Anthropology \& Education Quarterly, 24(1), 3-32.

Frei, R. (2006). Exploring the structures of teacher education programs: Constructing models that serve as frameworks for classroom teaching. Paper presented at the annual meeting of the American Association of Colleges for Teacher Education. Retrieved from http://www.allacademic.com/meta/p36058_index.html

Freire, P. (1995). Pedagogy of hope: Reliving pedagogy of the oppressed. New York, NY: Continuum Publishing Company

Gall, M. D., Gall, J. P., \& Borg, W. R. (2006). Educational research: An introduction ( $^{\text {th }}$ ed). Boston, MA: Allyn \& Bacon.

Gallo, D. (2003). Bold books for innovative teaching. English Journal, 93(1), 113116.

Gardner, H (2000). Intelligence reframed: Multiple intelligences for the $21^{\text {st }}$ Century. New York, NY: Basic.

Gay, G. (2000). Culturally responsive teaching theory research \& practice. New York, NY: Teachers College Press.

Gay, G. (2002). Preparing for culturally responsive teaching. Journal of Teacher Education, 53, 106-116.

Gay, G. (2010). Culturally responsive teaching theory research \& practice, ( $2^{\text {nd }}$ ed.). New York, NY: Teachers College Press.

Gibson, S. (2010). Critical readings: African American girls and urban fiction. Journal of Adolescent \& Adult Literacy, 53(7) 556-574.

Gillespie, C. (1993). College students reflections on reading. Reading Horizons, 33, 329340.

Greenberg, S., \& Petscher, Y. (2010). Florida assessments for instruction in reading. Florida: Buros Center for Testing. Retrieved from http://www.fldoe.org/Schools/pdf/AssessmentsInstructionReading.pdf

Greenleaf, C. L., \& Hinchman, K. (2009). Reimagining our inexperienced adolescent readers: From struggling, striving, marginalized, and reluctant to thriving. Journal of Adolescent and Adult Literacy, 53, 4-13.

Guerra, S.F. (2012). Using urban fiction to engage at-risk and incarcerated youths in literacy instruction. Journal of Adolescent and Adult Literacy, 55(5), 385-394. 
Guthrie, J. T. (2004). Teaching for literacy engagement. Journal of Literacy Research, $36,1-30$.

Guthrie, J. T., \& Cox, K. E. (2001). Classroom conditions for motivation and engagement. Educational Psychology Review, 13(3), 283-302.

Guthrie, J. T., McGough, K., Bennett, L., \& Rice, M. E. (1996). Concept-oriented reading instruction: An integrated curriculum to develop motivations and strategies for reading. In L. Baker, P. Afflerbach, \& D. Reinking (Eds.), Developing engaged readers in school and home communities (pp. 165-190). Hillsdale, NJ: Erlbaum.

Guthrie, J. T., \& Wigfield, A. (2000). Engagement and motivation in reading. In M. Kamil, P. Mosenthal, P. D. Pearson, \& R. Barr (Eds.). Handbook of reading research: Volume III (pp. 403-424). Mahwah, NJ: Lawrence Erlbaum.

Hill, M. L., Perez, B., \& Irby, D. J. (2008). Street fiction: What is it and what does it mean for English teachers? English Journal, 97(3), 76-82.

Hinchman, K. A., Alvermann, D. E., Boyd, F. B., Brozo, W. G., \& Vacca, R. T. (2004). Supporting older students' in- and out-of-school literacies. Journal of Adolescent and Adult Literacy, 47, 304-310.

Hinkle, D. E., Wiersma, W. \& Jurs, S. G. (2003). Applied statistics for the behavioral sciences. New York, NY: Houghton Mifflin.

Houge, T. T., \& Geier, C. (2009). Delivering one-to-one tutoring in literacy via videoconferencing. Journal of Adolescent and Adult Literacy, 53(2) 154-163.

Huang, G. H., \& Mason, K. L. (2008). Motivations of parental involvement in children's learning: Voices from urban African American families of preschoolers. Multicultural Education, 15(3), 20-27.

Israel, S. E., \& Duffy, G. G. (Eds.). (2009). Handbook of research on reading comprehension. New York, NY: Routledge.

Ivey, G. (1999). Reflections on teaching struggling middle school readers. Journal of Adolescent and Adult Literacy, 42, 372-381.

Ivey, G., \& Broaddus, K. (2001). “Just plain reading”: A survey of what makes students want to read in middle school classrooms. Reading Research Quarterly, 36, 350377. 
Kong, A., \& Fitch, E. (2002). Using book club to engage culturally and linguistically diverse learners in reading, writing, and talking about books. The Reading Teacher, 56(4), 352-362.

Ladson-Billings, G. (1992). Liberatory consequences of literacy: A case of culturally relevant instruction for African American students. The Journal of Negro Education, 61(3), 378-391.

Ladson-Billings, G. (1994). The dreamkeepers: Successful teachers for AfricanAmerican children. San Francisco, CA: Jossey-Bass.

Ladson-Billings, G. (1995a). But that's just good teaching! The case for culturally relevant pedagogy. Theory Into Practice, 34(3), 159-165.

Ladson-Billings, G. (1995b). Toward a theory of culturally relevant pedagogy. American Educational Research Journal, 32(3), 465-491.

Ladson-Billings, G. 2001. Crossing over to Canaan: The journey of new teachers in diverse classrooms. San Francisco, CA: Jossey-Bass.

Lapp, D., \& Fisher, D. (2009). It's all about the book: Motivating teens to read. Journal of Adolescent and Adult Literacy, 52(7), 556-561.

Lee, C. D. (2001). Is October brown Chinese? A cultural modeling activity system for under-achieving students. American Educational Research Journal, 38, 97-141.

Leland, C., Ociepka, A. \& Kuonen, K. (2012). Reading from different interpretive stances: In search of a critical perspective. Journal of Adolescent \& Adult Literacy, $55(5), 428-437$.

Lennon, C., and Burdick, H. (2004). The Lexile Framework as an approach for read-ing measurement and success [White paper]. Retrieved September 26, 2012, from www.lexile.com/PDF/LexileReading-Measurement -and-Success-0504.pdf.

Lenters, K. (2006). Resistance, struggle, and the adolescent reader. Journal of Adolescent \& Adult Literacy, 50(2), 136-146.

Lipson, M. Y. (2007). Teaching reading beyond the primary grades: A blueprint for helping intermediate students develop the skills they need to comprehend the texts they read. New York, NY: Scholastic.

MacGinitie, W. H., MacGinitie, R. K., Maria, R. K., \& Dreyer, L. G. (2002). GatesMacGinitie reading tests technical report form $S$ and $T$. Itasca, IL: Riverside Publishing. 
Mason, J. M., \& Au, K.H. (1991). Reading instructions for today. Glenview, IL: Scott Foresman.

McCarty, T. L., Wallace, S., Lynch, R. H., \& Benally, A. (1991). Classroom inquiry and Navajo learning styles: A call for reassessment. Anthropology \& Education Quarterly, 22(1), 42-59.

McCormack, R. L., \& Paratore, J. R. (2003). After early intervention, then what? Teaching struggling readers in grades 3 and beyond. Newark, DE: International Reading Association.

Medina, C. (2010). Reading across communities in biliteracy practices: Examining translocal discourses and cultural flows in literature discussions. Reading Research Quarterly, 45, 40-60.

MetaMetrics, Inc (2013). The Lexile Framework for reading. Retrieved February, 2013, from http://www.lexile.com/about-lexile/lexile-overview/

Moje, E. (2008). Foregrounding the disciplines in secondary literacy teaching and learning: A call for change. Journal of Adolescent \& Adult Literacy, 52(2), 96107.

Moore, D. W., Bean, T., Birdyshaw, D., \& Rycik, J. A. (1999). Adolescent literacy: A position statement for the commission on adolescent literacy of the International Reading. Association. Journal of Adolescent and Adult Literacy, 43, 97-112.

Morrell, E. \& Duncan-Andrade, J. (2002). Toward a critical classroom discourse: promoting academic literacy through engaging hip-hop culture with urban youth. English Journal, 91(6), 88-92.

Morris, V. (2011). The street lit author and the inner-city teen reader. Young Adult Library Services, 10(1), 21-24.

Morris, V., Hughes-Hassell, S., Agosto, D.P., \& Cottman, D.T. (2006). Street lit flying off teen fiction bookshelves in Philadelphia public libraries. Young Adult Library Services, 5(1), 16-23.

National Center for Education Statistics (2011a). The Nation's Report Card: NAEP Reading 2011 (NCES 2012-457). National Center for Education Statistics, Institute of Education Sciences, U.S. Department of Education, Washington, D.C. Retrieved from http://nces.ed.gov

National Center for Education Statistics (2011b). The Nation's Report Card: Trial Urban 
District Assessment Reading 2011 (NCES 2012-455). Institute of Education Sciences, U.S. Department of Education, Washington, D.C. Retrieved from http://nces.ed.gov

National Reading Panel (2000). Teaching children to read: An evidence-based assessment of the scientific research literature on reading and its implications for reading instruction. Bethesda, MD: National Institute of Child Health and Human Development.

Neuman, S., \& Celano, D. (2001). Access to print in low-income and middle-income communities: An ecological study of four neighborhoods. Reading Research Quarterly,36, 8-26.

Newman, I., Newman, C., Brown, R., \& Mcneely, S. (2006). Conceptual statistics for beginners $\left(3^{\text {rd }}\right.$ ed.). Lanham, MD: University Press of America.

Nieto, S. (1996). Affirming diversity: The sociopolitical context of multicultural education (2nd ed.). White Plains, NY: Longman.

Nichols, W. D., Rupley, W. H., Webb-Johnson, G., \& Tlusty, G. (2000). Teachers role in improving culturally responsive literacy instruction. Reading Horizons, 41, 1-18.

Noddings, N. (2002). Educating moral people: A caring alternative to character education. New York, NY: Teachers College Press.

Noguera, P. (2003). City schools and the American dream: Reclaiming the promise of public education. New York: Teachers College Press.

O'Donnell-Allen, C. (2006). The book club companion: Fostering strategic readers in the secondary classroom. Portsmouth, NH: Heinemann.

Osborne, G. (2001). The legacy of ghetto pulp fiction. Black Issues Book Review.

Pai, Y., Adler, S. A., \& Shadiow, L. K. (2006). Cultural foundations of education. Upper Saddle River, NJ: Pearson Education.

Pang, V.O. (2005). Multicultural education: A caring-centered, reflective approach, (2nd ed.). New York, NY: McGraw-Hill.

Paterson, P. O., \& Elliott, L. N. (2006). Struggling reader to struggling reader: High school students' responses to a cross-age tutoring program. Journal of Adolescent and Adult Literacy, 49(5), 378-389.

Paxton-Buursma, D., \& Walker, M. (2008). Piggybacking: A strategy to increase 
participation in classroom discussions by students with learning disabilities. Teaching Exceptional Children, 40(3), 28-34.

Powell, R., \& Rightmyer, E.C. (2011). Literacy for all students: An instructional framework for closing the gap. New York, NY: Routledge.

Pressley, M. (2000). What should comprehension instruction be the instruction of? In M. L. Kamil, P. B. Mosenthal, P. D. Pearson, \& R. Barr (Eds.), Handbook of reading research, Vol. III (pp.545-561). Mahwah NJ: Erlbaum.

Rampey, B. D., Dion, G. S., \& Donahue, P. L. (2009). The nation's report card: Trends in academic progress in reading and mathematics. Retrieved from nces.ed.gov/nationsreportcard/pubs/main2008/2009479.asp

Raphael, D., \& Wahlstrom, M. (1986). The semestered secondary school and student achievement results from the Second Ontario International Science Study. Canadian Journal of Education, 11, 180-183.

Raphael, T. E., Florio-Ruane, S., \& George, M. (2001). Book club plus: A conceptual framework to organize literacy instruction. Language Arts, 79(2), 159-169.

Raphael, T. E., Florio-Ruane, S., George, M., Hasty, N. L., \& Highfield, K. (2004). Book club plus! A literacy framework for the primary grades. Lawrence, MA: Small Planet.

Rasinski, T. V. (2000). Speed does matter in reading. Reading Teacher, 54, 146-151.

Rice, P.S. (2005). It "ain't" always so: Sixth graders' interpretations of HispanicAmerican stories with universal themes. Children's Literature in Education, 36(4), 343-362.

Risko, V. J., \& Walker-Dalhouse, D. (2007). Tapping students' cultural funds of knowledge to address the achievement gap. The Reading Teacher, 61, 98-100.

Rosenblatt, L. (1995). Literature as exploration (5th ed.). New York, NY: Modern Language Association of America.

Ryan, A. M., \& Patrick, H. (2001). The classroom social environment and changes in adolescents' motivation and engagement during middle school. American Educational Research Journal, 38(2), 437-460.

Phuntsog, N. (1999, Summer). The magic of culturally responsive pedagogy: In search of the genie's lamp in multicultural education. Teacher Education Quarterly, 26(3), $97-111$.

Phuntsog, N. (2001). Culturally responsive teaching: What do selected United States elementary school teachers think? Intercultural Education, 12, 51-64. 
Santa, C. M. (2006). A vision for adolescent literacy: Ours or theirs? Journal of Adolescent and Adult Literacy, 49(6), 466-476.

Schmidt, P. R. (2003). Cultural relevant pedagogy: A study of successful inservice. Paper presented at the annual meeting of the National Reading Conference. Scottsdale, AZ.

Schmidt, P. R. (2004). Supporting culturally relevant pedagogy: "It made the difference!" In R. Perry (Chair), Culturally responsive teaching and third space theory. Symposium conducted at the annual meeting of the National Reading Conference, San Antonio, TX.

Schmidt, P. R., \& Pailliotet, A. W. (2001). Exploring values through literature, multimedia, and literacy events: Making connections. Newark, DE: International Reading Association.

Shealey, M. W. \& Callins, T. (2007). Creating culturally responsive literacy programs in inclusive classrooms. Intervention in School and Clinic, 42(4), 195-197.

Sheets, Rosa Hernandez (1995). From remedial to gifted: Effects of culturally centered pedagogy. Theory into Practice 34(3), 186-193.

Sims, R. (1982). Shadow and substance: Afro-American experience in contemporary children's fiction. Urbana, IL:National Council of Teachers of English.

Souljah, S. (1999). The coldest winter ever. New York, NY: Pocket.

Spears-Bunton, L.A., \& Powell, R. (2009). Toward a literacy of promise: Joining the African American Struggle. New York, NY: Routledge.

Stevens, P. S. (2008). Adolescent literacy policy. Journal of Adolescent and Adult Literacy, 52, 70-73.

Stoicovy, C. (2002). A case for culturally responsive pedagogy. International Research in Geographical and Environmental Education, 11(1), 80-84.

Tatum, A. W. (2000). Breaking down barriers that disenfranchise African American adolescent readers in low-level tracks. Journal of Adolescent \& Adult Literacy, 44, 52 64.

Tatum, A. W. (2008). Overserved or underserved? A focus on adolescents and texts. English Journal, 98(2), 82-85.

Tullock-Rhody, R., \& Alexander, J. E. (1980). A scale for assessing attitudes 
toward reading in secondary schools. Journal of Reading, 23, 609-614.

Tyler, K. M., Boykin, A. W., Boelter, C. M., \& Dillihunt, M. L. (2005). Examining mainstream and Afro-cultural value socialization in African American households. Journal of Black Psychology, 31, 291-310.

Tyler, K. M., Uqdah, A. L., Dillihunt, M. L., Beatty-Hazelbaker, R., Conner, T., Gadson, N., Henchy, A., Hughes, T., Mulder, S., Owens, E., Roan-Belle, C., Smith, L., \&

Stevens, R. (2008). Cultural discontinuity: Toward a quantitative investigation of a major hypothesis in education. Educational Researcher, 37(5), 280-297.

U. S. Department of Education. (2007). NAEP 2007 reading report card for the nation and the states. (NCES 2007-496). Washington, DC: Office of Educational Research and Improvement. National Center for Education Statistics. Retrieved from http://nces.ed.gov

U. S. Department of Education. (2008). The condition of education 2008 in brief. (NCES 2008-032). Washington, DC: Office of Educational Research and Improvement. National Center for Education Statistics. Retrieved from http://nces.ed.gov

Van den Branden, K. (2000). Does negotiation of meaning promote reading comprehension? A study of multilingual primary school classes. Reading Research Quarterly, 35(3), 426-443.

Verhoeven, L. \& Snow, C. E. (2001). Literacy and motivation: Reading engagement in individuals and groups. Mahwah, NJ: Lawrence Erlbaum.

Villegas, A.M., \& Lucas, T. (2002). Preparing culturally responsive teachers. Journal of Teacher Education, 53, 20-32.

Vygotsky, L. (1978). Mind in society. Cambridge, MA: Harvard University Press.

Wang, X. (2000). Children's attitudes toward reading and their literacy development. Journal of Instructional Psychology, 27, 120-125.

Whelan, D. (2007). Yo, Hamlet! School Library Journal, 53(6),48-50.

Whittingham, J. L., \& Huffman, S. (2009). The effects of book clubs on the reading attitudes of middle school students. Reading Improvement, 46(3), 130-136.

Wilfong, L. G. (2009). Textmasters: Bringing literature circles to textbook reading across the curriculum. Journal of Adolescent Literacy \& Adult Literacy, 53(2), 164-171. 
Wolf, P. R. \& Rickard, J. A. (2003). Talking circles: A Native American approach to experiential learning. Multicultural Counseling and Development, 31, 39-43.

Worthy, J. (1998). “On every page someone gets killed!” Book conversations you don't hear in school. Journal of Adolescent Literacy \& Adult Literacy, 41, 508-517.

Worthy, J., Moorman, M. \& Turner, M. (1999). What Johnny likes to read is hard to find in school. Reading Research Quarterly 34(10), 12-27. 
APPENDICES 
Appendix A

Formal Letter to Principal 


\section{\begin{tabular}{|l|l|l|l|l} 
INTREA \\
INTERATIONAL \\
UNIVERSITY
\end{tabular}}

Formal Letter to Principal of School

Dear Mr. Campbell,

I am kindly seeking your permission to carry out a research study at your school. This investigation is being done as a partial requirement of the Ed. D in Curriculum and Instruction/Reading Education at Florida International University, under the supervision of Dr. Joyce Fine, my major professor. The purpose of this study is to examine the impact of culturally responsive instruction using culturally relevant literature on the reading comprehension and attitude of struggling adolescent readers.

In an effort to carry out this investigation, I will seek initial permission from the Broward County Public School to allow implementation of the intervention using Culturally Responsive Instruction at the school level. Additionally, parental consent and assent letters will also be drafted and sent home to allow students to participate in the study.

I am the sole investigator of this study and intend to conduct this investigation within my classroom using high interest, authentic, and culturally relevant texts that students can identify with.

If you seek to acquire more information about this research study, you can contact me at

Sincerely,

Rona Moore Olukolu 
Appendix B

Parental Consent Form 


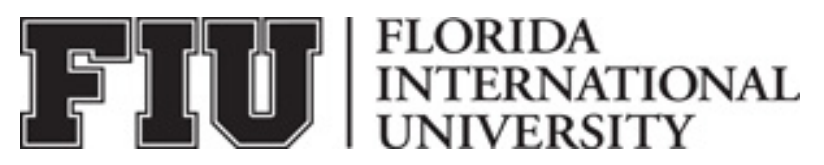

PARENTAL CONSENT TO PARTICIPATE IN A RESEARCH STUDY

The Relationship of Culturally Responsive Instruction and the Reading Comprehension and Attitude of Struggling Urban Adolescent Readers

\section{PURPOSE OF THE STUDY}

You are asked to give permission for your child to be part of a research study. The study will use novels that demonstrate the everyday experiences of some adolescents. Your child will read, write, and discuss these novels with other students in their class. As your child reads these novels, he/she may be able to connect to the reading, and this may help to build comprehension skills.

\section{NUMBER OF STUDY PARTICIPANTS}

If you agree to allow your child to part of this study, he/she will be one of 40 people in this research study.

\section{DURATION OF THE STUDY}

The estimated time for participation in this study is 40 days. For each day of the study, reading instruction will last for about 90 minutes ( $1 \frac{1}{2}$ hours) per day.

\section{PROCEDURES}

If your child participates in this study, your child will be asked do the following things:

- Take a pre-test to find his/her level of reading performance and reading attitude

- Learn about his/her duties and expectations of the study

- Read Novels

- Write a response to his/her reading by summarizing, connecting, reflecting, asking questions, and predicting according to what was read.

- Work in groups to discuss the reading.

- Answer questions about what was read in various assessments or tests.

- Complete a survey to find out his/her attitude or feelings about reading

- Take a post-test to check comprehension of what was read.

\section{RISKS AND/OR DISCOMFORTS}

Your child's participation in the study will involve no risk or danger.

\section{BENEFITS}

- No benefits will be achieved from this study.

\section{ALTERNATIVES}

There are no other choices available to your child. If after being part of the study, your child does not want to continue, he/she can choose not to remain in the study. 


\section{CONFIDENTIALITY}

The records of this study will be kept private and will be fully protected. Research records will be stored securely in individual folders in a locked file cabinet which can only be accessed by the investigator.

\section{COMPENSATION \& COSTS}

Your child will not be responsible for any costs in this study.

\section{RIGHT TO DECLINE OR WITHDRAW}

Your child's participation in this study is voluntary. Your child is free to participate in the study or withdraw his/her consent at any time during the study. Your child's withdrawal or lack of participation will not affect any benefits to which he/she is otherwise entitled. The investigator has the right to remove your child from the study without your consent or permission if it is in the best interest of the child or the investigator.

\section{RESEARCHER CONTACT INFORMATION}

If you have any questions about the purpose, procedures, or any other issues relating to this research study you may contact

\section{IRB CONTACT INFORMATION}

If you would like to talk with someone about your child's rights of being a subject in this research study or about ethical issues with this research study, you may contact the FIU Office of Research Integrity by phone at 305-348-2494 or by email at ori@fiu.edu.

\section{PARTICIPANT AGREEMENT}

I have read the information in this consent form and agree to allow my child to participate in this study. I have had a chance to ask questions about this study, and they have been answered for me. I understand that I am entitled to a copy of this form after it has been read and signed.

Signature of Parent/Guardian

$$
\text { Date }
$$

Printed Name of Parent/ Guardian

Printed Name of Child Participant

Signature of Person Obtaining Consent

Date 
Appendix $\mathrm{C}$

Child Assent Form 


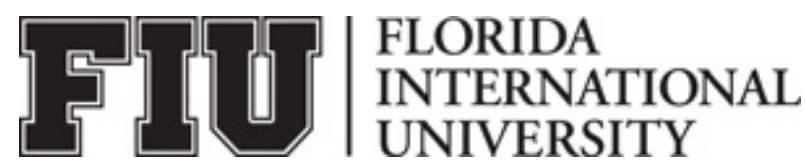

\section{CHILD ASSENT TO PARTICIPATE IN A RESEARCH STUDY}

The Relationship of Culturally Responsive Instruction and the Reading Comprehension and Attitude of Struggling Urban Adolescent Readers

\section{WHY ARE YOU DOING THIS STUDY?}

You are asked to be part of a study using novels that demonstrate the everyday experiences of some adolescents like you. You will read, write, and discuss these novels with other students in your class. As you read these novels, you may be able to connect to what you read, and this may help you to better understand what you are reading and also build your comprehension skills.

\section{HOW MANY OTHERS WILL BE IN THIS STUDY?}

If you agree to be part of this study, you will be reading, writing and discussing novels with about 40 students.

\section{HOW LONG WILL THE STUDY LAST?}

The study will last for a total of 40 days. On each day of the study, your reading instruction will last for about 90 minutes (1 $\frac{1}{2}$ hours) per day.

\section{WHAT WILL HAPPEN IN THIS STUDY?}

If you participate in this study, you will be asked to do the following things:

- Take a pre-test to find out your reading level and reading attitude (how you feel about reading).

- Learn about the duties and responsibilities of the study

- Read Novels

- Write a response to what you read in your reading journal. Your written response will show how you can summarize, connect, reflect, ask questions, and predict based on what you have read in the novels.

- Work in groups to discuss what you have read.

- Complete quizzes and tests to show your knowledge and understanding of what you have read.

- Complete a survey to find out your attitude or how you feel about reading

- Take a post-test to show your reading comprehension skills.

\section{CAN ANYTHING BAD HAPPEN TO ME?}

Your participation in this study will not cause you any harm or danger. 


\section{CAN ANYTHING GOOD HAPPEN TO ME?}

Participation in this study may help to build your reading comprehension skills and may improve your attitude (how you feel) towards reading.

\section{DO I HAVE OTHER CHOICES?}

There are no other choices available but you can decide not to participate in this study if you do not want to be involved.

\section{WILL ANYONE KNOW I AM IN THE STUDY?}

The records of this study will be kept private and will be protected. The information collected will be stored in individual folders in a locked file cabinet. After a period of five years, all data or information will be deleted or gotten rid of permanently.

\section{WILL I BE GIVEN ANYTHING FOR PARTICIPATING?}

You will not receive anything to participate in this study.

\section{WHAT IF I DO NOT WANT TO DO THIS?}

You do not have to be in this study if you don't want to and you can quit this study at any time. No one will get angry at you if you decide that you don't want to be involved in the study.

\section{WHO CAN I TALK TO ABOUT THE STUDY?}

If you have any questions about the research study you may contact

$$
\text { . If you would like to talk with someone about your }
$$
rights of being a participant in this research study, you may contact the FIU Office of

Research Integrity by phone at 305-348-2494 or by email at ori@fiu.edu.

\section{PARTICIPANT AGREEMENT}

This research study has been explained to me and I agree to be involved in this study.

Signature of Child Participant

Printed Name of Child Participant

Signature of Person Obtaining Consent
Date

Date 
Appendix D

The Rhody Secondary Reading Attitude Assessment (RSRAA) 


\section{The Rhody Secondary Reading Attitude Assessment}

Directions: This is a test to tell how you feel about reading. The score will not affect your grade in any way. As the statements are read to you, put an $\mathrm{X}$ on the line under the letter or letters that represent how you feel about the statement.
SD - Strongly Disagree
D- Disagree
U - Undecided
A - Agree
SA - Strongly Agree

\begin{tabular}{|l|l|l|l|l|l|}
\hline & SD & D & U & A & SA \\
\hline $\begin{array}{l}\text { 1. You feel you have better things } \\
\text { to do than read. }\end{array}$ & & & & & \\
\hline 2. You seldom buy a book. & & & & & \\
\hline $\begin{array}{l}\text { 3. You are willing to tell people } \\
\text { that you do not like to read. }\end{array}$ & & & & & \\
\hline $\begin{array}{l}\text { 4. You have a lot of books in your } \\
\text { room at home. }\end{array}$ & & & & & \\
\hline $\begin{array}{l}\text { 5. You like to read a book whenever } \\
\text { you have free time. }\end{array}$ & & & & & \\
\hline $\begin{array}{l}\text { 6. You get really excited about books } \\
\text { you have read. }\end{array}$ & & & & & \\
\hline $\begin{array}{l}\text { 7. You love to read. } \\
\text { 8. You like to read books by well- } \\
\text { known authors. }\end{array}$ & & & & & \\
\hline $\begin{array}{l}\text { 9. You never check out a book from } \\
\text { the library. }\end{array}$ & & & & & \\
\hline $\begin{array}{l}\text { 10. You like to stay at home and read. } \\
\text { have to a book report. }\end{array}$ & & & & & \\
\hline
\end{tabular}




\begin{tabular}{|l|l|l|l|l|l|}
\hline $\begin{array}{l}\text { 14. You think people are strange when } \\
\text { they read a lot }\end{array}$ & & D & U & A & SA \\
\hline $\begin{array}{l}\text { 15. You like to read to escape from } \\
\text { problems. }\end{array}$ & & & & & \\
\hline $\begin{array}{l}\text { 16. You make fun of people who read a } \\
\text { lot }\end{array}$ & & & & & \\
\hline $\begin{array}{l}\text { 17. You like to share books with your } \\
\text { friends. }\end{array}$ & & & & & \\
\hline $\begin{array}{l}\text { 18. You would rather someone just tell } \\
\text { you information so that you won't } \\
\text { have to read to get it }\end{array}$ & & & & & \\
\hline $\begin{array}{l}\text { 19. You hate reading. } \\
\text { so you can use more words. }\end{array}$ & & & & & \\
\hline $\begin{array}{l}\text { 20. You generally check out a book } \\
\text { when you go to the library. }\end{array}$ & & & & & \\
\hline $\begin{array}{l}\text { 21. It takes you a long time to read a } \\
\text { book. }\end{array}$ & & & & & \\
\hline $\begin{array}{l}\text { 22. You like to broaden your interests } \\
\text { through reading. }\end{array}$ & & & & & \\
\hline $\begin{array}{l}\text { 23. You read a lot. } \\
\text { 24. You like to improve your vocabulary }\end{array}$ & & & & & \\
\hline
\end{tabular}

Rhody Secondary Reading Attitude Assessment (Tullock-Rhody \& Alexander, 1980) 
Appendix E

Reading Response Sheet 


\section{Reading Response Sheet}

Title:

Author:

No. of Pages:

\begin{tabular}{|l|l|l|l|}
\hline Date & Pages: Start/Finish & Minutes Read & Parent Signature \\
\hline & & & \\
\hline & & & \\
\hline & & & \\
\hline & & & \\
\hline
\end{tabular}

Summary:

Connect: 
Reflect:

Ask Questions:

Predict: 


\section{Appendix F}

Reading Response Prompts 


\section{READING RESPONSE PROMPTS}

\section{SUMMARIZE:}

1. This story/part of the book is mainly about?

2. Chapter...basically talks about...

3. What I read is mainly about?

4. The main idea of the reading is...

5. This part of the story/book says that...

\section{CONNECT:}

1. This \{character, place, and event\} reminds me of... because...

2. [Character's Name] reminds me of [myself, a friend, a family member] because...

3. This situation or incident on page - reminds me of something that happened in my own life, (talk about the connection)

4. This book makes me thing about [an important social issue, a problem, and so on]...

5. This book reminds me of another book I read (give name of book), because...

7. I am like or different from [character]

8. I experienced this once when...

\section{REFLECT:}

1. I like/dislike this book because...

2. My favorite part of the book was...

3. The most exciting part of the book was...

4. The character I [like best, admire, dislike the most] is... because

5. I admire [character from book] because...

6. The setting of the story is important because. ..

7. The author got me interested when...

8. Some important details that I have noticed were... They were important because...

9. I found this book hard to follow when...

10. When I read this book I felt... Why?

11. My feelings about [the book, characters] changed when...

12. If I were this character (give name), I would or would have

13. What I want to remember about this book is...

14. I think the author wrote this book to...

15. This book makes me want to [action (do something), further reading]

\section{ASK QUESTIONS:}

1. A question that I have about this book is... because

2. If could talk to one of the characters in the book I would [ask or say]

3. I didn't understand the part of the story when...

4. I'm confused about...

5. I wonder why...

\section{PREDICT:}

1. 1 predict that... because...

2. After the book ends, I predict

3. As the story continues, I predict that... because... 
Appendix G

Rubric for SCRAP 


\section{Rubric for SCRAP}

\begin{tabular}{|c|c|c|c|c|}
\hline & $\begin{array}{c}\text { Below } \\
\text { Expectations }\end{array}$ & Basic & Proficient & Outstanding \\
\hline $\begin{array}{c}\text { Reading } \\
\text { Skills }\end{array}$ & Level 1 & Level 2 & Level 3 & Level 4 \\
\hline Summarize & $\begin{array}{l}\text { The student did } \\
\text { not describe the } \\
\text { important events } \\
\text { and concepts } \\
\text { from the text to } \\
\text { summarize. }\end{array}$ & $\begin{array}{l}\text { The student did } \\
\text { not describe } \\
\text { enough of the } \\
\text { important events } \\
\text { and concepts from } \\
\text { the text to } \\
\text { summarize }\end{array}$ & $\begin{array}{l}\text { The student } \\
\text { described some of } \\
\text { the important } \\
\text { events and } \\
\text { concepts with } \\
\text { some supporting } \\
\text { explanation from } \\
\text { the text to } \\
\text { summarize. . }\end{array}$ & $\begin{array}{l}\text { The student fully } \\
\text { described the } \\
\text { important events and } \\
\text { concepts with } \\
\text { supporting } \\
\text { explanation from the } \\
\text { text to summarize. }\end{array}$ \\
\hline Connect & $\begin{array}{l}\text { The student did } \\
\text { not make } \\
\text { connections nor } \\
\text { explain how they } \\
\text { relate to the text. }\end{array}$ & $\begin{array}{l}\text { The student did } \\
\text { not make enough } \\
\text { connections nor } \\
\text { explain how they } \\
\text { relate to the text. }\end{array}$ & $\begin{array}{l}\text { The student made } \\
\text { some connections } \\
\text { but did not fully } \\
\text { explain how they } \\
\text { relate to text. }\end{array}$ & $\begin{array}{l}\text { The student made } \\
\text { connections and } \\
\text { fully explained how } \\
\text { they relate to the } \\
\text { text. }\end{array}$ \\
\hline Reflect & $\begin{array}{l}\text { The student did } \\
\text { not show any } \\
\text { thoughtfulness in } \\
\text { personal } \\
\text { response. There } \\
\text { are no details that } \\
\text { move beyond a } \\
\text { description of } \\
\text { text. }\end{array}$ & $\begin{array}{l}\text { The student did } \\
\text { not show enough } \\
\text { thoughtfulness in } \\
\text { personal response. } \\
\text { There are a few } \\
\text { details that move } \\
\text { beyond a } \\
\text { description of text. }\end{array}$ & $\begin{array}{l}\text { The student shows } \\
\text { some } \\
\text { thoughtfulness in } \\
\text { personal response. } \\
\text { There are some } \\
\text { supporting details } \\
\text { that move beyond } \\
\text { a description of } \\
\text { text. }\end{array}$ & $\begin{array}{l}\text { The student shows } \\
\text { much thoughtfulness } \\
\text { and personal } \\
\text { response. There are } \\
\text { many supporting } \\
\text { details that move } \\
\text { beyond a description } \\
\text { of text. }\end{array}$ \\
\hline $\begin{array}{c}\text { Ask } \\
\text { Questions }\end{array}$ & $\begin{array}{l}\text { The student did } \\
\text { not ask or } \\
\text { respond to } \\
\text { questions relevant } \\
\text { to text. }\end{array}$ & $\begin{array}{l}\text { The student asked } \\
\text { and responded to a } \\
\text { few questions with } \\
\text { no supporting } \\
\text { evidence from the } \\
\text { text. }\end{array}$ & $\begin{array}{l}\text { The student asked } \\
\text { and responded to } \\
\text { questions with } \\
\text { limited supporting } \\
\text { evidence from the } \\
\text { text. }\end{array}$ & $\begin{array}{l}\text { The student asked } \\
\text { and responded to } \\
\text { questions, fully } \\
\text { supporting evidence } \\
\text { from the text. }\end{array}$ \\
\hline Predict & $\begin{array}{l}\text { The student did } \\
\text { not make } \\
\text { predictions based } \\
\text { on information } \\
\text { from the text. }\end{array}$ & $\begin{array}{l}\text { The student made } \\
\text { few predictions, } \\
\text { but did not justify } \\
\text { responses with } \\
\text { information from } \\
\text { the text. }\end{array}$ & $\begin{array}{l}\text { The student made } \\
\text { predictions, and } \\
\text { justified some } \\
\text { responses with } \\
\text { information from } \\
\text { the text. }\end{array}$ & $\begin{array}{l}\text { The student made } \\
\text { predictions and } \\
\text { clearly justified each } \\
\text { response with } \\
\text { information from the } \\
\text { text. }\end{array}$ \\
\hline
\end{tabular}


Appendix $\mathrm{H}$

Discussion Checklist 


\section{Discussion Checklist}

Date:

Observer:

Activity:

Class Period:

Student/Group \#:

Duration:

\begin{tabular}{|l|l|l|l|l|}
\hline Expectations & Student: & Student: & Student: & Student: \\
\hline $\begin{array}{l}\text { Speaks } \\
\text { Appropriately }\end{array}$ & & & & \\
\hline Asks a question & & & & \\
\hline Answers a question & & & & \\
\hline $\begin{array}{l}\text { Listens and responds } \\
\text { to others. }\end{array}$ & & & & \\
\hline $\begin{array}{l}\text { Makes logical } \\
\text { references to } \\
\text { literature during } \\
\text { discussion. }\end{array}$ & & & & \\
\hline Stays on topic. & & & & \\
\hline $\begin{array}{l}\text { Shows sensitivity to } \\
\text { others. }\end{array}$ & & & & \\
\hline $\begin{array}{l}\text { Summarizes ideas. } \\
\text { Sumply }\end{array}$ & & & & \\
\hline
\end{tabular}


Appendix I

Guidelines for Discussion

(Discussion Prompts) 


\title{
Guidelines for Discussion
}

Ask lots of questions.

Connect your responses with the responses of other group members.

Agree or disagree in respectful ways.

Don't strive for consensus-everyone doesn't have to agree.

Seek out the opinions of other group members.

Value your opinions and the opinions of others.

\section{Discussion Prompts: What can I say in my group?}

\author{
To start: \\ I really liked the part. . . \\ I wondered ... I have to think about that. \\ What did you think ... ? Can you show me that in the story? \\ I have an idea ... What made you think that? \\ I really wanted to talk about ... \\ To respond to someone else: \\ I agree with you because... \\ I disagree with you because... \\ I will like to add to what you just said... \\ I thought that too and ... \\ That's interesting. I saw it a little bit different. \\ I have to think about that. \\ Can you show me that in the story? \\ What made you think that? \\ To redirect the group: \\ Let's get back to the text. We're getting off the topic. \\ If the conversation lags: \\ I had another question ... \\ What other ideas do we have? \\ What was most intriguing about the story? \\ How does this story connect with other stories we've read? \\ How does the story connect with our own experiences?
}

Guidelines for Productive Literature Discussion (Kathleen F. Clark, 2009). 
Appendix J

GIST Template 


\section{GIST Template}

Name

Article Title

Article Source

1. Read the article.

2. Fill out the $5 \mathrm{Ws}$ and $\mathrm{H}$.

Who:

What:

Where:

When:

Why:

How:

3. Write a 20-word GIST. 
Appendix K

Samples of Researcher-Created Assessments for

Bluford Series 


\section{NOVEL TEST: LOST AND FOUND}

1. Read the following figurative expression from the book.

\section{It seemed fewer people were expected to do more work. It was like trying to climb a mountain that keeps getting taller as you go.}

What is the author comparing in this simile?
A. People to mountains
B. Work to climbing mountains
C. People to getting taller
D. Work to people

2. Read the following quote.

\section{"Mattie May Wills, we don't need you anymore. We can get somebody younger and cheaper."}

In this quote, what does the word cheaper mean?
A. poor quality
B. very stingy
C. less expensive
D. extremely mean

3. Personification is a literary device that gives something non-human human-like qualities. For example: the toy soldier shouted angrily at the boy.

Read the following excerpt.

\section{Mrs. Walker's pink and white roses bobbed proudly in the breeze.}

In this excerpt, what is being personified?
A. Mrs. Walkers
B. Morning breeze
C. Bobbed proudly
D. Pink and white roses

4. What is the strongest effect grandma's stroke has on Darcy?
A. she misses going to her house
B. she misses having someone to talk to
C. she misses eating her sweet potato pie
D. she misses hearing her stories 
5. How does Darcy's character change from beginning to end?
A. unpopular to popular
B. scared to brave
C. soft-spoken to out-spoken
D. critical to understanding

6. Which statement best describes Jamee's approach to life.
A. She is positive and confident
B. She is self-destructive and angry
C. She is full of self-pity
D. She is loving and helpful

7. What does Brisana mean when she says,

"If you lie down with dogs, you'll get fleas. I don't know what my parents would say if I brought home trash like Tarah Carson?"
A. if you have a dog, you will get fleas
B. if you hang out with dogs, you will become a dog
C. if you hang out with trash, you will smell like trash
D. if I brought home a dog, my parents would be mad

8. How did the conflict between Bobby and Darcy begin?
A. after he put a water bug in her back
B. after he started stalking her in his Toyota
C. after she saw the fight with Cooper
D. after she overheard him talking about Jamee

9. What is the best theme for this story?
A. You can't give up on people
B. If you lie down with dogs, you get fleas
C. Friends are forever
D. All is fair in love and war 
10. All of the choices below are conflicts in the story, but which is the main conflict?
A. Jamee's conflict with her dad about his abandonment
B. Darcy's conflict with Bobby about his treatment of Jamee
C. mom's conflict with dad about his betrayal
D. Jamee's conflict with Aunt Charlotte about her selfishness

11. The author describes the neighborhood setting at the beginning as
A. terrible, and very unkempt
B. peaceful and well-manicured
C. not terrible, just not good
D. modern, and industrial

12. What made Darcy suspicious that Jamee was lying to her mother about sleeping over Alisha's house?
A. Jamee forgot to take her dresses
B. Jamee and Alisha had a falling out a few weeks ago
C. Jamee had bruises on her face
D. Jamee missed cheerleading practice

13. Read the following excerpt.

\section{A cold breeze began to blow as they climbed back into Cooper's and headed toward the Canyon... The sun was getting lower, and a thick line of clouds was beginning to crawl into the sky from the west.}

What mood is created in this excerpt?
A. cheerful and lively
B. chilling and deadly
C. hopeful and energetic
D. frightening and goulash 
14. Read the following excerpt.

Darcy began to cry, her tears turning into wrenching sobs.

What is the meaning of wrenching as used in this sentence?
A. violent twist
B. twist suddenly
C. a tool for gripping
D. distressing strain

15. Read the following excerpt.

Sometimes she would even steal a glance at the diners sitting by the picture window at the Golden Grill Restaurant

In which sentence does the word steal have the same meaning as the one above?
A. She had to steal a loaf of bread to feed her children.
B. Can I steal a moment of your time?
C. The player had to steal third base.
D. The years just steal by.

16. What effect did father's leaving have on mom?
A. She had to work harder to support the family
B. she became depressed and slept all day
C. she was self-destructive and suicidal
D. she started to neglect her children

17. Read the following excerpt.

\section{"My mama says when folks who used to look down their noses at you start bein' nice, look out!"}

What does the speaker mean in the phrase 'look down their noses?'
A. they are taller than you
B. they are better than you
C. they think you are below them
D. they think you smell 
18. How does grandma's conversation about her adventure in the woods contribute to the outcome of the story?
A. it helps Jamee find the princess tree
B. it leads Darcy to where Jamee is
C. it helps Darcy understand her dad
D. it helps mom cope with Jamee's disappearance

19. Which pair of words used in the book are most similar?
A. nervous, frustrated
B. rambled, laughed
C. reluctant, afraid
D. shiver, tremble

20. Which word would best describe Darcy's feelings toward her father at the end of the book?
A. resentful
B. obedient
C. critical
D. appreciative 


\section{NOVEL TEST: BREAKING POINT}

1. Read the following excerpt. (page 8)

"No matter what happens, I'm proud of you for standing up for what you believe in...I am proud of you, Vicky, for getting everyone together." "Thanks," Vicky muttered, cringing at Mr. Mitchell's ominous words.

Using context clues, what is the beast definition for ominous?
A. kind and favorable
B. proud and admirable
C. fateful and menacing
D. hopeful and incorrigible

2. Read the following excerpt from the story. (page 9)

Vicky felt her stomach tremble. Her mind raced with questions.

\section{What if Martin is kicked out? \\ Would her be sent to juvenile hall? \\ Is this the end of us?}

The author uses the italicized text feature to allow the reader to know the story is being told in...
A. First person point of view
B. Second person point of view
C. Third person point of view
D. Third person omniscient point of view

3. After Martin's hearing, what is the primary reason Mr. Gates Makes his decision to allow Martin to stay at school? (page 13)
A. He feels sorry for Martin and his mother
B. He was influenced by all the support in the auditorium
C. He was moved by Martin's plead to stay at Buford
D. He is tired of expelling kids at Buford 
4. Read the following excerpt from the story. (page 17)

At first, Danny offered to sleep in the couch and gave Vicky his room but Mom refused.

“No, mijo. You have enough troubles staying focused on school right now. I not gonna have you loosing sleep watching TV or playing video games all night. Forget it," she said

In this excerpt the italicized words are important to the reader because they show the reader that ...
A. these are Vicky's personal thoughts
B. these words were spoken with emphasis
C. it is the title of a book
D. it is a flashback

5. How are Martin and Steve most similar?
A. both dislike and don't trust Teresa
B. both have recently lost a little brother
C. both handle problems aggressively
D. both have a long history with Vicky

6. Read the following excerpt from the story. (page 18)

“Vicky!"Mom's voice cut through her like an axe.

In this excerpt was which figurative device is the author using?
A. simile
B. metaphor
C. onomatopoeia
D. symbolism

7. On pages 20 and 21, the author uses words like angered, lips pressed together, and grabbed to contribute to the overall TONE of the event.

Which word best sets the overall TONE for these two pages?
A. merriment
B. hospitality
C. hostility
D. empowerment 
8. Read the following excerpt.

\section{"No, don't Yolanda me," Mom snapped. "I have been running all day, too! (Page 23)}

In this excerpt the italicized text feature is used to show the reader...
A. it's a personal thought
B. it's said with emphasis
C. it's a flashback
D. it's a book title

9. In Mr. Mitchell's class, there are several detailed discussions about Princess Ophelia in Shakespeare's Hamlet? (Pages 34 and 112)

Based on these discussions, the reader can conclude that the author is trying to reveal...
A. A contrast between Ophelia and Vicky
B. A comparison to Ophelia and Vicky
C. The effect Vicky's problems are having
D. The cause of Vicky's problems

Read the following character traits to respond to questions 10-13.
A. Takes troubles out on others
B. Holds extreme rage inside
C. Keeps troubles to oneself
D. Tries to talk things out

10. Which character trait above best describes how Vicky handles her troubles?

11. Which character trait best describes how Steve handles troubles?

12. Which character trait best describes how Teresa handles troubles

13. Which character trait best describes how Martin handles troubles

14. Read the following excerpt.

\section{Clarence looked puzzled as he walked by, leaving Steve alone in front of her locker. (Page 50)}

What does the word puzzled mean in this excerpt?
A. entangled
B. distracted
C. baffled
D. broken 
15. Which of the following are closest in meaning?
A. smirk and scowl
B. reluctantly and eagerly
C. snapped and shouted
D. braced and restrained

16. Read the following excerpt. (Page 63)

In the bottom corner (of Danny's backpack) she noticed a tiny drawing in black magic marker: a sphere with a lit fuse on top. The fuse was drawn in detail with sparks flying to show it was on fire. Underneath written in tight block style letters, was a word $T$-Bomb

Which figurative device is the author using in with the drawing of the $\boldsymbol{T}$-Bomb?
A. Symbol- for Danny's spray paint gang
B. Foreshadowing- for what Danny is going to do
C. Metaphor- for how Danny feels inside
D. Illustration- to set the mood

17. Throughout the story the "RING!" (Page 40) of a phone is constantly being repeated. The author uses this figurative device as a symbol. What is the symbol representing?
A. the Fallon's financial ruin
B. A reminder of the Fallon's better times
C. That the Fallon's are in imminent danger
D. A reminder that the Fallon's are late

18. On page 73 , the words struggle, cringe, shake create an overall nervous feeling. The use of these descriptive words helps the author to create what?
A. Tone
B. Mood
C. Conflict
D. setting

19. Which pair of words from the story are most similar in meaning?
A. flashed and scratched
B. stomp and jump
C. rattles and shutter
D. zoned and moaned

20. What is the best overall theme of this story?
A. Why is this happening to me?
B. Life's changes
C. Family and Friendship
D. Things aren't always what they seem 
Appendix L

Two-Week Sample of Instructional Guide 


\section{WEEK 1: PRE-INTERVENTION GUIDE (Experimental Group)}

\begin{tabular}{|c|c|c|c|c|}
\hline DAY 1 & DAY 2 & DAY 3 & $\begin{array}{c}\text { DAY } 4 \\
\end{array}$ & DAY 5 \\
\hline $\begin{array}{l}\text { Open Sharing } \\
\text { - Introduction to Study: } \\
\text { - An overview of the study } \\
\text { - Discuss: What is a "quick } \\
\text { write"? }\end{array}$ & $\begin{array}{l}\text { Pre-Intervention } \\
\text { Gates McGinitie } \\
\text { (GMRT) }\end{array}$ & $\begin{array}{l}\text { Pre-Intervention } \\
\text { Complete Rhody Secondary } \\
\text { Reading Attitude Assessment - } \\
\text { RSRAA (Appendix D). }\end{array}$ & $\begin{array}{l}\text { Open Sharing } \\
\text {-Teacher Read Aloud and } \\
\text { Discussion }\end{array}$ & $\begin{array}{l}\text { Open Sharing } \\
\text { - Students select novels } \\
\text { according to choice/interest } \\
\text { - Students create a pacing } \\
\text { guide for the daily reading } \\
\text { of novels. }\end{array}$ \\
\hline $\begin{array}{l}\text { Before Reading } \\
\text { - Teacher discusses and models } \\
\text { expected" Before Reading" } \\
\text { behaviors } \\
\text { - Discusses expectations when a } \\
\text { mini lesson is taught } \\
\text {-Vocabulary Enrichment and its } \\
\text { purpose }\end{array}$ & $\begin{array}{l}\text { Pre-Intervention } \\
\text { Gates McGinitie } \\
\text { (GMRT) }\end{array}$ & $\begin{array}{l}\text { Before Reading } \\
\text { Teacher introduces novels } \\
\text { (Bluford Series) and provides } \\
\text { background information on } \\
\text { each. }\end{array}$ & $\begin{array}{l}\text { Pre-Intervention } \\
\text { Florida Assessments for } \\
\text { Instructions in Reading (FAIR) }\end{array}$ & $\begin{array}{l}\text { Before Reading. } \\
\text {-Teacher reviews the } \\
\text { rotation of the intervention: } \\
\text { Open Sharing; Independent } \\
\text { Reading; and Writing; } \\
\text { Small Group and Whole } \\
\text { Group Discussion }\end{array}$ \\
\hline $\begin{array}{l}\text { During Reading } \\
\text {-Teacher discusses and models } \\
\text { expected "During Reading" } \\
\text { behaviors } \\
\text {-Active Reading Task - Use of } \\
\text { post it notes/journals). }\end{array}$ & $\begin{array}{l}\text { Pre-Intervention } \\
\text { Gates McGinitie } \\
\text { (GMRT) }\end{array}$ & $\begin{array}{l}\text { After Reading } \\
\text { Teacher introduces novels } \\
\text { (Bluford Series) and provides } \\
\text { background information } \\
\text {-Students select novels } \\
\text { according to choice/interest }\end{array}$ & $\begin{array}{l}\text { Pre-Intervention } \\
\text { Florida Assessments for } \\
\text { Instructions in Reading (FAIR) }\end{array}$ & $\begin{array}{l}\text { During Reading } \\
\text {-Teacher discusses the } \\
\text { importance of working } \\
\text { collaboratively. } \\
\text {-Students discuss and create } \\
\text { group discussion rules for } \\
\text { success. } \\
\text {-Chart rules on paper }\end{array}$ \\
\hline $\begin{array}{l}\text { After Reading } \\
\text {-Teacher discusses and models } \\
\text { expected "After Reading" } \\
\text { behaviors. } \\
\text { Teachers discusses the writing } \\
\text { of "SCRAP" ( Appendices E, F, } \\
\text { G ) } \\
\text {-Use of Discussion Prompts } \\
\text { (Appendix I) to guide group } \\
\text { discussions. }\end{array}$ & $\begin{array}{l}\text { Pre-Intervention } \\
\text { Gates McGinitie } \\
\text { (GMRT) }\end{array}$ & & $\begin{array}{l}\text { Pre-Intervention } \\
\text { Florida Assessments for } \\
\text { Instructions in Reading (FAIR) }\end{array}$ & $\begin{array}{l}\text { After Reading } \\
\text {-Teacher discusses the } \\
\text { expectations for after } \\
\text { reading. } \\
\text {-Students create group } \\
\text { discussion rules. } \\
\text {-Students review handout } \\
\text { explaining discussion } \\
\text { prompts - What Can I Say in } \\
\text { My Group? (Appendix I). }\end{array}$ \\
\hline$\frac{\text { HOME CONNECTION }}{\text { Return signed Assent Forms. }}$ & $\begin{array}{l}\text { HOME } \\
\text { CONNECTION }\end{array}$ & HOME CONNECTION & $\begin{array}{l}\text { HOME CONNECTION } \\
\text { Select a personal novel }\end{array}$ & $\begin{array}{l}\text { HOME CONNECTION } \\
\text { Select a personal novel }\end{array}$ \\
\hline
\end{tabular}


WEEK 2: BLUFORD SERIES - Chapters 1-5 (Experimental Group)

\begin{tabular}{|c|c|c|c|c|}
\hline DAY 6 & DAY 7 & DAY 8 & DAY 9 & DAY 10 \\
\hline $\begin{array}{l}\text { Open Sharing } \\
\text {-Preview Novel } \\
\text {-Predict story's plot based on } \\
\text { title and illustration }\end{array}$ & $\begin{array}{l}\text { Open Sharing } \\
\text {-Teacher Read Aloud } \\
\text { and discussion }\end{array}$ & $\begin{array}{l}\text { Open Sharing } \\
\text { - Mini-Lesson: Character } \\
\text { Development }\end{array}$ & $\begin{array}{l}\text { Open Sharing } \\
\text { Teacher Read Aloud and } \\
\text { Discussion }\end{array}$ & $\begin{array}{l}\text { Open Sharing } \\
\text {-Review vocabulary words of } \\
\text { the week. }\end{array}$ \\
\hline $\begin{array}{l}\text { Before Reading } \\
\text { - Complete anticipation guide } \\
\text { for Bluford Series } \\
\text { - Mini-Discussion on } \\
\text { responses to anticipation } \\
\text { guide }\end{array}$ & $\begin{array}{l}\text { Before Discussion } \\
\text { - Review and complete task } \\
\text { before group literature group } \\
\text { discussion - SCRAP } \\
\text { - Discuss and post new } \\
\text { vocabulary words to the word } \\
\text { wall. }\end{array}$ & $\begin{array}{l}\text { Before Reading } \\
\text { - Complete Quick Write: } \\
\text { "Identify your most favorite } \\
\text { character so far and explain } \\
\text { why?" } \\
\text { - Discussion of quick write }\end{array}$ & $\begin{array}{l}\text { Before Discussion } \\
\text { Review and complete task } \\
\text { before group literature group } \\
\text { discussion. } \\
\text {-Discuss and post new } \\
\text { vocabulary words to the word } \\
\text { wall. }\end{array}$ & $\begin{array}{l}\text { Group Activity } \\
\text { - Create a Wanted Poster }\end{array}$ \\
\hline $\begin{array}{l}\text { During Reading } \\
\text { - Independent Reading } \\
\text { following Pacing Guide. } \\
\text { - Use of Post it notes/journals } \\
\text { for active reading and } \\
\text { recording (vocabulary, } \\
\text { quotes, important/confusing } \\
\text { information). }\end{array}$ & $\begin{array}{l}\text { During Discussion - Groups } \\
\text {-Present information recorded } \\
\text { in response journals and post } \\
\text { its } \\
\text { - Use Discussion Prompts } \\
\text { (What Can I say in My Group) } \\
\text { to guide group discussion } \\
\text { (Appendix) } \\
\text { - Ask and respond to questions } \\
\text { and piggy back on ideas. }\end{array}$ & $\begin{array}{l}\text { During Reading } \\
\text { - Independent Reading } \\
\text { following Pacing Guide. } \\
\text { - Use of Post it notes/journals } \\
\text { for active reading and } \\
\text { recording. } \\
\text { (vocabulary, quotes, } \\
\text { important/confusing } \\
\text { information,) }\end{array}$ & $\begin{array}{l}\text { During Discussion } \\
\text {-Present information recorded in } \\
\text { response journals and post its } \\
\text { - Use Discussion Prompts } \\
\text { (What Can I say in My Group) } \\
\text { to guide group discussion } \\
\text { (Appendix) } \\
\text { - Ask and respond to questions } \\
\text { and piggy back on ideas. }\end{array}$ & $\begin{array}{l}\text { Group Activity } \\
\text { - Create a wanted poster } \\
\text { - Present poster to whole } \\
\text { group }\end{array}$ \\
\hline $\begin{array}{l}\text { After Reading } \\
\text {-Complete SCRAP in } \\
\text { Response Journals } \\
\text { (Appendix) } \\
\text {-Create illustrations }\end{array}$ & $\begin{array}{l}\text { After Discussion } \\
\text {-Groups presents to entire } \\
\text { class } \\
\text {-Class identifies and discusses } \\
\text { common themes }\end{array}$ & $\begin{array}{l}\text { After Reading: } \\
\text {-Complete SCRAP using } \\
\text { Response Prompts ( } \\
\text { Appendix) } \\
\text { - Create illustrations }\end{array}$ & $\begin{array}{l}\text { After Reading } \\
\text {-Groups presents to entire class } \\
\text { - Groups presents to entire class } \\
\text {-Class identifies and discusses } \\
\text { common theme. }\end{array}$ & $\begin{array}{l}\text { Whole Group and Sharing } \\
\text { - Critical Discussion of Text } \\
\text { (Critical Literacy Framework } \\
\text { (Figure } 2\end{array}$ \\
\hline $\begin{array}{l}\text { Closing Sharing } \\
\text { Respond to "I was surprised } \\
\text { when..." and discuss with } \\
\text { whole class. } \\
\end{array}$ & $\begin{array}{l}\text { Close Sharing } \\
\text { Choose one theme and explain } \\
\text { why it is important to the } \\
\text { development of the novel. }\end{array}$ & $\begin{array}{l}\text { Close Sharing } \\
\text { Complete Character Map } \\
\text { with traits. Explain }\end{array}$ & $\begin{array}{l}\text { Close Sharing } \\
\text { Favorite quotes. Why? }\end{array}$ & \\
\hline HOME CONNECTION & HOME CONNECTION & HOME CONNECTION & HOME CONNECTION & HOME CONNECTION \\
\hline Read your personal novel. & Read your personal novel. & Read your personal novel. & Read your personal novel. & Read your personal novel. \\
\hline
\end{tabular}


VITA

\section{RONA MOORE OLUKOLU}

Born, Charlotteville, Tobago

Trinidad and Tobago

$1991 \quad$ Elementary/Secondary Education

Valsayn Teachers' College

Valsayn, Trinidad

1997 Diploma, Literacy Studies

University of the West Indies

Mona Campus, Jamaica

1998 Educator, Charlotteville Methodist School

Ministry of Education

Trinidad and Tobago

1998-1999 Music Curriculum Facilitator

Tobago House of Assembly, Education Division

Scarborough, Tobago

2003 B.S., Music Education

Montclair State University

Upper Montclair, New Jersey

2004 M.A., Applied Educational Psychology, Reading Specialist Colombia University

New York, New York

2011 Ed. S., Curriculum and Instruction, Reading Education

Florida International University

Miami, Florida

2013 Doctoral Candidate, Curriculum and Instruction

Reading Education/Instructional Leadership

Florida International University

Miami, Florida 


\section{PRESENTATIONS AND PUBLICATIONS}

Olukolu, R. M. (2013, June). How to ensure your child's academic success. Paper presented at the annual meeting of the Broward Alliance for Caribbean Educators (BACE) Parent Seminar, Fort Lauderdale, Florida.

Olukolu, R. M. \& Fine, J. C. (2012, December). Using culturally responsive instruction with urban, Black and Hispanic Adolescents to improve reading attitude and achievement. Paper presented at the annual meeting of the American Reading Forum, Sanibel Island, Florida.

Olukolu, R. M. (2011, February). Understanding your learning style. Paper presented at the annual Parent Family Night, Pembroke Pines, Florida.

Moore, R. A. (2010, February). Building reading stamina. Paper presented at annual Parent Family Night, Pembroke Pines, Florida.

Moore, R. A., Castillo, I., Burke, E. \& Hewitt, N. (2009, December). Read for the record. Paper presented at the annual meeting of the American Reading Forum, Sanibel Island, Florida.

\section{WORK IN PROGRESS:}

Olukolu, R. M. (in review). The use of SCRAP: A comprehension strategy to improve reading comprehension and response to literature for struggling urban adolescent readers. International Reading Association, Middle School reading Special Interest Group, New Orleans, LA.

Olukolu, R. M. \& Fine, J. C. (in review). Using culturally responsive instruction with urban, Black and Hispanic Adolescents to improve reading attitude and achievement. American Reading Forum Yearbook.

http://www.americanreadingforum.org 